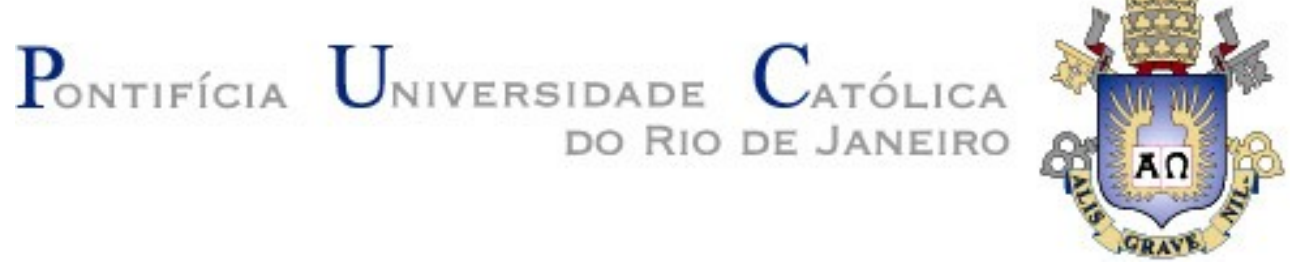

Renata Neves de Almeida

\title{
Análise Numérica de Processos Termomecânicos em Problemas de Estabilidade de Taludes Rochosos
}

Dissertação de Mestrado

Dissertação apresentada como requisito parcial para obtenção do grau de Mestre pelo programa de PósGraduação em Engenharia Civil do Departamento de Engenharia Civil e Ambiental da PUC-Rio.

Orientador: Prof. Eurípedes do Amaral Vargas Jr Co-Orientadora: Prof. ${ }^{a}$ Raquel Quadros Velloso 


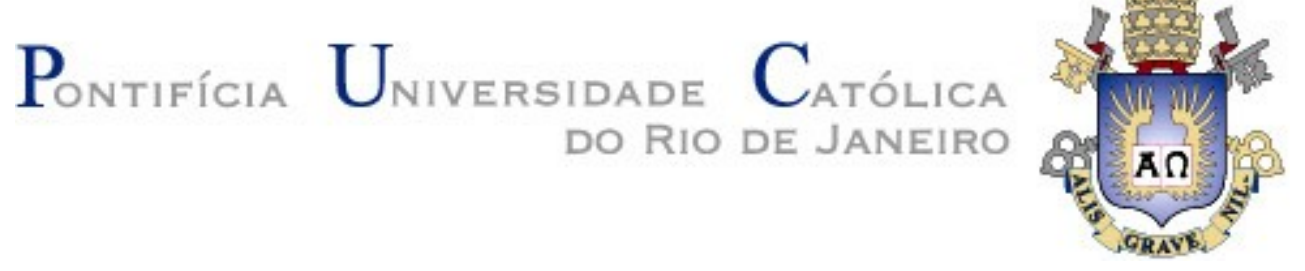

Renata Neves de Almeida

\section{Análise Numérica de Processos Termomecânicos em Problemas de Estabilidade de Taludes Rochosos}

Dissertação apresentada como requisito parcial para obtenção do grau de Mestre pelo Programa de PósGraduação em Engenharia Civil do Departamento de Engenharia Civil e Ambiental da PUC-Rio. Aprovada pela Comissão Examinadora abaixo.

Prof. Eurípedes do Amaral Vargas Jr

Orientador

Departamento de Engenharia Civil e Ambiental - PUC-Rio

Prof. ${ }^{a}$ Raquel Quadros Velloso

Co-Orientadora

Departamento de Engenharia Civil e Ambiental - PUC-Rio

Prof. Luiz Fernando Campos Ramos Martha

Departamento de Engenharia Civil e Ambiental - PUC-Rio

Prof. Emílio Velloso Barroso

Universidade Federal do Rio de Janeiro - UFRJ 
Todos os direitos reservados. É proibida a reprodução total ou parcial do trabalho sem autorização da universidade, da autora e do orientador.

\section{Renata Neves de Almeida}

Graduou-se em Engenharia Ambiental pela Universidade Federal Fluminense em 2013 e em Engenharia Civil também pela Universidade Federal Fluminense em 2017. Ingressou em 2017 no curso de mestrado em Engenharia Civil na Pontifícia Universidade Católica do Rio de Janeiro, na área de Geotecnia atuando na linha de pesquisa de Mecânica das Rochas e Geologia de Engenharia.

Ficha Catalográfica

Almeida, Renata Neves de

Análise numérica de processos termomecânicos em problemas de estabilidade de taludes rochosos/ Renata Neves de Almeida; orientador: Eurípedes do Amaral Vargas Jr; co-orientadora: Raquel Quadros Velloso. - 2019

97f. :il. color.; $30 \mathrm{~cm}$

Dissertação (Mestrado)-Pontifícia Universidade Católica do Rio de Janeiro, Departamento de Engenharia Civil e Ambiental, 2019.

Inclui bibliografia

1. Engenharia Civil e Ambiental - Teses. 2. Análise termomecânica. 3. Estabilidade de taludes rochosos 4. Análise numérica I. Vargas Júnior, Eurípedes A. II. Velloso, Raquel Quadros. III. Pontifícia Universidade Católica do Rio de Janeiro. Departamento de Engenharia Civil e Ambiental. IV. Título. 
Dedico este trabalho a Deus, que se traduz na força que existe em nós para continuar sem esmorecer 


\section{Agradecimentos}

À minha família, aos meus pais Carmen e Luiz Vitor, mas em especial à minha mãe, pelo amor e pela voz firme que sempre me manteve no caminho certo.

Ao meu amor Juan, por sempre estar ao meu lado e por fazer da longa distância até a PUC um caminho muito mais colorido.

Aos meus filhos do coração, Princesa, Dudu, Lalinha, Tob, Max e Raj, por fazerem meus dias mais leves e alegres.

Aos meus colegas, que viveram comigo todos os desafios de se tornar mestre.

Aos meus orientadores, professor Eurípedes do Amaral Vargas Jr. e professora Raquel Quadros Velloso, pela orientação e por todo o apoio durante o trabalho.

À CAPES e à PUC-Rio, pelos auxílios concedidos, sem os quais este trabalho não poderia ter sido realizado

O presente trabalho foi realizado com apoio da Coordenação de Aperfeiçoamento de Pessoal de Nível Superior - Brasil (CAPES) - Código de Financiamento 001 


\section{Resumo}

Almeida, Renata Neves de; Vargas Jr., Eurípedes do Amaral; Velloso, Raquel Quadros. Análise numérica de processos termomecânicos em problemas de estabilidade de taludes rochosos. Rio de Janeiro, 2019. 97p. Dissertação de Mestrado - Departamento de Engenharia Civil e Ambiental, Pontifícia Universidade Católica do Rio de Janeiro.

$\mathrm{O}$ entendimento dos processos que levam à instabilidade de taludes rochosos é de grande importância em análises de risco. Normalmente, desplacamentos e quedas de blocos de rocha ocorrem em épocas sem chuva, levando a crer que existem outros fatores deflagradores que devem ser analisados. Estudos relativamente recentes tem levantado a importância das tensões térmicas na propagação de fissuras e noacúmulo de tensões de tração. De forma a avaliar o impacto da ciclagem térmica sobre a rocha, foram realizadas análises termomecânicas utilizando o software de elementos finitos Abaqus 6.14. Nas simulações efetuadas foram utilizadas geometrias simplificadas, representativas de placas rochosas reais de áreas costeiras do Brasil. O maciço rochoso foi considerado isotrópico e homogêneo e os parâmetros térmicos utilizados (condutividade, calor específico e coeficiente de expansão térmica) foram adotados de acordo com valores obtidos na literatura para rochas de origem e constituição similar às rochas presentes na costa da região sudeste do Brasil (Gnaisses e Granitos). As condições de contorno de temperatura foram obtidas através de campanhas experimentais extraídas de estudo anterior. Admitiu-se ainda, apenas a ocorrência do modo I de propagação de fraturas, sendo a análise da propagação restrita a comparação entre $K_{1 c}$ e os valores $K_{1}$ desenvolvidos. Os resultados das simulações numéricas mostraram que a ocorrência de baixas temperaturas e de altos gradientes térmicos entre as faces externa e interna da placa ocasionam os maiores valores de $\mathrm{K}_{1}$, cuja magnitude é comparável aos valores de $\mathrm{K}_{1 \mathrm{c}}$ típicos para rochas encontradas na região sudeste do Brasil.

\section{Palavras-chave}

Análise termomecânica; Estabilidade de taludes rochosos; Análise numérica. 


\section{Abstract}

Almeida, Renata Neves de; Vargas Jr., Eurípedes do Amaral (Advisor); Velloso, Raquel Quadros (Co-advisor). Numerical analysis of thermomechanical processes in slope stability problems of rock masses. Rio de Janeiro, 2019. 97p. Dissertação de Mestrado - Departamento de Engenharia Civil e Ambiental, Pontifícia Universidade Católica do Rio de Janeiro

The understanding of the processes that lead to instability of rock slopes is of great importance in risk analysis. Normally, detachments and rockfalls occur in times without rain, leading to belief that there are other triggering factors that need to be evaluated. Relatively recent studies have raised the importance of thermal stresses in the propagation of cracks and in the accumulation of tensile stresses. In order to evaluate the impact of thermal cycling on the rock, thermomechanical analyzes were performed using Abaqus 6.14 finite element software. In the simulations, simplified geometries were used, representative of real rock plates of coastal areas of Brazil. The rock mass was considered isotropic and homogeneous and the thermal parameters (conductivity, specific heat and coefficient of thermal expansion) were adopted according to values obtained in the literature for rocks of origin and constitution similar to the rocks present in the coast of the southeastern region of Brazil (Gneisses and Granites). The temperature contour conditions were obtained through experimental campaigns extracted from a previous study. Only the occurrence of mode I of fracture propagation was allowed, with propagation analysis being restricted to the comparison between $K_{1 c}$ and the $K_{1}$ values developed. The results of the numerical simulations showed that the occurrence of low temperatures and high thermal gradients between the outer and inner faces of the plate cause the highest values of $\mathrm{K}_{1}$, whose magnitude is comparable to the values of $\mathrm{K}_{1 \mathrm{c}}$ typical for rocks found in the southeastern region of Brazil

\section{Keywords}

Thermomechanical analysis; Stability of rock slopes; Numerical analysis 


\section{Sumário}

1.Introdução 16

1.1. Objetivos 20

1.2. Estrutura da dissertação 20

2. Tensões e deformações de origem térmica em sólidos 22

2.1. Tensões e deformações de origem térmica em sólidos de geometrias simplificadas

3. Mecânica da fratura 26

3.1. Mecânica da Fratura Linear Elástica: 27

4. Processos termomecânicos em problemas de estabilidade de taludes rochosos: estudos anteriores

5. Simulação computacional

5.1. Geometrias 36

5.2. Condições de contorno 39

5.2.1.Condições de contorno mecânicas 39

5.2.2. Condições de contorno de temperatura 40

5.3. Propriedades do material 42

5.4. Malha de elementos finitos 43

5.5. Cenários simulados 45

6. Resultados e discussão 46

6.1.Placa submetida apenas à ação da gravidade $\quad 47$ 
$\begin{array}{lr}\text { 6.1.1.Placa rochosa intacta } & 47\end{array}$

6.1.2.Placa rochosa fraturada 49

6.2. Placa submetida apenas a variações não uniformes de temperatura

6.2.1. Placa rochosa intacta 51

6.2.2. Placa rochosa fraturada 63

6.3. Placa submetida à gravidade e a variações não uniformes de temperatura $\quad 74$

6.3.1. Placa rochosa intacta $\quad 74$

6.3.2. Placa rochosa fraturada 83

$\begin{array}{ll}\text { 7. Conclusão } & 94\end{array}$ 


\section{Lista de Figuras}

Figura 2.1: Representação do mecanismo de expansão e contração de ocorre em uma foliação de comprimento "L" e espessura "d", localizada em um talude de inclinação média " $\beta$ ", com curvatura topográfica " $k$ ". (Collins \& Stock, 2016)

Figura 3.1: Placa infinita com entalhe elíptico submetida à tração (Anderson, 2005)

Figura 3.2: Placa infinita com abertura plana carregada biaxialmente (Albuquerque, 1998).

Figura 3.3: Modos de propagação de fraturas (Silva, 2015) 30

Figura 4.1: a) Foto da área instrumentada. b) Geometria utilizada para modelagem numérica - corte perpendicular ao vale. (Gunzburguer et al., 2005)

Figura 4.2: Geometria simplificada utilizada nas análises numéricas (Vargas et al., 2012)

Figura 4.3: Modelo esquemático utilizado na determinação das tensões térmicas (Lamp et al., 2016

Figura 4.4: a)Modelo simplificado utilizado na determinação do efeito da ciclagem térmica sobre o desprendimento do bloco deslizante. b) Geometria exata do Bloco 1 na encosta leste de Masada, com fragmentos de rocha representados pelo bloco em cunha localizado na fratura. Sd é a 
profundidade na qual há alteração de temperatura, Lw é o comprimento da cunha e Lb é o comprimento do bloco. (Bakun-Mazor et al., 2013) ....35

Figura 5.1: Geometria 3D simplificada de uma placa contendo uma fratura não persistente representando a condição mostrada na Figura 5.2 .........37

Figura 5. 2: Foto retratando um grande desplacamento de rocha ocorrido no estado do Espírito Santo, Brasil 37

Figura 5. 3: Fotos retratando um grande desplacamento de rocha ocorrido no bairro da Posse em Petórpolis, Rio de Janeiro, Brasil - a) visão geral da área afetada e b) placas rochosas parcialmente presas ao maciço....38

Figura 5. 4: Condições de contorno mecânicas 39

Figura 5. 5: Disposição dos blocos e dos sensores utilizados para determinação das temperaturas na fratura, na superfície e no interior do bloco submetido a condições de campo (Vargas et al., 2012) 40

Figura 5. 6: Variação da temperatura nas faces superior e inferior ao longo do tempo (Modificado de Vargas et al. 2012) 41

Figura 5. 7: Malha de elementos finitos utilizada na modelagem da placa rochosa intacta

Figura 5. 8: Malha de elementos finitos utilizada na modelagem da placa rochosa fraturada 44

Figura 5. 9: Contorno utilizado no cálculo das integrais de contorno- Vista superior da placa rochosa 45 
Figura 6.1: Distribuição de tensões de tração que ocorre em uma placa intacta submetida apenas à ação da gravidade: (a) Perspectiva isométrica (b) Vista superior (c) Vista inferior (d) Seção transversal central - Fator de escala de deformação: 2000

Figura 6.2: Distribuição de tensões de tração que ocorre em uma placa fraturada submetida apenas à ação da gravidade: (a) Perspectiva isométrica (b) Vista superior (c) Vista inferior (d) Seção transversal central - Fator de escala de deformação: 2000 . 50

Figura 6.3: Variação de temperatura nas faces inferior e superior e na parte interna da placa ao longo do tempo 52

Figura 6.4: Exemplo de distribuição de tensões de tração em placa submetida à variação não uniforme de temperatura ( $\mathrm{t}=1,5$ dias): (a)Perspectiva isométrica (b) Vista inferior (c) Seção transversal central 54

Figura 6.5: Exemplo de distribuição de tensões de tração em placa submetida à variação não uniforme de temperatura ( $t=2$ dias): (a)Perspectiva isométrica (b) Vista inferior (c) Seção transversal central 56

Figura 6.6: Exemplo de distribuição de tensões de tração em placa submetida à variação não uniforme de temperatura ( $t=9,5$ dias): (a)Perspectiva isométrica (b) Vista superior (c) Vista inferior (d) Seção transversal central 58

Figura 6.7: Exemplo de distribuição de tensões de tração em placa submetida à variação não uniforme de temperatura ( $\mathrm{t}=8$ dias): (a)Perspectiva isométrica (b) Vista superior (c) Vista inferior (d) Seção transversal central 60 
Figura 6.8: Exemplo de distribuição de tensões de tração em placa submetida à variação não uniforme de temperatura ( $\mathrm{t}=9$ dias): (a)Perspectiva isométrica (b) Vista inferior (c) Seção transversal central 62

Figura 6.9: $\mathrm{K}_{1}\left(\mathrm{~Pa} \mathrm{~m}^{1 / 2}\right)$ ao longo do tempo para placa submetida a variações não uniformes de temperatura 63

Figura 6.10: Exemplo de distribuição de tensões de tração em placa fraturada submetida à variação não uniforme de temperatura ( $t=1,5$ dias): (a)Perspectiva isométrica (b) Vista inferior (c) Seção transversal central 65

Figura 6.11: Exemplo de distribuição de tensões de tração em placa fraturada submetida à variação não uniforme de temperatura ( $\mathrm{t}=2$ dias): (a)Perspectiva isométrica (b) Vista inferior (c) Seção transversal central 67

Figura 6.12: Exemplo de distribuição de tensões de tração em placa fraturada submetida à variação não uniforme de temperatura ( $t=9,5$ dias): (a)Perspectiva isométrica (b) Vista superior (c) Vista inferior (d) Seção transversal central 69

Figura 6.13: Exemplo de distribuição de tensões de tração em placa fraturada submetida à variação não uniforme de temperatura ( $\mathrm{t}=8$ dias): (a)Perspectiva isométrica (b) Vista superior (c) Vista inferior (d) Seção transversal central 71

Figura 6.14: Exemplo de distribuição de tensões de tração em placa fraturada submetida à variação não uniforme de temperatura ( $\mathrm{t}=9$ dias): (a)Perspectiva isométrica (b) Vista inferior (c) Seção transversal central 73

Figura 6.15: Exemplo de distribuição de tensões de tração em placa submetida à gravidade e à variação não uniforme de temperatura $(\mathrm{t}=1,5$ dias): (a)Perspectiva isométrica (b) Vista inferior (c) Seção transversal central 
Figura 6.16: Exemplo de distribuição de tensões de tração em placa submetida à gravidade e à variação não uniforme de temperatura ( $\mathrm{t}=2$ dias): (a)Perspectiva isométrica (b) Vista inferior (c) Seção transversal central 77

Figura 6.17: Exemplo de distribuição de tensões de tração em placa submetida à gravidade e à variação não uniforme de temperatura $(t=9,5$ dias): (a)Perspectiva isométrica (b) Vista inferior (c) Seção transversal central 79

Figura 6.18: Exemplo de distribuição de tensões de tração em placa submetida à gravidade e à variação não uniforme de temperatura ( $\mathrm{t}=8$ dias): (a)Perspectiva isométrica (b) Seção transversal central 80

Figura 6.19: Exemplo de distribuição de tensões de tração em placa submetida à gravidade e à variação não uniforme de temperatura ( $\mathrm{t}=9$ dias): (a)Perspectiva isométrica (b) Vista inferior (c) Seção transversal central 82

Figura 6.20: $\mathrm{K} 1(\mathrm{~Pa} \mathrm{~m} 1 / 2)$ ao longo do tempo para placa submetida à ação da gravidade e a variações não uniformes de temperatura 83

Figura 6.21: Exemplo de distribuição de tensões de tração em placa fraturada submetida à gravidade e à variação não uniforme de temperatura ( $t=1,5$ dias): (a)Perspectiva isométrica (b) Vista inferior (c) Seção transversal central 85

Figura 6.22: Exemplo de distribuição de tensões de tração em placa fraturada submetida à gravidade e à variação não uniforme de temperatura ( $\mathrm{t}=2$ dias): (a)Perspectiva isométrica (b) Vista inferior (c) Seção transversal central 
Figura 6.23: Exemplo de distribuição de tensões de tração em placa fraturada submetida à gravidade e à variação não uniforme de temperatura ( $t=9,5$ dias): (a)Perspectiva isométrica (b) Vista inferior (c)

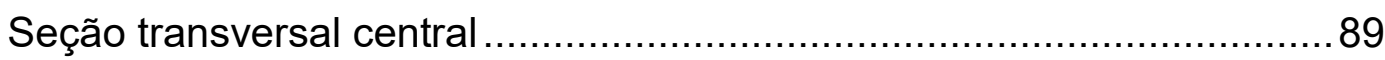

Figura 6.24: Exemplo de distribuição de tensões de tração em placa fraturada submetida à gravidade e à variação não uniforme de temperatura ( $\mathrm{t}=8$ dias): (a)Perspectiva isométrica (b) Vista inferior (c) Seção transversal central ................................................................. 91

Figura 6.25: Exemplo de distribuição de tensões de tração em placa fraturada submetida à gravidade e à variação não uniforme de temperatura ( $\mathrm{t}=9$ dias): (a)Perspectiva isométrica (b) Vista inferior (c) Seção transversal central ..................................................................93 


\section{Lista de tabelas}

Tabela 5.1: Variação da temperatura ao longo do tempo nas faces superior e inferior

Tabela 5.2: Propriedades da rocha utilizada na simulação

Tabela 6.1: Valores de $K_{1 \mathrm{c}}$ de Granitos e Gnaisses do Rio de Janeiro ....47

Tabela 6.2: Fator de intensidade de tensões do modo I para placa submetida apenas à gravidade

Tabela 6.3:Tensões de tração e compressão máximas desenvolvidas na placa intacta em decorrência da variação não uniforme de temperatura: caso I.

Tabela 6.4:Tensões de tração e compressão máximas desenvolvidas na placa intacta em decorrência da variação não uniforme de temperatura: caso II.

Tabela 6.5:Tensões de tração e compressão máximas desenvolvidas na placa intacta em decorrência da variação não uniforme de temperatura: caso III

Tabela 6.6:Tensões de tração e compressão máximas desenvolvidas na placa intacta em decorrência da variação não uniforme de temperatura: caso IV 
Tabela 6.7:Tensões de tração e compressão máximas desenvolvidas na placa intacta em decorrência da variação não uniforme de temperatura: caso $\mathrm{V}$

Tabela 6.8: Valores de $\mathrm{K}_{1}\left(\mathrm{MPa} \mathrm{m}^{1 / 2}\right)$ desenvolvidos em decorrência variação não uniforme de temperatura: caso I

Tabela 6.9: Valores de $\mathrm{K} 1\left(\mathrm{MPa} \mathrm{m}^{1 / 2}\right)$ desenvolvidos em decorrência variação não uniforme de temperatura: caso II

Tabela 6.10:Tensões de tração e compressão máximas desenvolvidas na placa fraturada em decorrência da variação não uniforme de temperatura: caso III. 68

Tabela 6.11:Valores de K1 (MPa $\mathrm{m}^{1 / 2}$ ) desenvolvidos em decorrência variação não uniforme de temperatura: caso III

Tabela 6.12: Valores de $\mathrm{K} 1\left(\mathrm{MPa} \mathrm{m}{ }^{1 / 2}\right)$ desenvolvidos em decorrência variação não uniforme de temperatura: caso IV

Tabela 6.13: Valores de K1 (MPa ${ }^{1 / 2}$ ) desenvolvidos em decorrência variação não uniforme de temperatura: caso $\mathrm{V}$.

Tabela 6.14: Tensões de tração e compressão máximas desenvolvidas na placa intacta em decorrência da ação da gravidade combinada à variação não uniforme de temperatura: caso I 74

Tabela 6.15: Tensões de tração e compressão máximas desenvolvidas na placa intacta em decorrência da ação da gravidade combinada à variação não uniforme de temperatura: caso II 76

Tabela 6.16: Tensões de tração e compressão máximas desenvolvidas na placa intacta em decorrência da ação da gravidade combinada à variação não uniforme de temperatura: caso III 
Tabela 6.17: Tensões de tração e compressão máximas desenvolvidas na placa intacta em decorrência da ação da gravidade combinada à variação não uniforme de temperatura: caso IV

Tabela 6.18: Tensões de tração e compressão máximas desenvolvidas na placa intacta em decorrência da ação da gravidade combinada à variação não uniforme de temperatura: caso $\mathrm{V}$

Tabela 6.19: Valores de K1 (MPa m ${ }^{1 / 2}$ ) desenvolvidos em decorrência da ação da gravidade combinada à variação não uniforme de temperatura: caso I.

Tabela 6.20: Valores de K1 (MPa m ${ }^{1 / 2}$ ) desenvolvidos em decorrência da ação da gravidade combinada à variação não uniforme de temperatura: caso II.

Tabela 6.21: Valores de K1 (MPa $\mathrm{m}^{1 / 2}$ ) desenvolvidos em decorrência da ação da gravidade combinada à variação não uniforme de temperatura: caso III

Tabela 6.22: Valores de K1 (MPa $\mathrm{m}^{1 / 2}$ ) desenvolvidos em decorrência da ação da gravidade combinada à variação não uniforme de temperatura: caso IV

Tabela 6.23: Valores de $\mathrm{K}_{1}\left(\mathrm{MPa} \mathrm{m}^{1 / 2)}\right.$ desenvolvidos em decorrência da ação da gravidade combinada à variação não uniforme de temperatura: caso $\mathrm{V}$ 


\section{1.}

\section{Introdução}

É comum que acidentes geotécnicos sejam associados a deslizamentos de terra. Entretanto, acidentes envolvendo desplacamentos e queda de blocos de rocha também ocorrem com relativa frequência.

Apesar da aparente solidez e imutabilidade, o maciço rochoso não é um meio contínuo e perfeitamente homogêneo impassível diante dos efeitos do tempo. A rocha possui falhas, juntas, planos de fraqueza e zonas formadas por materiais diversos cujos comportamentos geomecânicos podem diferir razoavelmente. É um material e, como qualquer outro, se degrada e é susceptível às agressões do meio. Presença de água, como agente químico ou físico (aumento da poropressão nas fraturas, por exemplo), bem como variações diárias e sazonais de temperatura desempenham papeis importantes nesse processo, que pode, por sua vez culminar em uma ruptura.

Em regiões que possuem paredões rochosos expostos naturais ou artificiais é comum que existam fenômenos de instabilidade com certa frequência. Normalmente há uma tendência em associar tais eventos a épocas de pluviosidade significativa, entretanto, diversos trabalhos têm abordado o efeito das variações térmicas sobre os maciços rochosos, evidenciando a sua importância em eventuais eventos de instabilidade. Os estudos elaborados por Vargas et al. (2012), Collins \& Stock (2016), Lamp et al. (2016) e Bakun-Mazor et al. (2013) são alguns exemplos de pesquisas desenvolvidas nessa área.

O fenômeno descrito até aqui é parte de um processo natural. A questão é que muitas vezes este processo não é observado ou monitorado como deveria, 
principalmente em locais de risco, como é o caso de certos pontos da cidade do Rio de Janeiro. Sendo assim, o presente trabalho visa estudar a influência das variações diárias de temperatura na geração de tensões de origem térmica, avaliando as tensões máximas desenvolvidas e a variação do fator de intensidade de tensões para o modo I, de maneira a estudar a possibilidade de ruptura da rocha por tração ou por propagação de fraturas sem considerar a ocorrência de fadiga. A simulação foi realizada no software Abaqus 6.14 mediante modelagem por elementos finitos, utilizando geometrias tridimensionais simplificadas para as placas rochosas intacta e fraturada.

\section{1.}

\section{Objetivos}

O presente trabalho visa estudar os efeitos das oscilações diárias de temperatura no que tange ao desenvolvimento de tensões de tração e à propagação de fraturas, como consequência de processos intermitentes de expansão e contração de rochas expostas ao tempo.

Como objetivos específicos, tem-se:

- Determinar a magnitude das tensões e do fator de intensidade de tensões desenvolvidos, considerando a ação da gravidade e das variações não uniformes de temperatura. As ações foram simuladas em separado e combinadas, de forma a analisar a influência de cada;

- Comparar, respectivamente, os fatores de intensidade de tensão e os valores de tensão de tração na direção perpendicular ao plano da fratura com o valor de tenacidade à fratura para o modo I e com o limite de resistência à tração da rocha;

\section{2.}

\section{Estrutura da dissertação}

Para adequada explanação do estudo desenvolvido, o presente trabalho foi particionado em 7 capítulos. No Capítulo 1 é feita a contextualização do estudo, expondo sua motivação e relevância, bem como os objetivos que almeja alcançar com o desenvolvimento do trabalho. 
Já nos Capítulos 2 e 3 é apresentada uma seleção dos conceitos imprescindíveis ao entendimento, concepção e análise do estudo. São abordados no Capítulo 2 os conceitos de tensões e deformações de origem térmica em sólidos e no Capítulo 3 a teoria da mecânica da fratura.

No Capítulo 4 é apresentada uma seleção de estudos nos quais os processos termomecânicos são relacionados aos problemas de estabilidade de taludes rochosos

No Capítulo 5 é abordada a confecção da simulação. São apresentadas as geometrias, dados e parâmetros utilizados, bem como métodos de análise e demais considerações feitas.

No Capítulo 6 são apresentados os resultados obtidos, além de análises e discussões.

No Capítulo 7, são feitas as considerações finais a respeitos dos resultados obtidos, contemplando avaliações comparativas e conclusões. São enumeradas também sugestões para possíveis estudos futuros.

Por fim, no Capítulo 8, são apresentadas as referências utilizadas para eventuais consultas. 
2.

\section{Tensões e deformações de origem térmica em sólidos}

A variação de temperatura é capaz de impor deformações e modificar o estado de tensões de um corpo. O estudo das tensões de origem térmica envolve uma série de fatores que vão além da variação térmica em si. O grau de restrição à deformação, os parâmetros térmicos dos diferentes materiais que podem compor um único corpo e a distribuição das variações de temperatura, que na maioria dos casos não é uniforme, são alguns dos fatores mais importantes.

Neste item serão abordados, portanto, alguns conceitos básicos de tensões e deformações em sólidos de geometrias simplificadas, demonstrando o efeito de cada um dos fatores enumerados acima. Os conceitos podem ser extrapolados para outras geometrias e são de grande importância no entendimento dos resultados das simulações realizadas.

\section{1.}

\section{Tensões e deformações de origem térmica em sólidos de geometrias simplificadas}

Quando sob condição de livre deformação, a variação de temperatura (T) de uma barra cilíndrica isostática, por exemplo, produz uma configuração deformada na qual o alongamento/ contração longitudinal $(\lambda)$ é função do coeficiente de expansão térmica linear $(\alpha)$ do material, do comprimento da barra (l) e da variação de temperatura (T.) Caso haja a atuação de alguma força externa, a deformação total é dada pela soma da deformação produzida por esta força, calculada através da lei de Hooke, com a deformação de origem térmica dada pela Eq. (2.1)

$\varepsilon=\frac{\lambda}{l}=\frac{\alpha T l}{l}=\alpha T$

Já no caso de uma barra hiperestaticamente vinculada e, portanto, impedida de se deformar, a restrição à livre deformação produz tensões que atuam anulando 
a deformação induzida pela variação da temperatura. Supondo uma barra submetida a uma variação positiva de temperatura, o alongamento que ocorreria, caso fosse permitida sua deformação, é combatido por uma força de reação $\mathrm{P}$, responsável pela geração da tensão normal $\sigma$ (Eq. 2.2).

$\sigma=-\alpha \mathrm{ET}$

Entretanto, caso o mesmo sólido hiperestaticamente vinculado seja submetido a diferentes variações de temperatura ao longo da sua espessura surgirá um momento de curvatura virtual, tal qual a força de reação P, capaz de anular a curvatura imposta pelo gradiente de temperatura. Como consequência, a distribuição da tensão térmica $\sigma$ será condicionada ao padrão de distribuição de temperatura que a originou. Se a variação da temperatura entre as fibras inferior e superior for linear, as tensões também possuirão distribuição linear. Assim como, se a variação for quadrática, a distribuição de tensões também será. Os valores de tensões serão condicionados também à forma com que os vínculos restringem as deformações.

As duas situações citadas até então retratam condições de livre deformação ou de total restrição à deformação. Há situações, no entanto, onde há condição de restrição parcial e nestes casos as tensões geradas são outras. Tomando como exemplo duas barras de comprimento $(l)$ com $\alpha_{1} \neq \alpha_{2}, T_{1} \neq T_{2}$ e $A_{1} \neq A_{2}$, vinculadas de forma a manter o mesmo comprimento,o alongamento de cada barra será composto pela soma das parcelas devida à livre deformação e devida à tensão térmica originada pela restrição parcial. As tensões térmicas desenvolvidas nas barras 1 e 2 serão dadas pela Eq. (2.3).

$\sigma_{1}=-K \alpha_{1} E_{1} T_{1} \quad \sigma_{2}=-\sigma_{1} \frac{A_{1}}{A_{2}}$

Onde,

$K=\frac{1-\frac{\alpha_{2} T_{2}}{\alpha_{1} T_{1}}}{1+\frac{A_{1} E_{1}}{A_{2} E_{2}}}$

O coeficiente K (Eq. 2.4) é conhecido como coeficiente de restrição. Em problemas desta forma, valores negativos de $\mathrm{K}$ implicam em tensões de tração na barra 1 e de compressão na barra 2. Isto ocorre quando o produto $\alpha_{2} \mathrm{~T}_{2}$ é maior do 
que o produto $\alpha_{1} T_{1}$, ou seja, com tais valores de coeficiente de expansão térmica e temperatura a barra 1 se alongaria menos do que a barra 2, que devido à restrição parcial, tem o alongamento combatido pela força de reação $\mathrm{P}$, responsável pelo surgimento da tensão de compressão $\sigma_{2}$. O mesmo tipo de raciocínio se aplica para valores positivos de $\mathrm{K}$, onde se verifica o inverso: tensões de compressão na barra 1 e tensões de tração na barra 2.

É importante destacar que o fato de existirem tensões de tração e de compressão não significa dizer que existe contração em uma das barras. As variações de temperatura $T_{1}$ e $T_{2}$ sendo positivas implicam necessariamente no alongamento de ambas. Os diferentes parâmetros de cada material, áreas das seções e valores de variação de temperatura é que, associados à condição de restrição parcial, serão responsáveis pelas diferentes tensões.

Portanto, fica evidente que quando se trata de um sistema nos quais os sólidos estão sob restrição parcial, é leviano afirmar que as tensões desenvolvidas são de tração ou compressão apenas sabendo se a variação de temperatura é positiva ou negativa.

Um exemplo do efeito das variações de temperatura aplicado especificamente a placas rochosas foi abordado por Collins \& Stock (2016). Segundo os autores, uma placa de rocha do tipo da Figura 2.1 pode apresentar dois tipos de deformação como resposta à incidência de calor. A camada pode se curvar, devido ao gradiente térmico entre a parte externa, mais aquecida, e a parte interna mais fria, ou pode se dilatar igualmente devido ao aquecimento uniforme. Os dois comportamentos dependem do grau de restrição à deformação que a placa está submetida, do quanto de calor será cedido à placa e se este será suficiente para aquecê-la igualmente ou não.

Collins \& Stock (2016) explicam que no caso onde ocorre gradiente de temperatura ao longo da espessura da placa, a curvatura provém de deformações diferenciais entre as faces interna e externa da placa, que, respectivamente, sofrem contração (compressão) e expansão (tração) simultaneamente. Se, devido à existência das zonas fraturadas nas extremidades da placa, é permitida a rotação dessa superfície, então haverá deflexão da placa. 


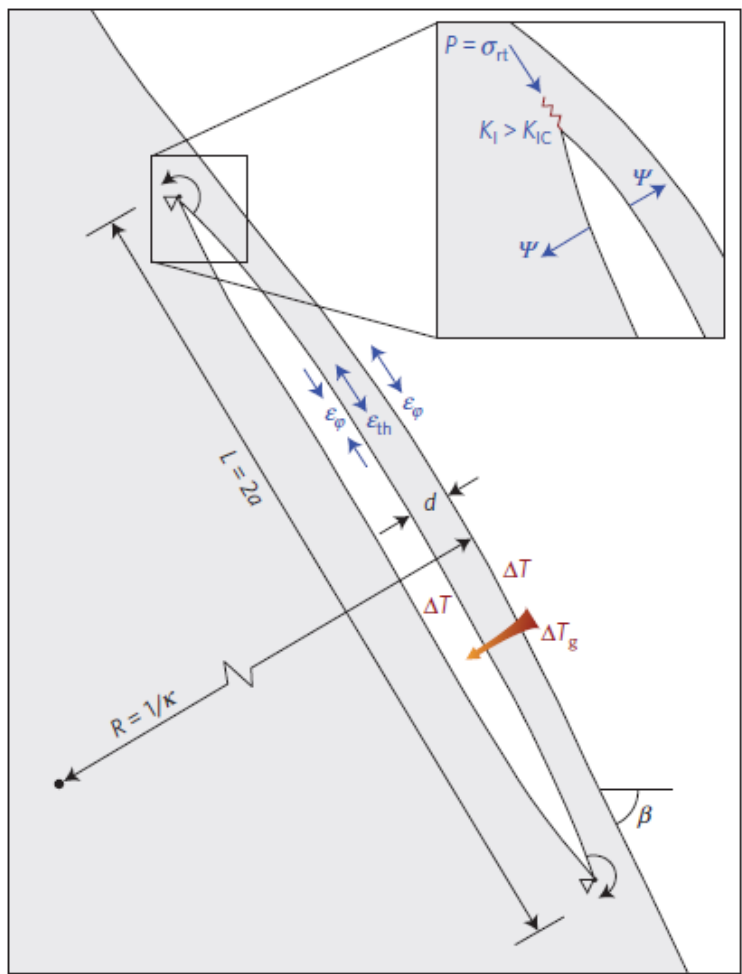

Figura 2.1: Representação do mecanismo de expansão e contração de ocorre em uma foliação de comprimento "L" e espessura " $d$ ", localizada em um talude de inclinação média " $\beta$ ", com curvatura topográfica "k". (Collins \& Stock, 2016)

Ainda neste mesmo estudo, Collins \& Stock (2016) mostraram, mediante comparação entre as deformações calculadas e medidas, que apenas parte da energia potencial de deformação térmica é convertida em deformação de fato. A junção entre o maciço e a placa atua como restrição parcial à livre deformação, o que faz com que haja geração de tensões nessas extremidades. Dito isto, a outra parcela da energia potencial de deformação térmica se manifesta como tensão térmica resultante $\left(\sigma_{\mathrm{rt}}\right)$ cuja contrapartida é a tensão de tração ortogonal à fratura " $\psi$ ", responsável pela propagação da fratura pelo modo I. 


\section{3.}

\section{Mecânica da fratura}

A mecânica do contínuo não considera a existência de descontinuidades e, portanto, não admite a possibilidade de colapso por propagação de fraturas. $\mathrm{O}$ estudo da mecânica da fratura surge na intenção de suprir a ausência de uma teoria no campo da resistência dos materiais que contemplasse o efeito das fraturas na resistência dos sólidos.

Dentro deste universo a mecânica da fratura é dividida em dois seguimentos: a Mecânica da Fratura Linear Elástica (MFLE) e a Mecânica da Fratura Elásto-Plástica (MFEP). A MFLE é aplicável a sólidos fraturados frágeis, já a Mecânica da Fratura Elásto-Plástica (MFEP) abrange também o efeito das fraturas em materiais dúcteis. A diferença reside no tamanho da zona plástica que se desenvolve durante o processo de propagação. Segundo Medina (2014), o MFLE admite que tensões elásticas regem o processo de propagação, pois a zona plástica na ponta da fratura em materiais frágeis é considerada pequena quando comparada às dimensões do sólido. Em materiais elastoplásticos, no entanto, a zona plástica adquire dimensões consideráveis na ponta da fratura, invalidando a premissa básica do MFLE e sendo assim necessária uma abordagem específica (MFEP).

As rochas, na condição de material de comportamento frágil, podem ser representadas satisfatoriamente pela MFEL e por esta razão apenas esta metodologia será descrita em maior detalhe. 


\section{1 .}

\section{Mecânica da Fratura Linear Elástica}

O engenheiro britânico Charles Edward Inglis conduziu um dos estudos precursores da mecânica da fratura ainda no início do século XX. Nele, uma placa de dimensões infinitas e dotada de um entalhe elíptico central é submetida a tensões de tração aplicadas ortogonalmente ao seu eixo maior, conforme a Figura 3.1 .

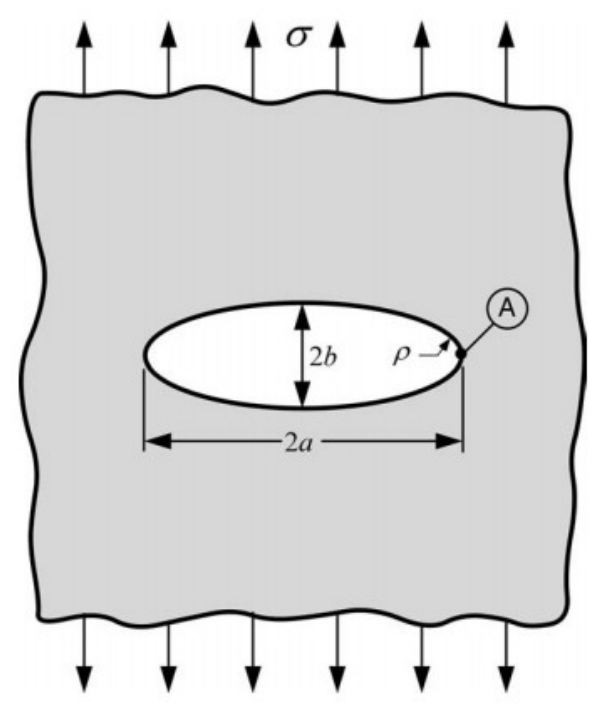

Figura 3.1: Placa infinita com entalhe elíptico submetida à tração (Anderson, 2005).

Inglis (1913) apud Anderson (2005) concluiu que nas pontas do entalhe elíptico ocorrem tensões superiores às aplicadas na placa, evidenciando assim a geração de concentração de tensões nas extremidades de aberturas.

A tensão na ponta da abertura, na direção das tensões de tração aplicadas, é dada pela Eq. 3.1, onde $\sigma$ é a tensão de tração aplicada na placa e $2 a$ e b são, respectivamente, o comprimento e a metade da largura da abertura.

$$
\sigma_{A}=\sigma(1+2 a / b)
$$

Considerando que o valor de $b$ é muito inferior ao valor de $a$, e que o raio de curvatura no ponto A é dado por $\rho=b^{2} / a$ a expressão acima se reduz a:

$\sigma_{A}=2 \sigma(a / \rho)^{\frac{1}{2}}$ 
Isto significa que a relação entre comprimento e espessura é o que influencia fortemente na magnitude da concentração de tensão. Ou seja, dependendo da forma que possui, o efeito do comprimento da fratura sobre o processo de propagação pode ser "amortizado" pela sua largura, o que vai de encontro aos resultados experimentais, onde se observa que fraturas maiores causam maior redução na resistência dos sólidos.

Além disso, segundo a Eq. (3.2), para raios de curvatura infinitesimais, a tensão na ponta da fratura tenderia ao infinito independentemente da tensão aplicada, o que sabidamente não é verídico.

Mediante tal constatação, alguns anos mais tarde o também engenheiro britânico Alan Arnold Griffith divulgou outro estudo sobre o assunto. Griffith (1920) abordou o efeito de fraturas na resistência mecânica dos sólidos e como, devido às solicitações cíclicas, a fadiga pode levar sólidos fraturados à ruptura com tensões máximas inferiores ao limite elástico do material.

Ciente da inadequação das hipóteses anteriores, Griffith (1920) elaborou um novo critério teórico de ruptura para sólidos elásticos pautado no Teorema da Mínima Energia. Segundo este novo critério, o equilíbrio de um sólido elástico submetido a forças de superfície é alcançado na condição de energia potencial mínima. Ou seja, o equilíbrio pode ser obtido através de um processo envolvendo a contínua redução na energia potencial por meio da propagação de fraturas (aumento da energia de superfície), de forma que não haja variação da energia total do sistema.

Dito isto, Griffiht (1920), estudando o balanço energético de uma placa infinita com uma abertura elíptica, propôs que a tensão aplicada à placa que é capaz de provocar o início da propagação da fratura é dada pela Eq. (3.3), onde $E$ é o módulo de elasticidade do material, $\gamma_{S}$ é a energia específica de superfície elástica (energia necessária para abrir uma fissura) e $a$ é metade do comprimento da fissura.

$$
\sigma f=\sqrt{\frac{2 E \gamma_{S}}{\pi a}}
$$


Segundo Griffith (1920), se a energia de deformação liberada durante um avanço infinitesimal da fratura for maior do que a energia necessária para forma uma nova superfície fraturada, então a trinca tende a se propagar de maneira instável.

Entretanto, o modelo proposto por Griffith era limitado a materiais frágeis e baseava-se em um parâmetro experimental (energia superficial específica) que não era, de fato, uma característica do material.

Westergaard (1939) apud Anderson (2005) examinou analiticamente o problema sob a luz da teoria da elasticidade e determinou a distribuição de tensões que ocorre em um ponto genérico próximo à ponta de uma fratura plana contida em uma placa infinita biaxialmente carregada (Figura 3.2). A Eq. 3.4 apresenta a tensão de tração $\left(\sigma_{y}\right)$ responsável por propagar a fratura desenvolvida no ponto "A".

$\sigma_{y}=\sigma \sqrt{\frac{a}{2 r}} \cos (\theta / 2)(1+\sin (\theta / 2) \sin (3 \theta / 2)$

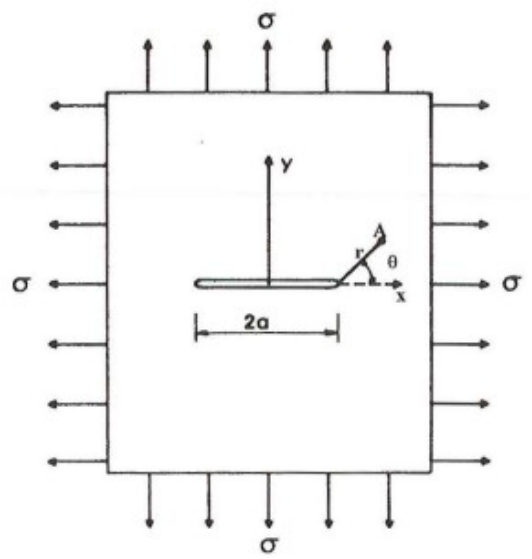

Figura 3.2: Placa infinita com abertura plana carregada biaxialmente (Albuquerque, 1998)

Quando $\theta$ tende à zero, a expressão da Eq. (3.4) se reduz a Eq. (3.5).

$\sigma_{y}=\sigma \sqrt{\frac{a}{2 r}}$

Multiplicando ambos os lados por $\sqrt{\pi}$ chegamos ao fator intensidade de tensão K para o modo I, que é função apenas da tensão aplicada e do comprimento da fratura (Eq. 3.6) 
$K_{I}=\sigma \sqrt{\pi a}$

Além de definir o fator de intensidade de tensão para o modo $\mathrm{I}\left(\mathrm{K}_{\mathrm{I}}\right)$, ainda neste estudo Westergaard (1939) propôs que a propagação da fratura se dá quando " $K$ " alcança um valor crítico chamado de tenacidade à fratura $\left(\mathrm{K}_{\mathrm{I}} \mathrm{c}\right)$, um parâmetro intrínseco do material.

Apesar de a fratura poder se desenvolver segundo a combinação de mais de um modo de propagação, são enumerados separadamente os três modos principais com seus respectivos fatores de intensidade de tensão. O Modo I $\left(\mathrm{K}_{\mathrm{I}}\right)$ corresponde à propagação exclusivamente por ocorrência de tração normal ao plano da fratura (Figura 3.2). Já no Modo II ( $\left.\mathrm{K}_{\mathrm{II}}\right)$ a propagação decorre de tensões cisalhantes existentes no plano da fratura e, por fim, o Modo III ( $\mathrm{K}_{\mathrm{III}}$ rasgamento) também é produto de tensões cisalhantes, porém normais ao plano da fratura (Figura 3.3)

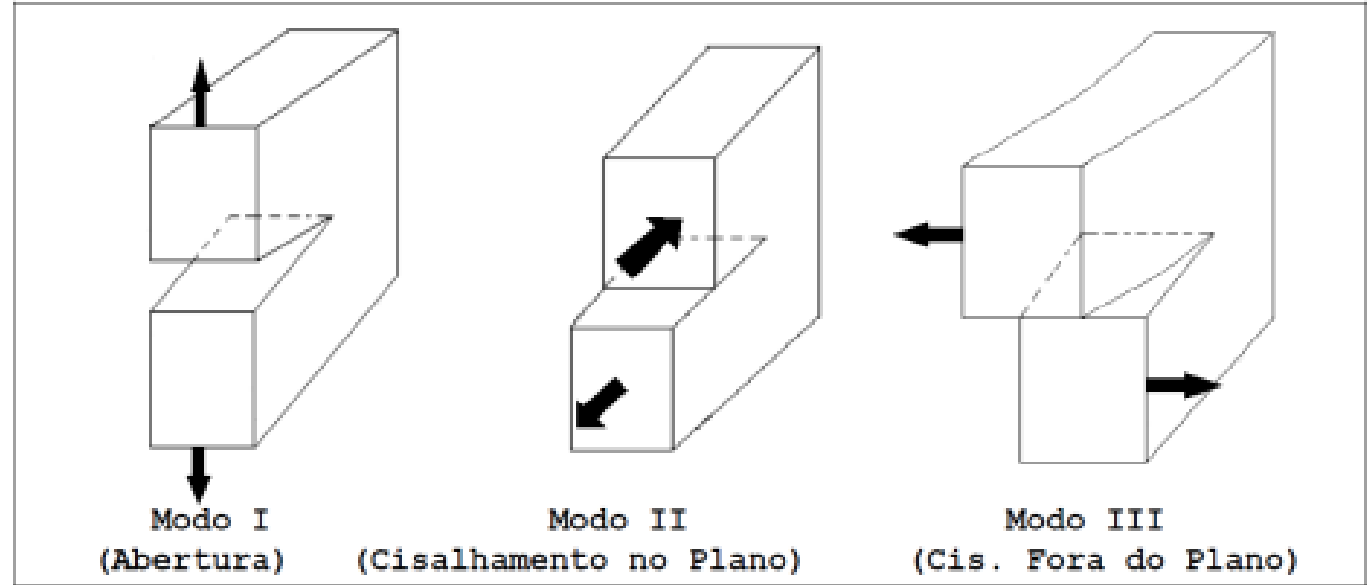

Figura 3.3: Modos de propagação de fraturas (Silva, 2015)

É válido, no entanto, discutir a ideia de que a propagação da fratura ocorre estritamente quando o valor do fator de intensidade de tensões é superior à tenacidade à fratura. Vargas et al. (2012) referenciando Atkinson (1987) menciona que a propagação da fratura por fadiga está atrelada ao número de ciclos e à magnitude da diferença $\mathrm{KI}_{\text {máx }}-\mathrm{K}_{\text {Imín. }}$ Collins \& Stock (2016) destacam também que o carregamento cíclico e o aumento da temperatura podem causar o crescimento subcrítico da fratura quando $\mathrm{k}_{\mathrm{I}}$ é superior ao limite de corrosão para tensões, $\mathrm{k}_{0}$, cuja magnitude pode ser tomada como sendo igual ou até inferior à $10 \%$ do valor de $\mathrm{k}_{\mathrm{Ic}}$. Dito isto, apesar de $\mathrm{K}_{\mathrm{I}}$ ser inferior a $\mathrm{K}_{\mathrm{I}} \mathrm{c}$, é provável que a 
fratura se propague após anos sofrendo ciclos diários de aquecimento e resfriamento.

Ainda mais tarde, Irwin (1956) apud Anderson (2005) complementou a teoria de Griffith e propôs analisar a taxa na qual ocorre a transformação da energia de deformação em energia de superfície como função do comprimento da fratura. Tal abordagem deu origem ao parâmetro de variação da liberação da energia de deformação $(\mathrm{G})$, que se relaciona ao fator de intensidade de tensões $(\mathrm{K})$ segundo a Eq. (3.7) para o estado plano de tensões e segundo a Eq. (3.8) para o caso de estado plano de deformação:

$G=K^{2} / E$

$G=K^{2}\left(1-v^{2}\right) / E$ 


\section{4. \\ Processos termomecânicos em problemas de estabilidade de taludes rochosos: estudos anteriores}

Especialmente nos últimos anos, muitos estudos têm relacionado a ciclagem térmica à propagação de fraturas em maciços rochosos. Em 2005, um deslizamento de grande impacto regional ocorrido em Rochers de Valabresbres Alpes franceses motivou Gunzburger et al. (2005) a avaliarem melhor os fatores responsáveis pela ruptura de um dos taludes da região. $\mathrm{Na}$ ocasião, tal evento geotécnico não pôde ser associado a nenhuma chuva intensa, atividade sísmica, congelamento /descongelamento ou qualquer outra causa comum na literatura. Diante da inexistência de um fator desencadeante óbvio para o deslizamento ocorrido, Gunzburger et al. (2005) deduziram que deveriam existir pequenos eventos imperceptíveis e não suficientes para causar ruptura, que quando acumulados poderiam deflagrar o deslizamento. Para comprovar essa teoria, uma parte vulnerável da mesma encosta foi instrumentada (Figura 4. 1a) com uma estação total e os deslocamentos medidos foram comparados com os resultados obtidos na modelagem numérica. O modelo numérico (Figura 4. 1b) mostrou que as deformações induzidas termicamente podem ser suficientes para causar a fluência descendente gradual de um bloco de rocha localizado em uma posição desconfortável, o que foi compatível com os deslocamentos medidos. 


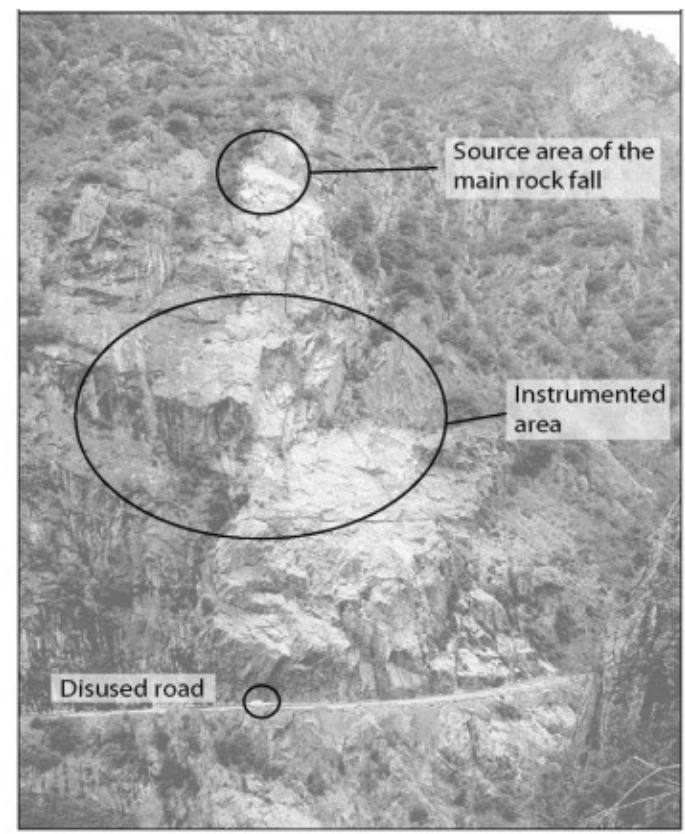

(a)

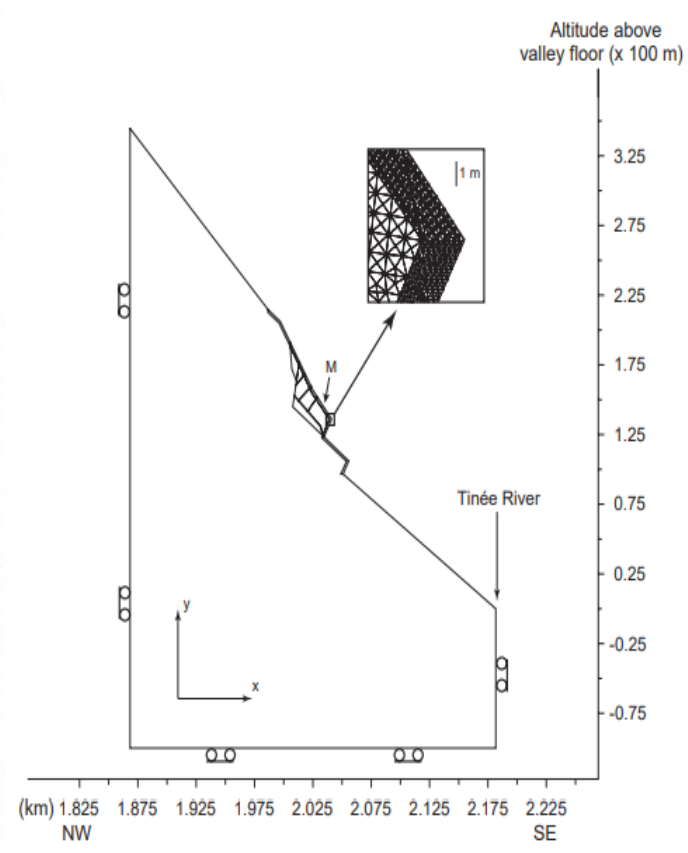

(b)

Figura 4. 1: a) Foto da área instrumentada. b) Geometria utilizada para modelagem numérica corte perpendicular ao vale. (Gunzburguer et al., 2005)

Já Vargas et al. (2012) simularam, por meio de análises numéricas bidimensionais, as tensões térmicas e os valores de $\mathrm{K}_{1}$ gerados em um bloco rochoso localizado em um talude típico da região sudeste do Brasil dotado de uma fratura não persistente e submetido a ação da gravidade e a variações não uniformes de temperatura (Figura 4. 2).

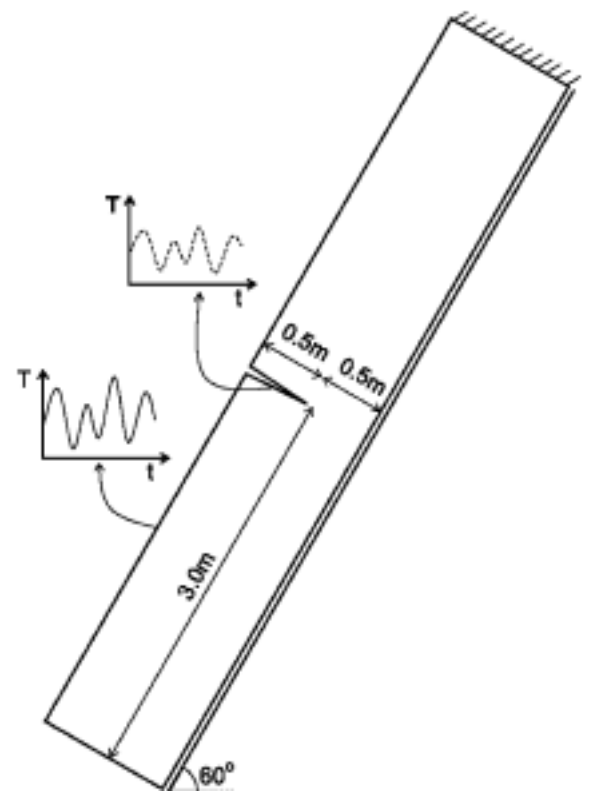

Figura 4. 2: Geometria simplificada utilizada nas análises numéricas (Vargas et al., 2012) 
Vargas et al. (2012) detectaram que o processo de ciclagem térmica faz com que $\mathrm{K}_{1}$ oscile ao longo do tempo, o que pode levar à fadiga. Concluiu também que os maiores valores de $\mathrm{K}_{1}$ ocorrem nos dias mais frios e que a sua magnitude é suficiente para propagar fraturas pré-existentes, de acordo com valores de $\mathrm{K}_{1 \mathrm{c}}$ típicos das rochas do Rio de Janeiro, ocasionando o deslizamento e queda de parte do bloco.

Lamp et al. (2016) também atestaram o impacto das tensões térmicas no intemperismo de taludes rochosos, desta vez em taludes do McMurdo Dry Valleys, Antartica. Neste estudo, a modelagem numérica tridimensional associada à teoria da propagação subcrítica de fraturas, permitiu quantificar o impacto do intemperismo devido à fadiga térmica sobre a estabilidade de placas de rocha. $\mathrm{O}$ modelo utilizado para determinação das tensões térmicas é apresentado na Figura 4. 3. Nele, uma placa retangular de rocha dolerítica, dotada de uma casca de alteração na sua superfície, foi submetida a condições de contorno de temperatura obtidas em campanhas experimentais. Foi determinada a tensão de tração máxima normal na base da crosta de alteração onde era esperado o descolamento. Utilizando a teoria da MFEL e as tensões calculadas, Lamp et al. (2016) confirmaram que a ciclagem térmica, decorrente dos altos gradientes de temperatura e das bruscas variações de temperatura superficial durante o verão, levam à fadiga e à lenta propagação de fissuras pré-existentes, culminando, por sua vez, no descolamento total de placas rochosas.

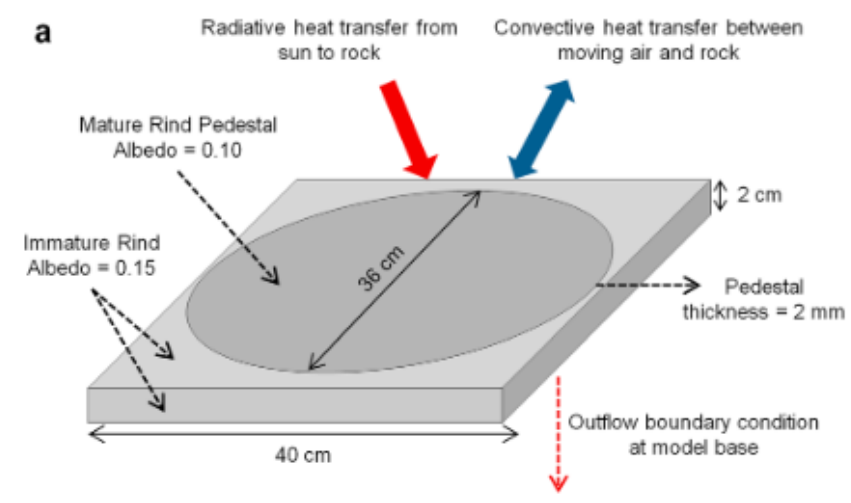

Figura 4. 3: Modelo esquemático utilizado na determinação das tensões térmicas (Lamp et al., 2016

Já Collins \& Stock (2016) avaliaram o efeito das variações térmicas em placas do tipo da Figura 2.1, encontradas no Parque Nacional de Yosemite, EUA. 
Neste caso, os maiores valores de $\mathrm{K}_{1}$ ocorrem concomitantemente às altas temperaturas. Isto, pois nesta configuração a expansão térmica promove a flexão da placa gerando tensões de tração suficientes para propagar a fratura pelo modo I, conforme explicado detalhadamente no item anterior.

Bakun-Mazor et al. (2013) mostraram ainda que em algumas situações a instabilidade do talude rochoso devido a propagação de trincas e fraturas pode ser fortemente regida pelas solicitações de origem térmica. Neste estudo, realizado na Montanha Masada, Israel, concluiu-se que a alta amplitude térmica é responsável por deslocamentos considerados de importante influência na erosão dos taludes rochosos em detrimento dos efeitos da atividade sísmica que ocorre na região. A Figura 4. 4 apresenta o modelo conceitual utilizado na determinação analítica do deslocamento do bloco deslizante devido à ciclagem térmica. Neste caso, com a redução da temperatura o bloco deslizante se contrai causando a propagação da fratura, que por sua vez permite a penetração do bloco em cunha. Quando ocorre o aumento da temperatura, no entanto, o bloco deslizante se expande comprimindo o bloco em cunha, gerando tensões de compressão responsáveis por empurrar o bloco deslizante para baixo. Este processo sazonal se repete até que a fratura se propague, o bloco se desprenda do maciço e deslize.

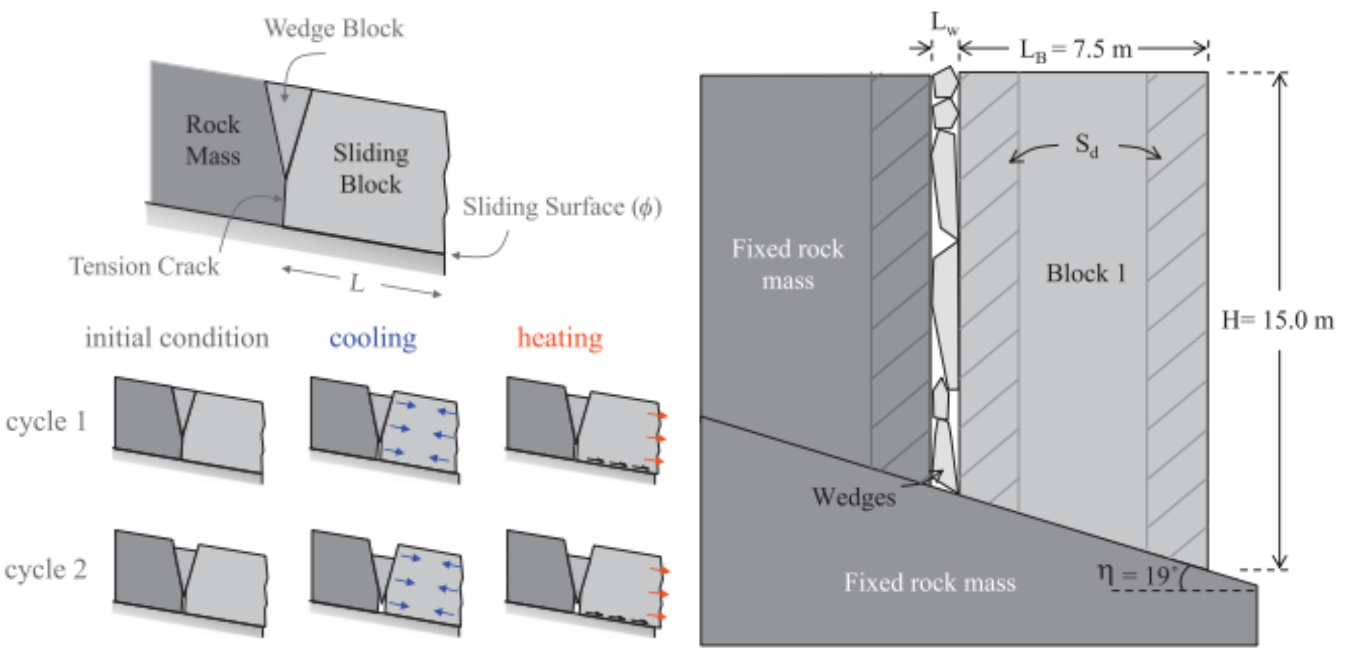

Figura 4. 4: a)Modelo simplificado utilizado na determinação do efeito da ciclagem térmica sobre o desprendimento do bloco deslizante. b) Geometria exata do Bloco 1 na encosta leste de Masada, com fragmentos de rocha representados pelo bloco em cunha localizado na fratura. Sd é a profundidade na qual há alteração de temperatura, Lw é o comprimento da cunha e Lb é o comprimento do bloco. (Bakun-Mazor et al., 2013) 
5.

\section{Simulação computacional}

A simulação computacional foi realizada com o auxílio do software de elementos finitos Abaqus 6.14, que efetuou a análise numérica das tensões de origem térmica geradas pelas variações de temperatura impostas na superfície da placa.

O estudo teve como objetivo fornecer dados para avaliação da magnitude e distribuição das tensões de tração de origem térmica geradas pelas variações diárias de temperatura impostas às placas rochosas expostas ao tempo. Foi avaliado também, para o caso da placa fraturada, o fator de intensidade de tensões para o modo I.

\section{1.}

\section{Geometrias}

No estudo foram consideradas duas placas de rocha tridimensionais retangulares, uma intacta e outra fraturada., sendo a ultima dotada de uma única fratura central não persistente de $10 \mathrm{~m}$ de comprimento, ausente de material de preenchimento. Ambas as placas foram elaboradas com as mesmas dimensões: $15 \mathrm{~m}$ de altura (w), 30m de comprimento (1) e 1,5m de espessura (h), como mostra a Figura 5.1. 

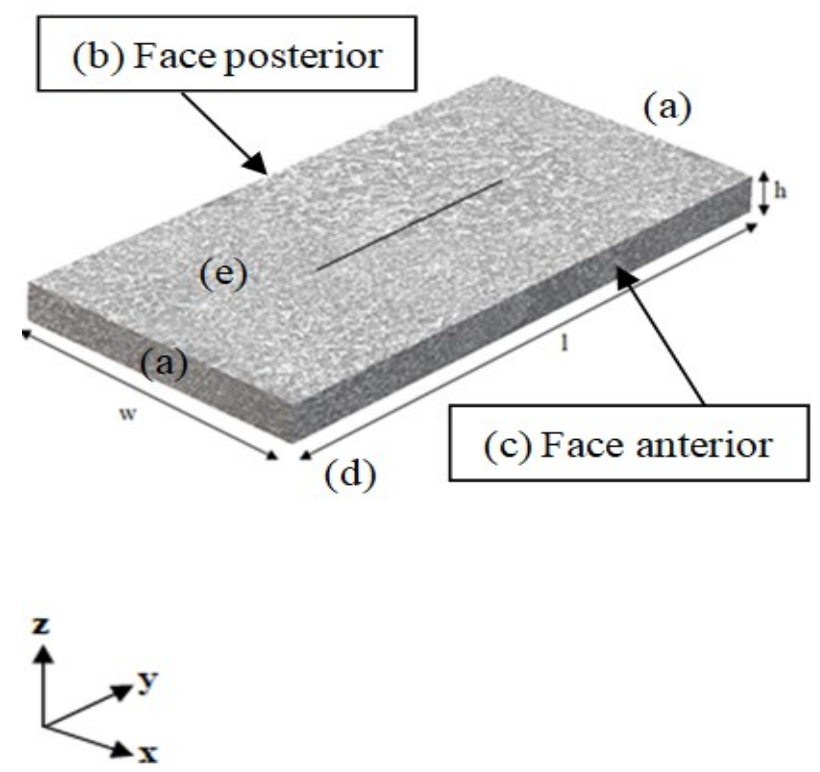

Figura 5.1: Geometria 3D simplificada de uma placa contendo uma fratura não persistente representando a condição mostrada na Figura 5.2

As geometrias adotadas para as placas representam condições simplificadas, mas condizentes com o que se verifica em encostas rochosas do sudeste do Brasil. A Figura 5. 2 mostra o exemplo de uma grande placa rochosa que se separou abruptamente de um maciço localizado no estado do Espírito Santo, em um dia claro. Já a Figura 5. 3 apresenta um acidente muito similar, ocorrido no bairro da Posse em Petrópolis, Rio de Janeiro. É possível observar a existência de placas parcialmente ligadas ao maciço em maior detalhe na Figura 5. 3b.

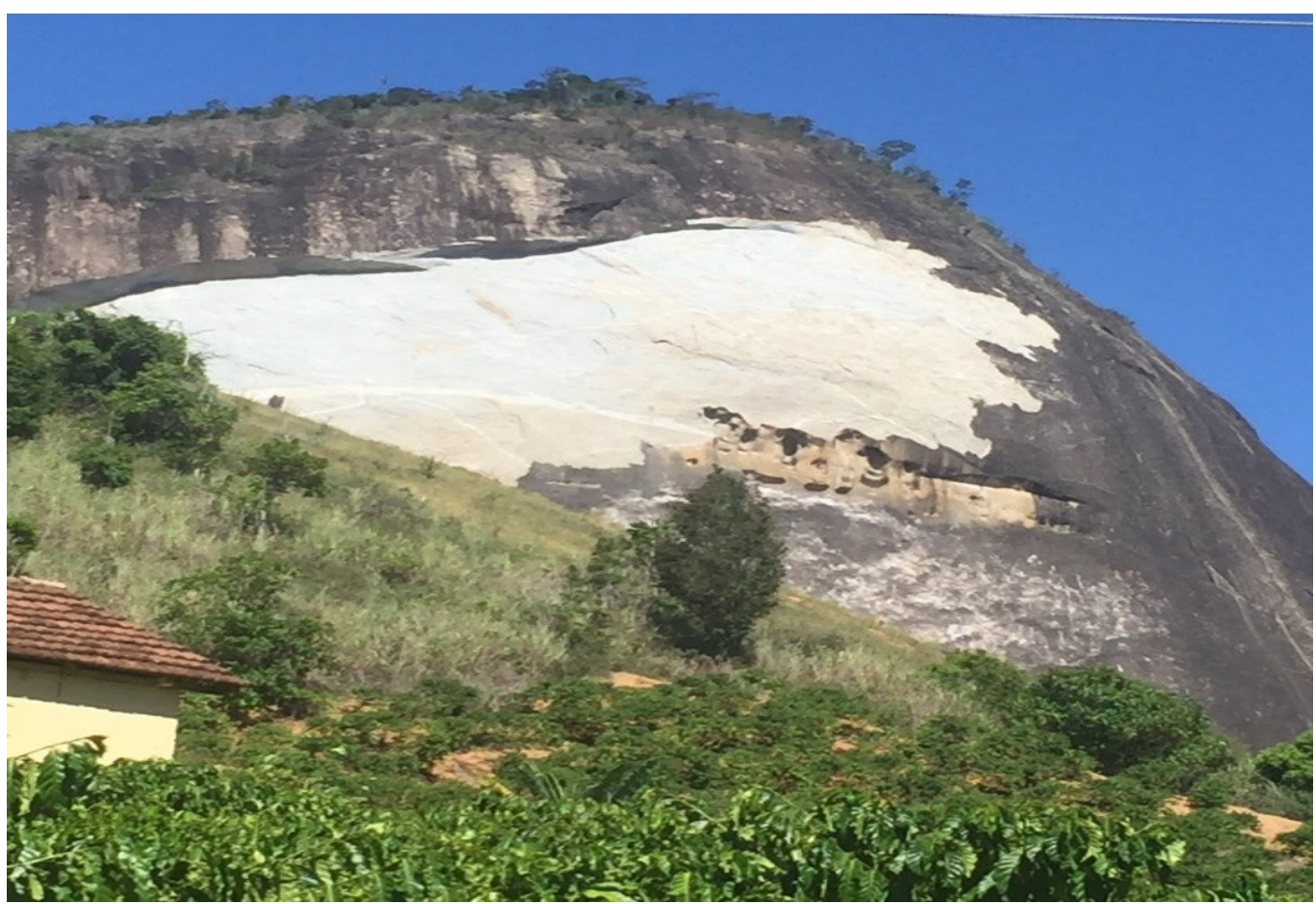

Figura 5. 2: Foto retratando um grande desplacamento de rocha ocorrido no estado do Espírito Santo, Brasil 


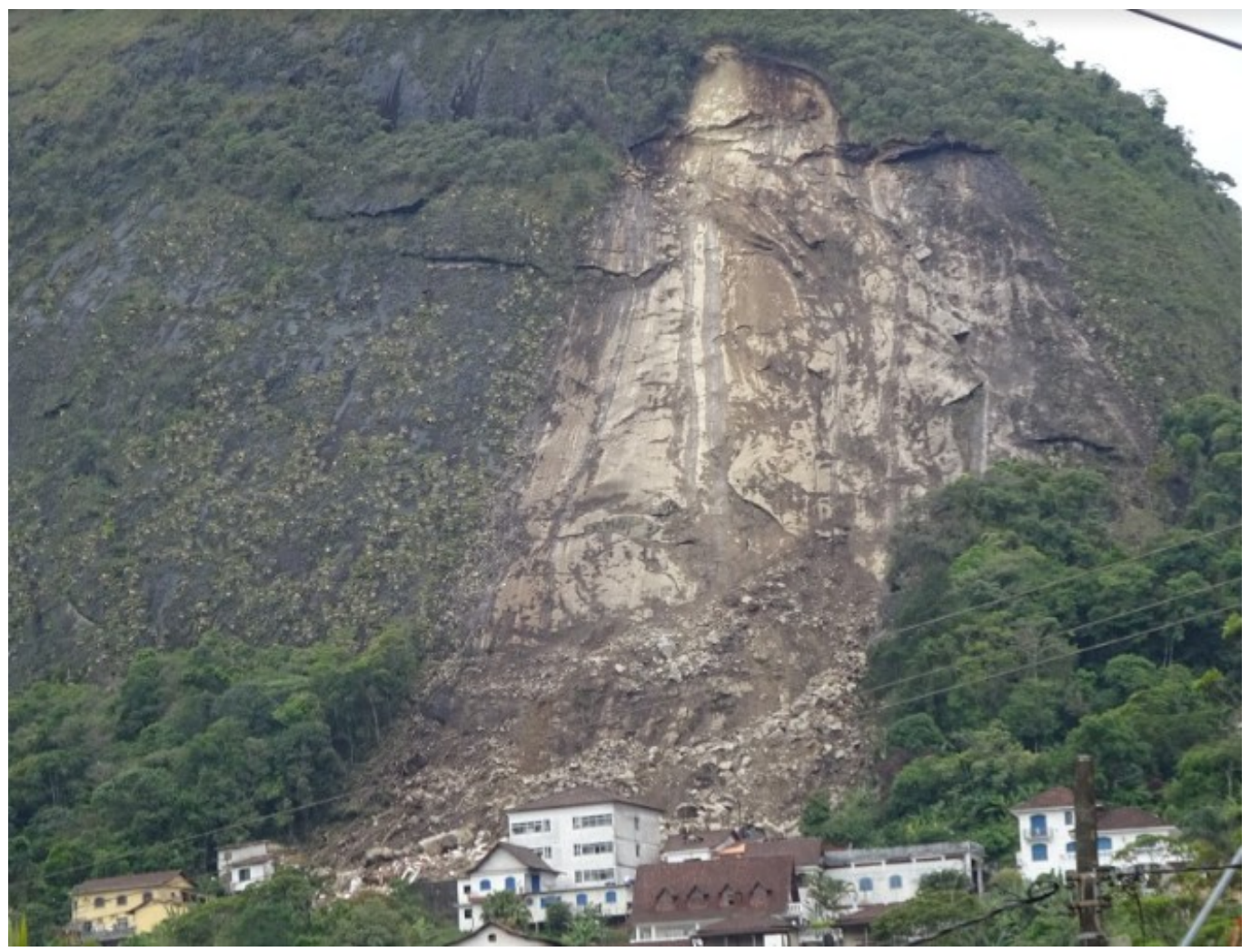

(a)

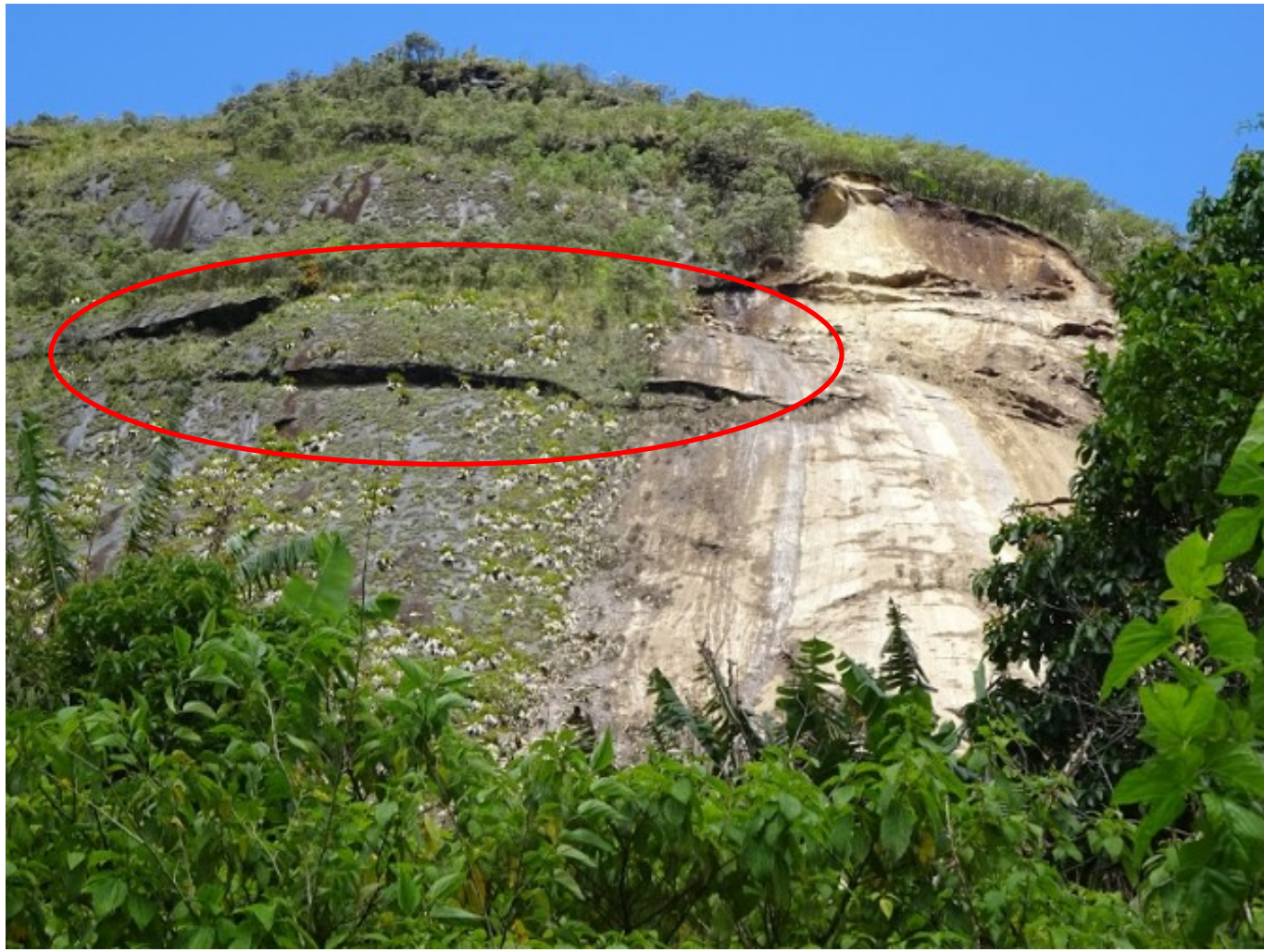

(b)

Figura 5. 3: Fotos retratando um grande desplacamento de rocha ocorrido no bairro da Posse em Petórpolis, Rio de Janeiro, Brasil - a) visão geral da área afetada e b) placas rochosas parcialmente presas ao maciço. 


\section{2.}

\section{Condições de contorno}

\subsection{1.}

\section{Condições de contorno mecânicas}

Ambas as placas foram vinculadas da mesma forma, procurando reproduzir a situação de campo observada na Figura 5. 2 e na Figura 5. 3. As faces laterais (a) e a face posterior (b) foram engastadas, representando a ligação monolítica da placa com o maciço rochoso, enquanto que a face anterior (c) foi mantida totalmente livre. Na superfície inferior (d) da placa foi adotado um apoio de primeiro gênero, com restrição de deslocamento vertical e liberdade de deslizamento, simulando o simples contato entre a placa e o maciço (Figura 5. 4).

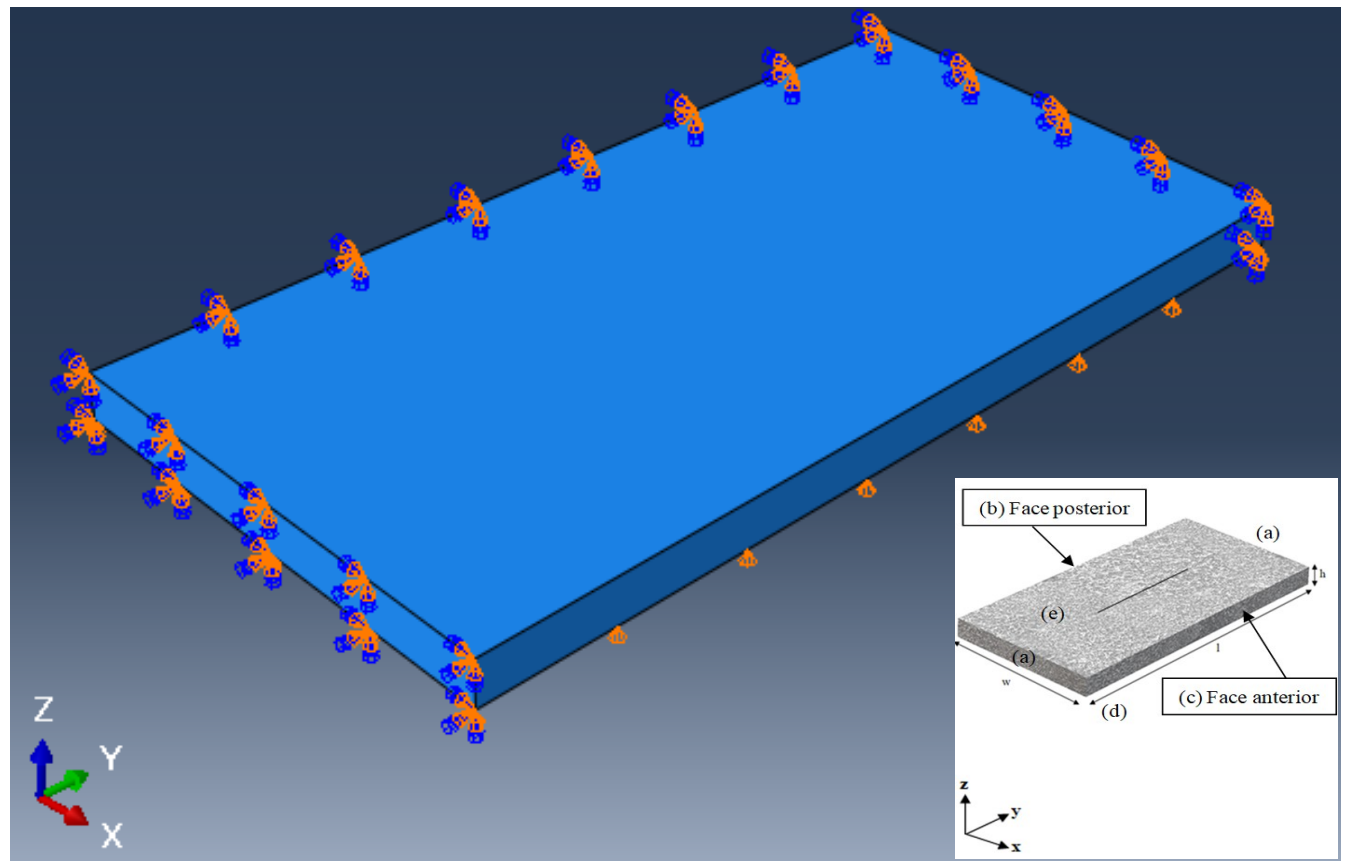

Figura 5. 4: Condições de contorno mecânicas

Admitiu-se que as placas estão localizadas em um talude com $70^{\circ}$ de inclinação, representando uma condição comum dos taludes costeiros rochosos do Rio de Janeiro. Na simulação, o efeito da inclinação foi incorporado por meio da inserção dos componentes horizontal e vertical do vetor gravidade $\left(\mathrm{g}=10 \mathrm{~m} / \mathrm{s}^{2}\right)$. Em virtude da alta inclinação do talude, o atrito entre a placa e o maciço é tido como desprezível e, portanto, foi desconsiderado. 


\subsection{2.}

\section{Condições de contorno de temperatura}

Os dados de temperatura empregados na simulação foram extraídos de Vargas et al (2012) apud Chavez (2007). Neste trabalho é brevemente descrita a campanha experimental através da qual foram gerados os dados que também utiliza. Em linhas gerais, foi montado um sistema composto por dois blocos de rocha isotrópicos e de textura granítica, de dimensão $30 \mathrm{~cm} \times 20 \mathrm{~cm} \times 20 \mathrm{~cm}$, justapostos de forma a simular a existência de uma fratura no contato entre eles (Figura 5. 5).
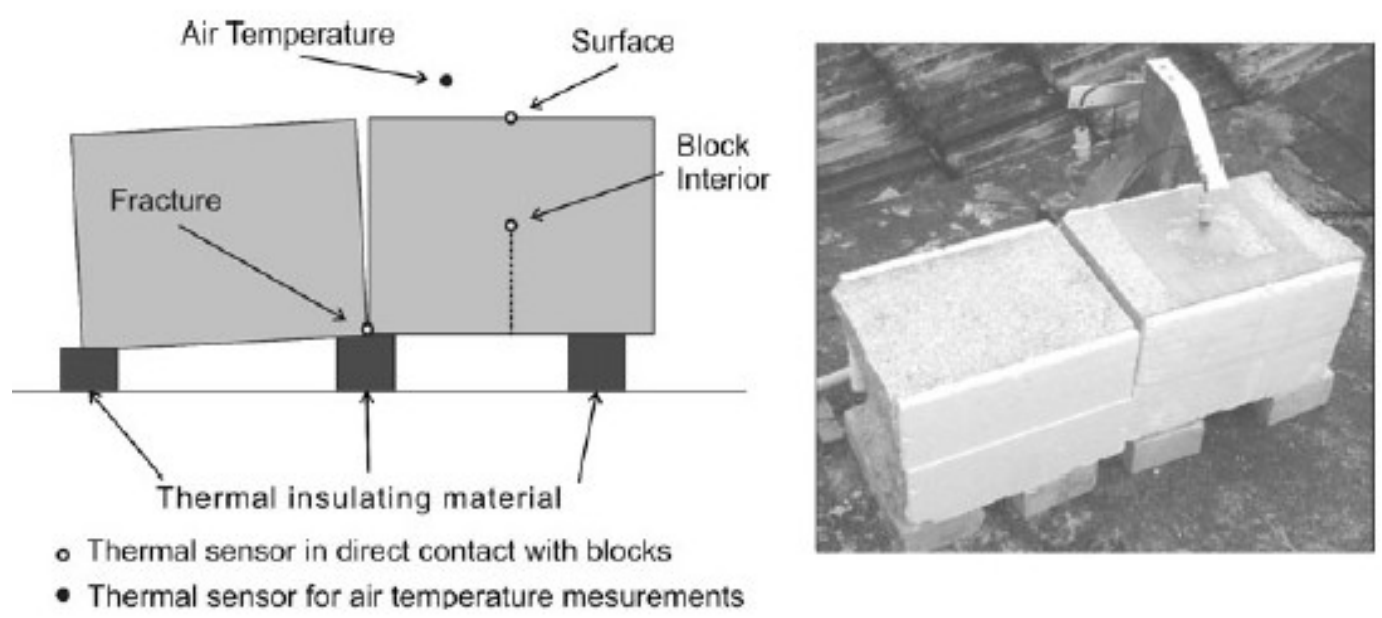

Figura 5. 5: Disposição dos blocos e dos sensores utilizados para determinação das temperaturas na fratura, na superfície e no interior do bloco submetido a condições de campo (Vargas et al., 2012)

Os blocos foram deixados ao tempo, simulando as condições de campo. O monitoramento contínuo das temperaturas foi realizado por sensores associados a um sistema de aquisição de dados automático, gerando séries de dados de temperatura ao longo do tempo na superfície dos blocos e na fratura.

Nas faces internas da fratura, nenhuma condição de contorno de temperatura foi imposta. A temperatura nas faces da fratura foi calculada de acordo com as variações de temperatura impostas nas faces (e), (c) e (d) (respectivamente, faces superior, anterior e inferior da Figura 5.1)

No presente trabalho, portanto, o conjunto de valores correspondentes à irradiação direta (superfície) foi atribuído às faces superior e anterior, ao passo em 
que o conjunto de dados correspondente ao aquecimento indireto (fratura) foi atribuído à face inferior. (Figura 5. 6 e Tabela 5. 1)

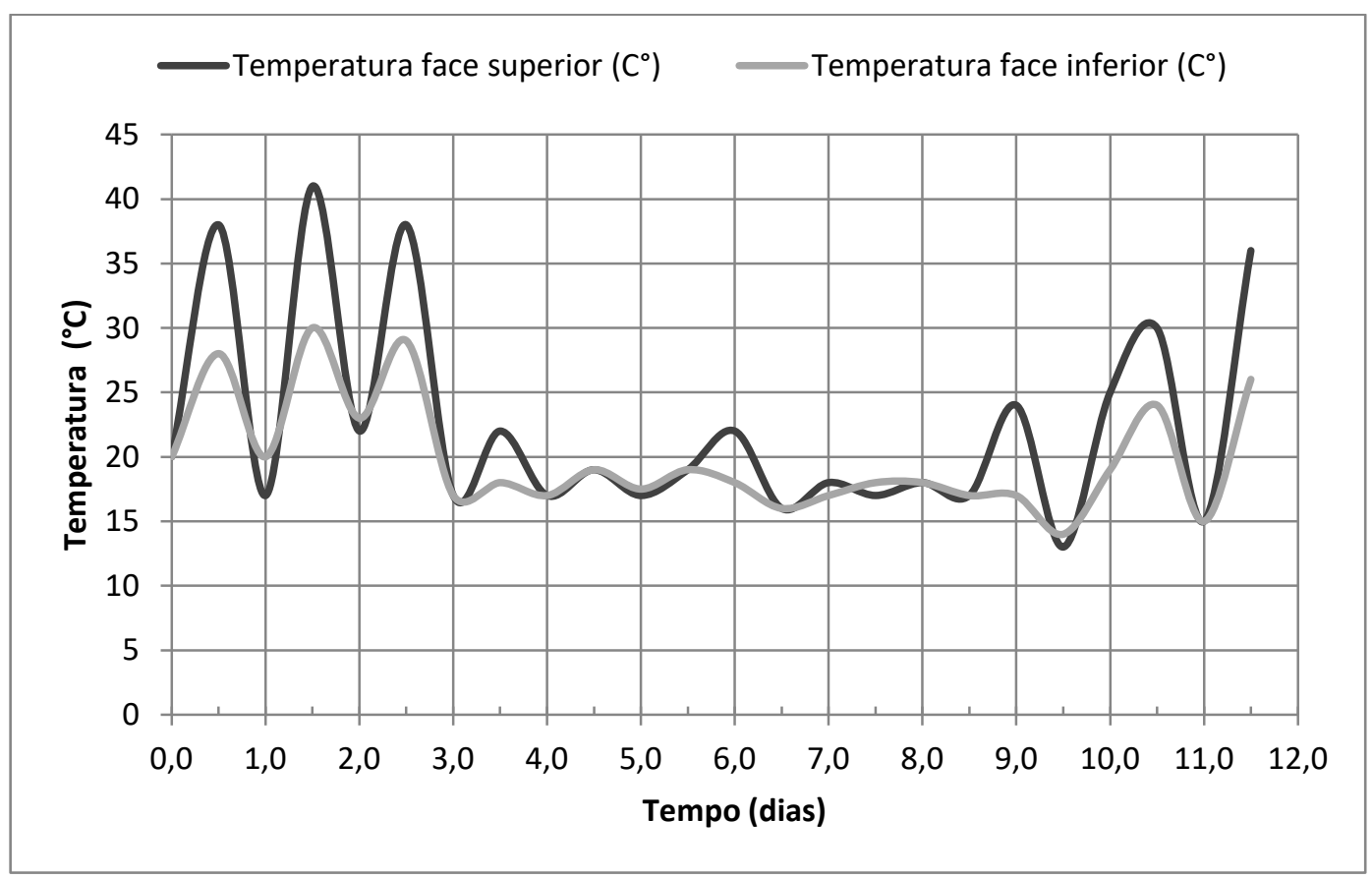

Figura 5. 6: Variação da temperatura nas faces superior e inferior ao longo do tempo (Modificado de Vargas et al. 2012) 
Tabela 5. 1: Variação da temperatura ao longo do tempo nas faces superior e inferior

\begin{tabular}{|c|c|c|c|}
\hline Tempo (d) & Tempo (s) & $\begin{array}{c}\text { Temperatura face } \\
\text { superior }\left(\mathbf{C}^{\circ}\right)\end{array}$ & $\begin{array}{c}\text { Temperatura } \\
\text { face inferior }\left(\mathbf{C}^{\circ}\right)\end{array}$ \\
\hline 0 & 0 & 20 & 20 \\
\hline 0,5 & 43200 & 38 & 28 \\
\hline 1 & 86400 & 17 & 20 \\
\hline 1,5 & 129600 & 41 & 30 \\
\hline 2 & 172800 & 22 & 23 \\
\hline 2,5 & 216000 & 38 & 29 \\
\hline 3 & 259200 & 17 & 17 \\
\hline 3,5 & 302400 & 22 & 18 \\
\hline 4 & 345600 & 17 & 17 \\
\hline 4,5 & 388800 & 19 & 19 \\
\hline 5 & 432000 & 17 & 17,5 \\
\hline 5,5 & 475200 & 19 & 19 \\
\hline 6 & 518400 & 22 & 18 \\
\hline 6,5 & 561600 & 16 & 16 \\
\hline 7 & 604800 & 18 & 17 \\
\hline 7,5 & 648000 & 17 & 18 \\
\hline 8 & 691200 & 18 & 18 \\
\hline 8,5 & 734400 & 17 & 17 \\
\hline 9 & 777600 & 24 & 17 \\
\hline 9,5 & 820800 & 13 & 14 \\
\hline 10 & 864000 & 25 & 19 \\
\hline 10,5 & 907200 & 30 & 24 \\
\hline 11 & 950400 & 15 & 15 \\
\hline 11,5 & 993600 & 36 & 26 \\
\hline & & & \\
\hline
\end{tabular}

\section{3.}

\section{Propriedades do material}

Os parâmetros da rocha foram obtidos em Vargas et al. (2012) referenciando trabalhos da literatura nos quais foram definidas as propriedades de rochas típicas do Rio de Janeiro. A Tabela 5. 2 apresenta a relação de propriedades mecânicas e térmicas utilizadas. 
Tabela 5. 2: Propriedades da rocha utilizada na simulação

\begin{tabular}{|l|l|}
\hline Módulo de Young & $40(\mathrm{GPa})$ \\
\hline Coeficiente de Poisson & 0,20 \\
\hline Condutividade Térmica & $3 \mathrm{~J} / \mathrm{s} \mathrm{m}{ }^{\circ} \mathrm{C}$ \\
\hline Coeficiente de expansão térmica & $8 \times 10-6^{\circ} \mathrm{C}-1$ \\
\hline Calor específico & $0,75 \times 10-3 \mathrm{MJ} / \mathrm{kg}^{\circ} \mathrm{C}$ \\
\hline Massa específica & $2650 \mathrm{~m}^{3}$ \\
\hline
\end{tabular}

\section{4 .}

\section{Malha de elementos finitos}

Para a análise termomecânica acoplada da placa intacta foram adotados elementos hexagonais estruturados do tipo C3D20RT (integração reduzida e ordem quadrática, com descrição triquadrática do deslocamento e trilinear da temperatura) perfazendo um total de 5400 elementos (Figura 5. 7). Neste tipo de análise a temperatura é responsável por gerar deformações, mas o inverso não se verifica.

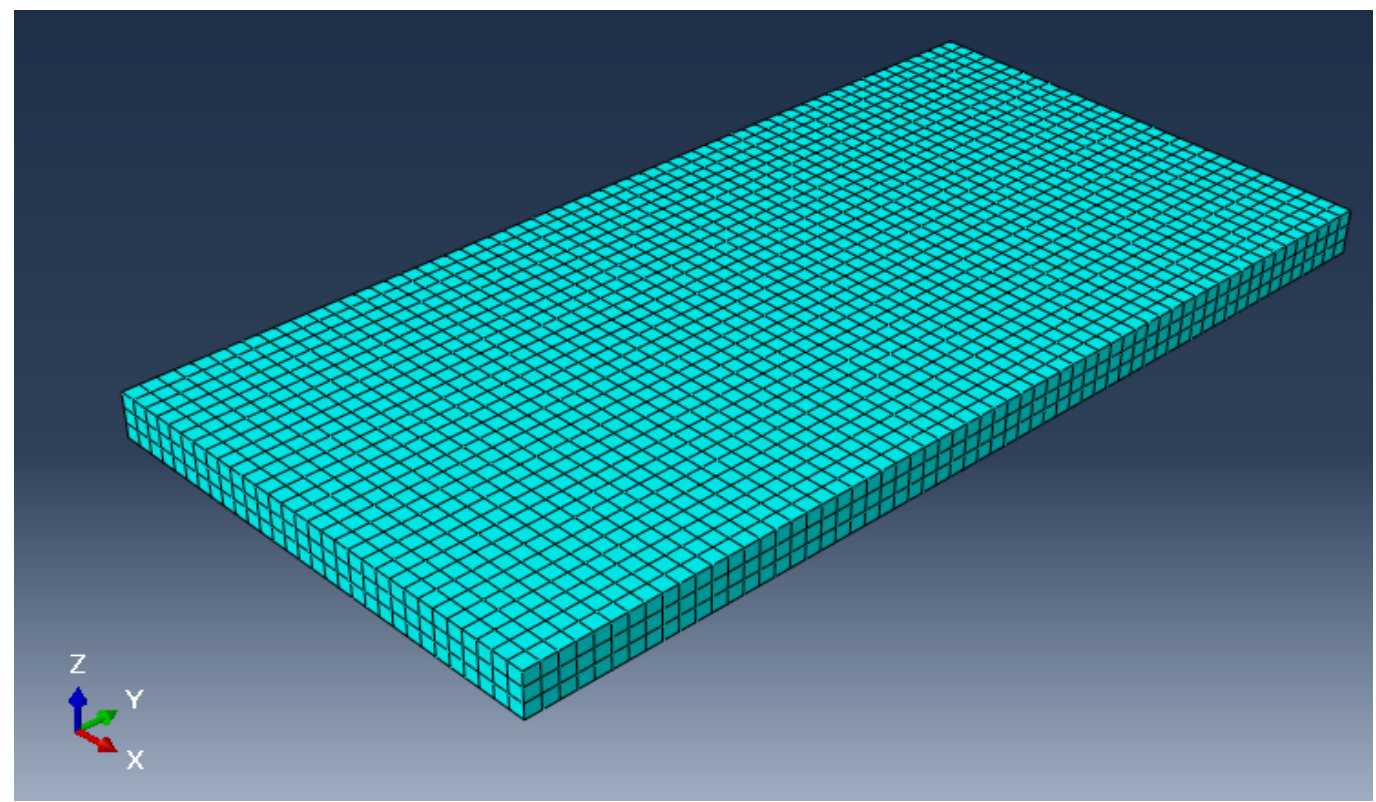

Figura 5. 7: Malha de elementos finitos utilizada na modelagem da placa rochosa intacta

Já para a geometria dotada de fratura central foram utilizados dois tipos de elementos: hexagonais estruturados do tipo C3D8T (8 nós, descrição trilinear da 
temperatura e do deslocamento) e prismáticos triangulares do tipo C3D6T (6 nós, descrição linear da temperatura e do deslocamento).

Apesar dos elementos de ordem quadrática normalmente gerarem resultados mais precisos, o emprego de integrais de contorno na modelagem da fratura preconiza a utilização de contornos circulares no entorno das pontas da fratura, o que por sua vez, induz à escolha de elementos prismáticos triangulares. A adoção deste elemento é interessante no que diz respeito à estrutura da malha, porém impõe a utilização da ordem linear, posto que apenas elementos prismáticos triangulares lineares são disponibilizados pelo software para a análise do tipo termomecânica acoplada. Por esta razão, e por questão de compatibilidade entre as regiões do modelo, os elementos hexagonais também foram sujeitos à ordem linear. A malha usada na modelagem da placa faturada é composta por um total de 6045 elementos tal qual descrito acima e apresentado na Figura 5. 8. A alta discretização do modelo é interessante especialmente neste caso, pois reduz o impacto da utilização de elementos lineares na qualidade dos resultados.

A fratura foi avaliada segundo integrais de contorno (J-Integral) a partir das quais são calculados os valores de $\mathrm{K} 1$ em cada passo de tempo considerado. Foram extraídos apenas os valores de $\mathrm{K}_{1}$ calculados no primeiro contorno, localizado imediatamente após a ponta da fratura (Figura 5.9)

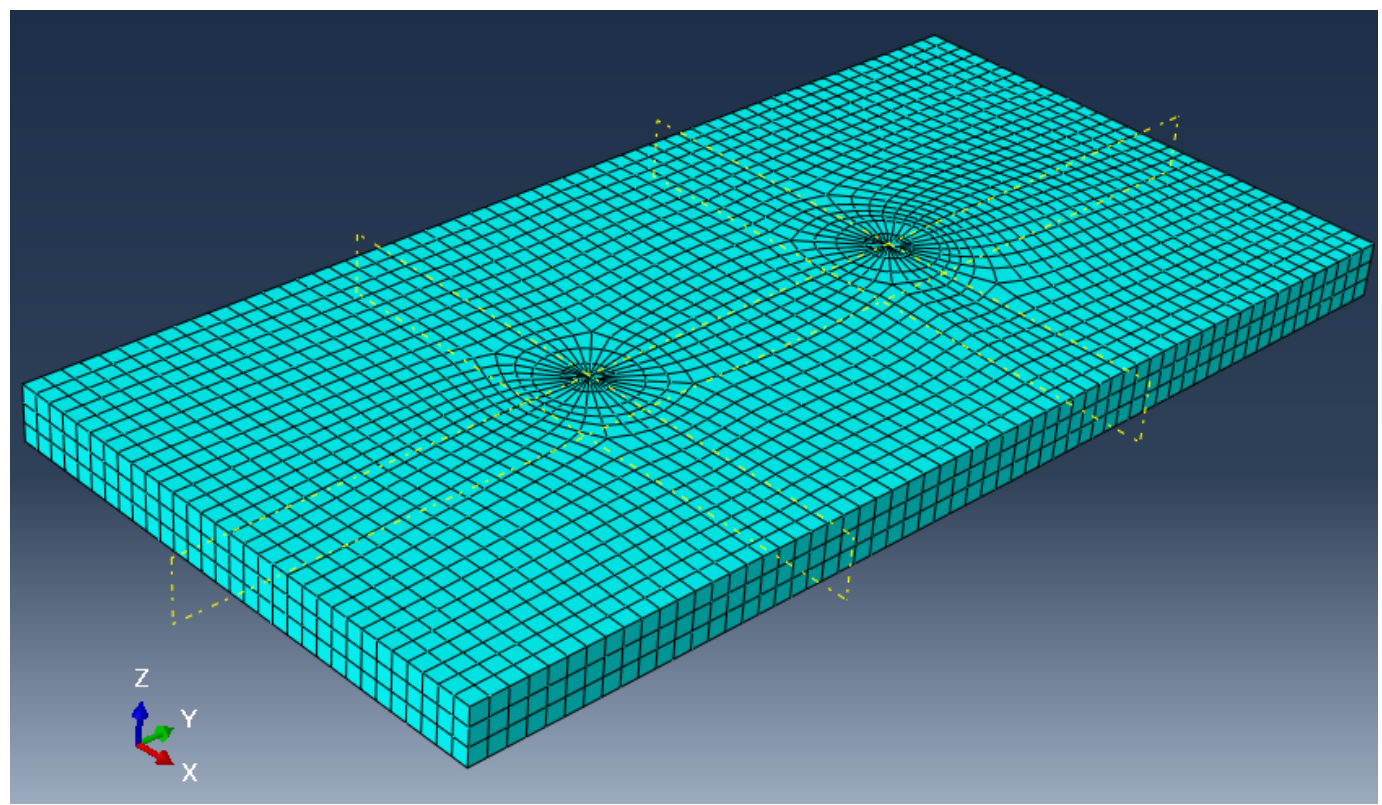

Figura 5. 8: Malha de elementos finitos utilizada na modelagem da placa rochosa fraturada 


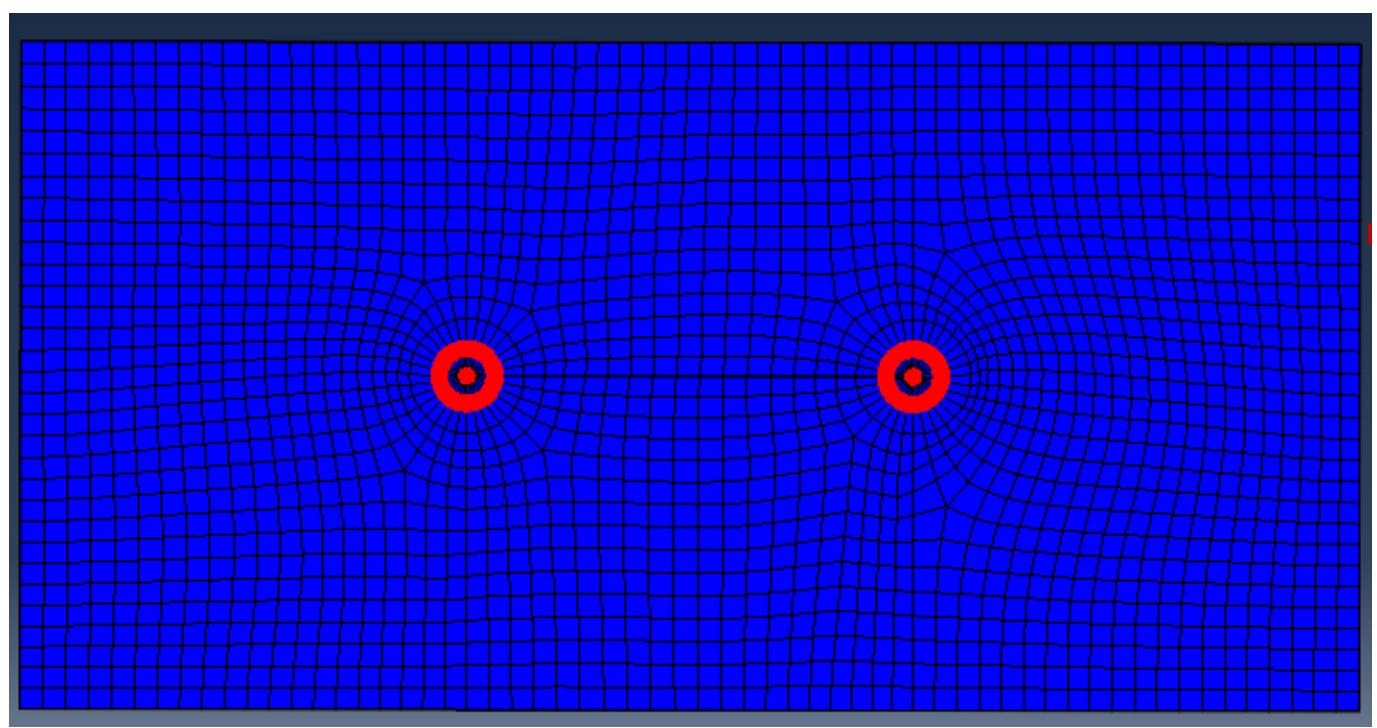

Figura 5. 9: Contorno utilizado no cálculo das integrais de contorno- Vista superior da placa rochosa

\section{5 .}

\section{Cenários simulados}

De forma a avaliar a influência isolada das variações de temperatura uniformes e não uniformes na geração de tensões, foram simulados os seguintes casos:

1. Placa submetida apenas a ação da gravidade

2. Placa submetida apenas a ação das variações não uniformes de temperatura

3. Placa submetida à ação da gravidade e das variações não uniformes de temperatura 
6.

\section{Resultados e discussão}

Foram obtidas as tensões normais de tração desenvolvidas na direção perpendicular ao eixo da fratura (eixo x da Figura 5.1), com o intuito de avaliar a magnitude das tensões de tração geradas em decorrência da atuação das variações de temperatura. Para efeito de comparação, foi considerado que a resistência à tração é de $10 \mathrm{MPa}$, valor condizente com rochas graníticas sãs. Destaca-se, no entanto, que é um valor ainda alto, pois em campo tais rochas quando alteradas possuem resistência a tração bem inferior, podendo chegar até a 5MPa.

A ação da gravidade foi dissociada em um primeiro momento para que fosse possível avaliar o efeito de cada tipo de carregamento sob as placas. $\mathrm{Na}$ apresentação dos resultados, as tensões normais de tração em x são identificadas como S11 (Pa), nomenclatura atribuída pelo software. As vistas apresentadas nas figuras que se seguem fazem referência ao sistema de coordenadas apresentado na Figura 5.1

Da geometria contendo uma fratura central foram obtidos os valores do fator de intensidade de tensão para o modo I, para o primeiro contorno (localizado imediatamente após a ponta da fratura-Figura 5. 9). A avaliação deste fator visa determinar se haverá de fato a propagação da fratura pelo modo I, o que pode possivelmente culminar num evento de desplacamento futuro. $\mathrm{O}$ valor da tenacidade, utilizado na comparação com os fatores de intensidade de tensão obtidos, foi também extraído de Vargas et al. (2012),em referência a outros estudos, nos quais foram obtidos tais valores para rochas típicas do Rio de Janeiro (Tabela 6.1) 


\begin{tabular}{|l|c|c|}
\hline \multirow{2}{*}{ Tipos de rocha } & \multicolumn{2}{|c|}{$\mathbf{K}_{\mathbf{1 c}}\left(\mathbf{M P a} \mathbf{~ m}^{\mathbf{1 / 2}}\right)$} \\
\cline { 2 - 3 } & Mín. & Máx \\
\hline Granito Favela (Almeida et al. 2004) & 0.80 & 1.25 \\
\hline Granito Utinga (Almeida et al. 2004) & 0.55 & 0.95 \\
\hline Gnaisse Facoidal (Augen) (Santos 2004) & 0.73 & 1.23 \\
\hline
\end{tabular}

Tabela 6.1: Valores de $\mathrm{K}_{1 \mathrm{c}}$ de Granitos e Gnaisses do Rio de Janeiro (Adaptado de Vargas et al., 2012)

\section{1.}

\section{Placa submetida apenas à ação da gravidade}

\subsection{1.}

\section{Placa rochosa intacta}

Apesar de a gravidade atuar uniformemente em toda a placa, a existência de engastes nas laterais restringe a deformação gerando uma variação não uniforme das tensões de tração ao longo do comprimento da placa (Figura 6. 1).

Os valores máximos de tração $(0,36 \mathrm{MPa})$ e compressão $(0,045 \mathrm{MPa})$ são encontrados, respectivamente, na seção central do engaste posterior e nos vértices anteriores (junção dos engastes laterais com a face livre). Destaca-se que a presença de compressão, mesmo ínfima, é produto unicamente da condição de vínculo da placa. 


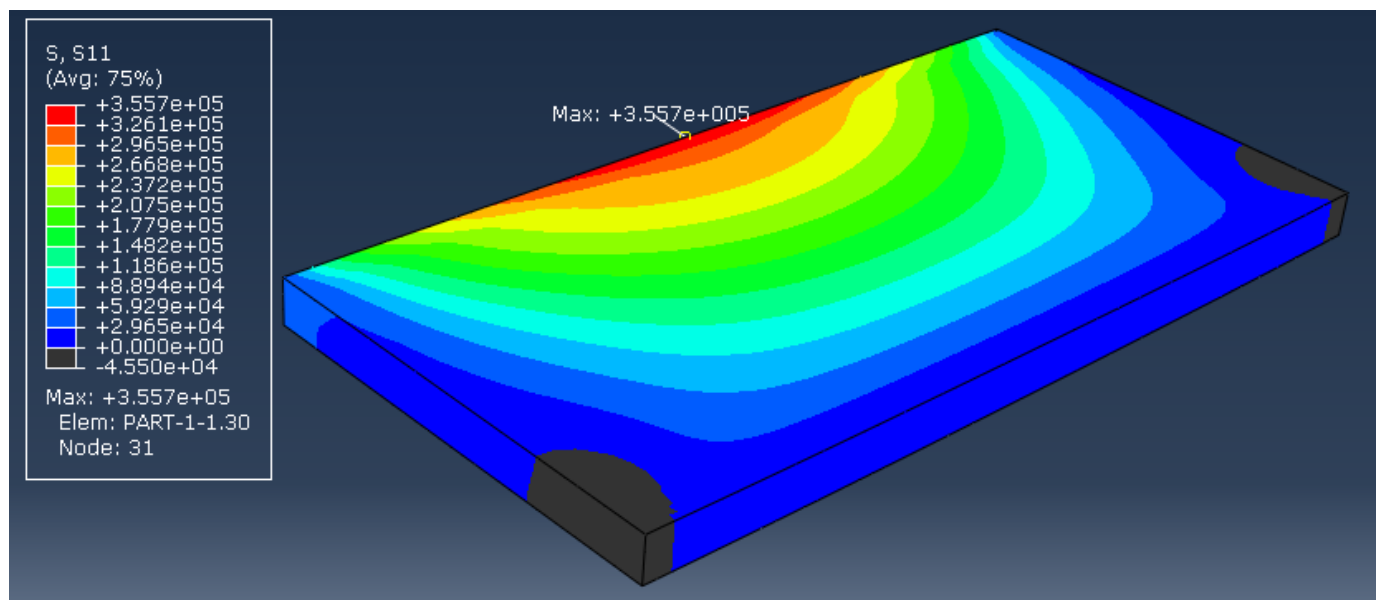

(a)

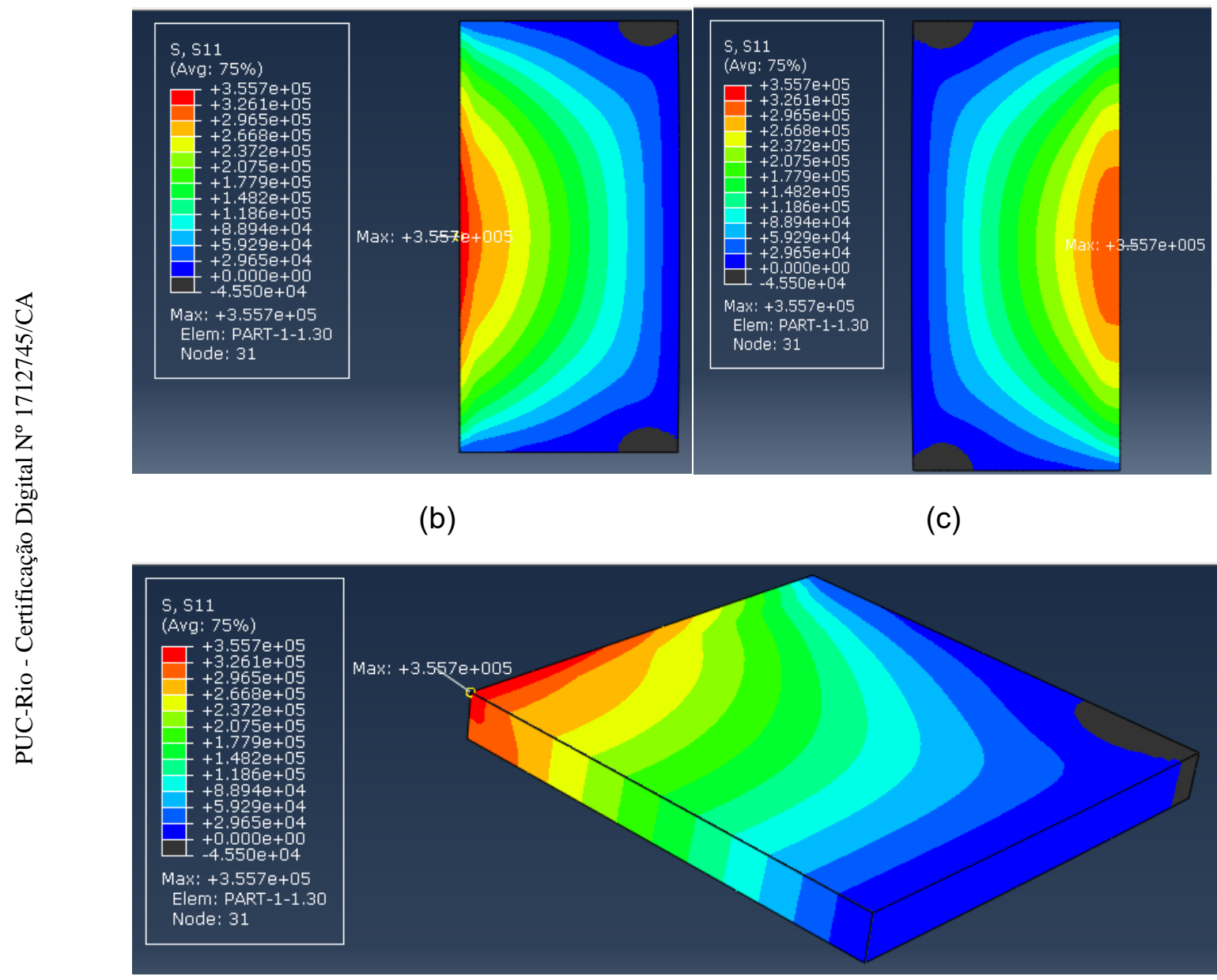

(d)

Figura 6. 1: Distribuição de tensões de tração que ocorre em uma placa intacta submetida apenas à ação da gravidade: (a) Perspectiva isométrica (b) Vista superior (c) Vista inferior (d) Seção transversal central - Fator de escala de deformação: 2000 


\subsection{2.}

\section{Placa rochosa fraturada}

Como é possível observar na Figura 6. 2, a presença da fratura implica em distribuições de tensões de tração diferentes das encontradas em uma placa intacta sob as mesmas condições de contorno.

As tensões de tração predominam, sendo os maiores valores encontrados nas extremidades da fratura. Há compressão, representada pela área escura, na parte anterior da fratura e na metade inferior do engaste posterior onde alcança seu valor máximo $(0,44 \mathrm{MPa})$. Percebe-se que a simples presença da fratura é capaz de mais que dobrar a tensão de tração no engaste e de multiplicar por 10 a tensão de compressão máxima. Nota-se também que apenas a ação da gravidade é suficiente para gerar valores importantes de concentração de tensão de tração nas pontas da fratura. Os fatores de intensidade de tensão desenvolvidos no primeiro contorno, em quatro pontos posicionados ao longo da espessura são apresentados na Tabela 6.1

Tabela 6. 2: Fator de intensidade de tensões do modo I para placa submetida apenas à gravidade

\begin{tabular}{|c|c|}
\hline Distância do contorno à face superior $\mathbf{( m )}$ & $\mathbf{K}_{\mathbf{I c}}\left(\mathbf{M P a} \cdot \mathbf{m}^{\mathbf{1 / 2}}\right)$ \\
\hline 0 & 0,67 \\
\hline 0,5 & 0,37 \\
\hline 1,0 & 0,65 \\
\hline 1,5 & 0,40 \\
\hline
\end{tabular}




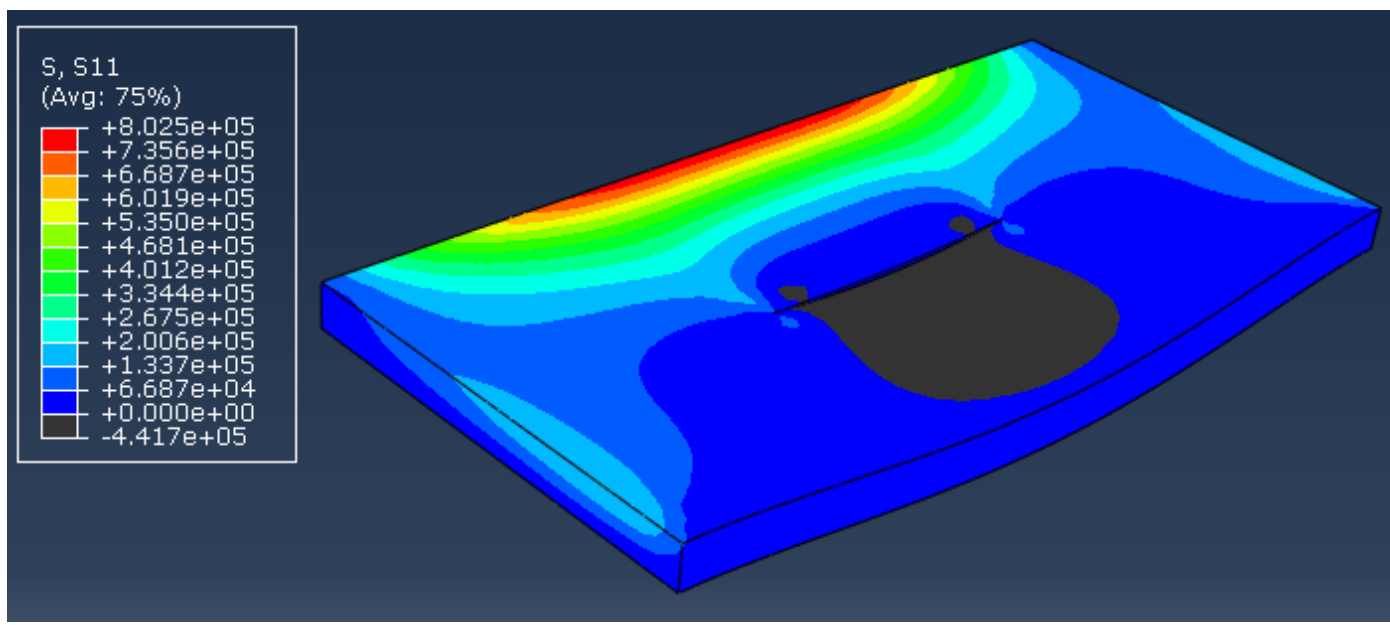

(a)

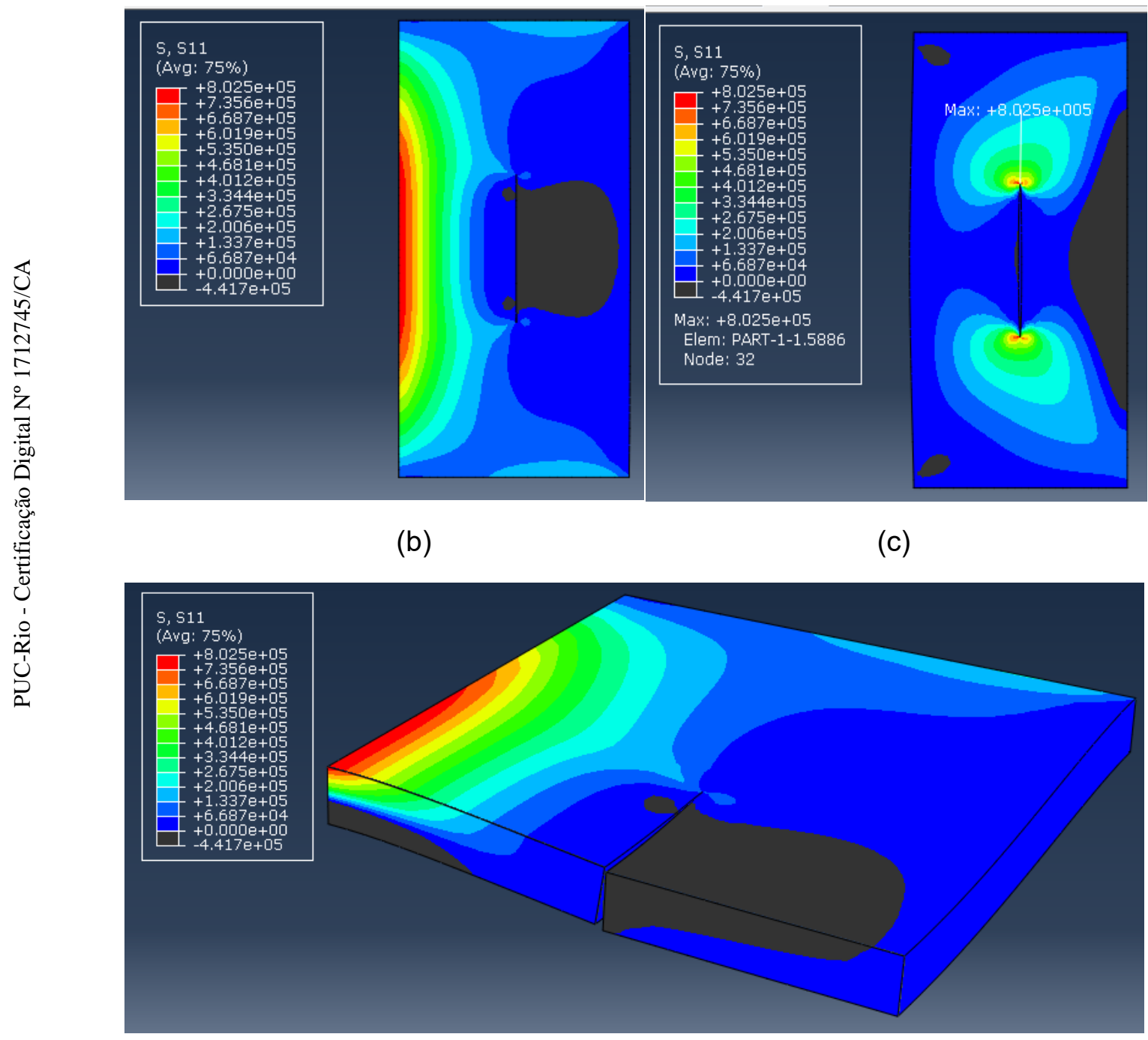

(d)

Figura 6. 2: Distribuição de tensões de tração que ocorre em uma placa fraturada submetida apenas à ação da gravidade: (a) Perspectiva isométrica (b) Vista superior (c) Vista inferior (d) Seção transversal central - Fator de escala de deformação: 2000 


\section{2.}

\section{Placa submetida apenas a variações não uniformes de temperatura.}

\subsection{1.}

\section{Placa rochosa intacta}

Nesta simulação foram impostas às faces inferior, superior e anterior as variações não uniformes de temperatura apresentadas na Tabela 6. 3 e na Figura 6. 3. Normalmente a radiação que incide sobre a placa não é suficiente para aquecê-la uniformemente, gerando gradientes de temperatura entre as superfícies e o interior da placa rochosa. Ocorreram, por esta razão, 5 padrões típicos de distribuição de temperatura que podem ser facilmente identificados na Figura 6.3. São eles:

I. Interior da placa mais frio do que as faces inferior e superior $(\mathrm{t}=0.5,1.5$, $2.5,10.5$ e 11.5 dias);

II. Interior da placa mais quente do que as faces inferior e superior $(t=1$ e 2 dias)

III. Interior da placa mais quente do que as faces inferior e superior, de mesma temperatura $(\mathrm{t}=3,4,4.5,5,6.5,8.5,9.5$ e 11 dias $)$

IV. Interior da placa mais frio do que as faces inferior e superior, de mesma temperatura $(\mathrm{t}=5.5$, e 8 dias $)$;

V. Variação uniforme de temperatura entre as faces superior e inferior $(\mathrm{t}=$ 3.5, 6, 7, 7.5, 9 e 10 dias); 


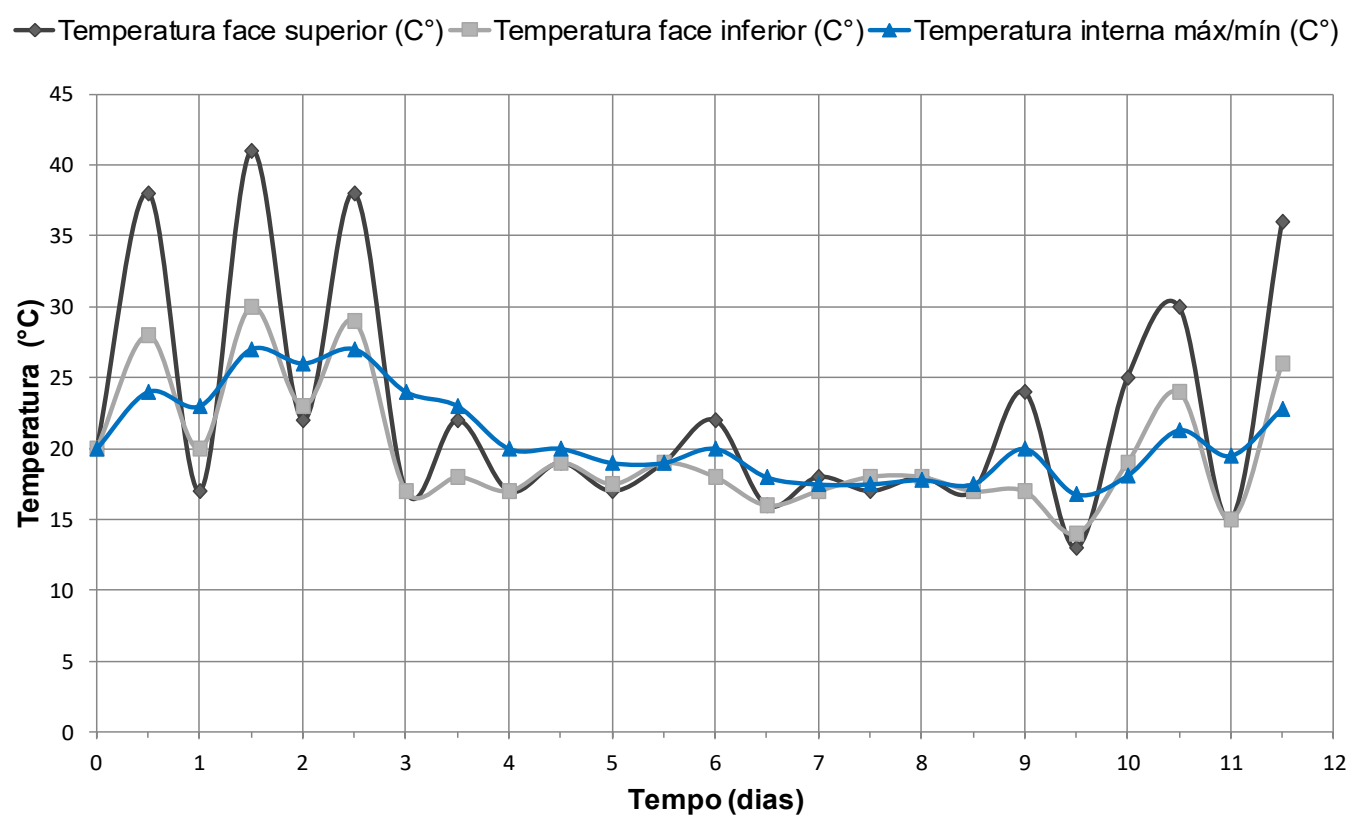

Figura 6. 3: Variação de temperatura nas faces inferior e superior e na parte interna da placa ao longo do tempo

\subsubsection{1.}

\section{Caso I}

Observando a Figura 6. 4 é possível perceber que a face mais quente apresenta tensões de compressão (área escura) enquanto a face menos aquecida desenvolve tensões de tração. Os maiores valores de tração são encontrados principalmente na seção transversal central, na região próxima ao encontro das faces inferior e anterior. Já os maiores valores de compressão ocorrem na junção entre a face superior e as faces laterais engastadas, com o valor máximo no vértice posterior. No eixo de simetria que divide a face superior da inferior ocorre uma linha tênue onde não são desenvolvidas tensões de origem térmica. Isto, pois nesta região verifica-se o aquecimento uniforme da placa.

Como apresentado na Tabela 6. 3, as maiores tensões de compressão e tração ocorrem em momentos onde se verifica o maior gradiente térmico entre as faces inferior e superior. Dentro de um mesmo valor de gradiente térmico, maiores tensões são geradas em temperaturas mais altas. Comparando na Tabela 6. 3 os valores obtidos para 0,5 dia e 11,5 dias é possível perceber o que foi descrito acima. Nota-se, no entanto, que a maioria dos valores máximos de tração corresponde a cerca de $10 \%$ da resistência à tração adotada, não configurando situação de ruptura. 
Tabela 6. 3: Tensões de tração e compressão máximas desenvolvidas na placa intacta em decorrência da variação não uniforme de temperatura: caso I

\begin{tabular}{|c|c|c|c|c|c|}
\hline $\begin{array}{c}\text { Tempo } \\
(\mathbf{d i a s})\end{array}$ & \begin{tabular}{c}
$\mathbf{T}_{\text {face superior }}\left({ }^{\circ} \mathbf{C}\right)$ \\
\hline 0,5
\end{tabular} & $\begin{array}{c}\mathbf{T}_{\text {face inferior }} \\
\left({ }^{\circ} \mathbf{C}\right)\end{array}$ & $\begin{array}{c}\Delta \mathbf{T}_{\text {faces }} \\
\left({ }^{\circ} \mathbf{C}\right)\end{array}$ & $\boldsymbol{\sigma}_{\text {t máx }}(\mathbf{M P a})$ & $\boldsymbol{\sigma}_{\mathbf{c} \text { máx }}(\mathbf{M P a})$ \\
\hline 1,5 & 41 & 28 & 10 & 0,93 & 5,60 \\
\hline 2,5 & 38 & 30 & 11 & 0,99 & 6,92 \\
\hline 10,5 & 30 & 29 & 9 & 0,87 & 6,49 \\
\hline 11,5 & 36 & 26 & 10 & 0,90 & 3,02 \\
\hline
\end{tabular}




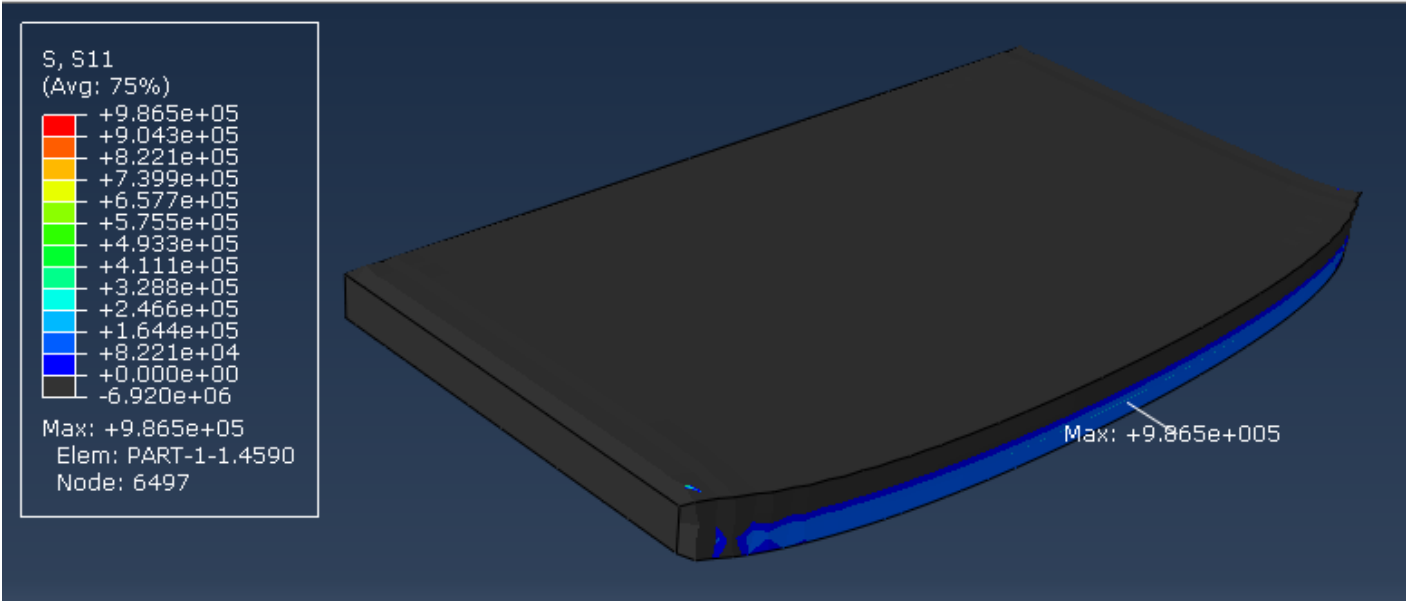

(a)

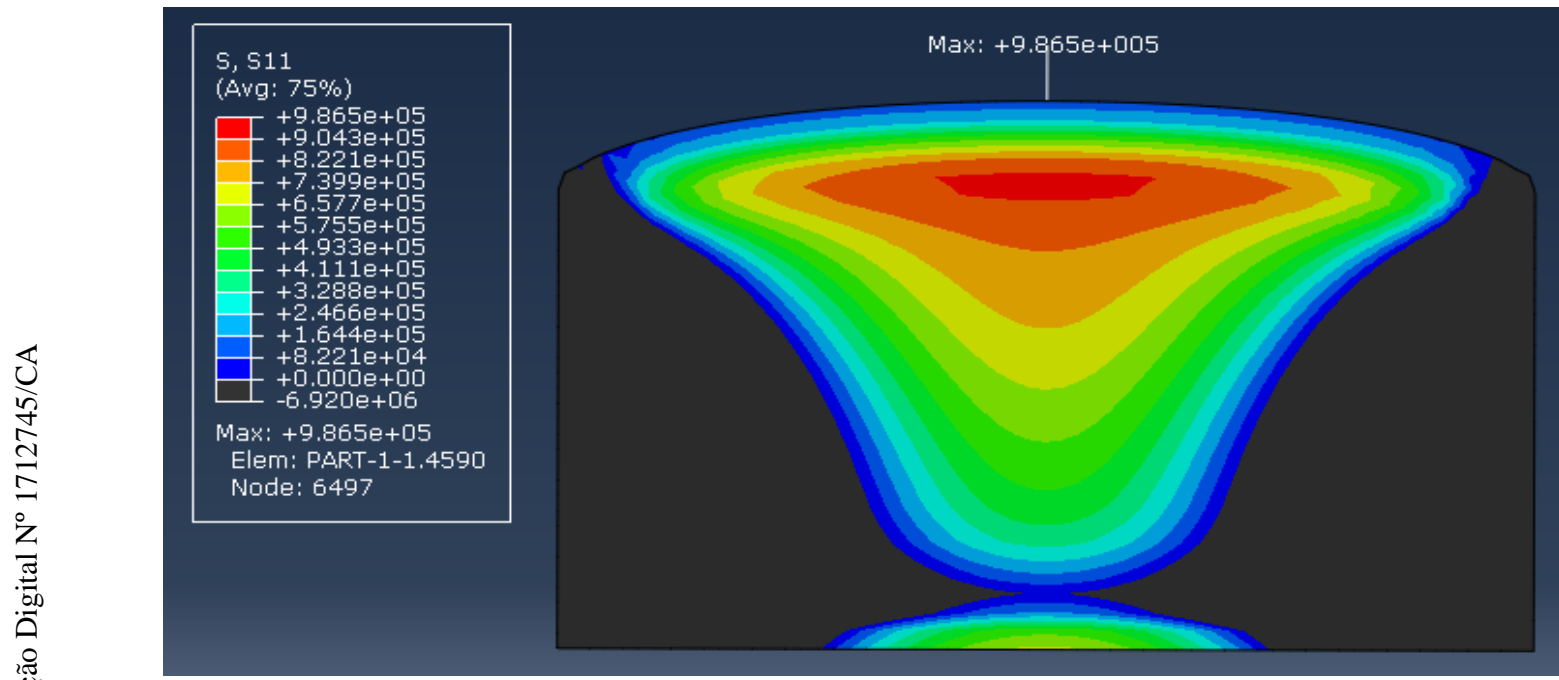

(b)

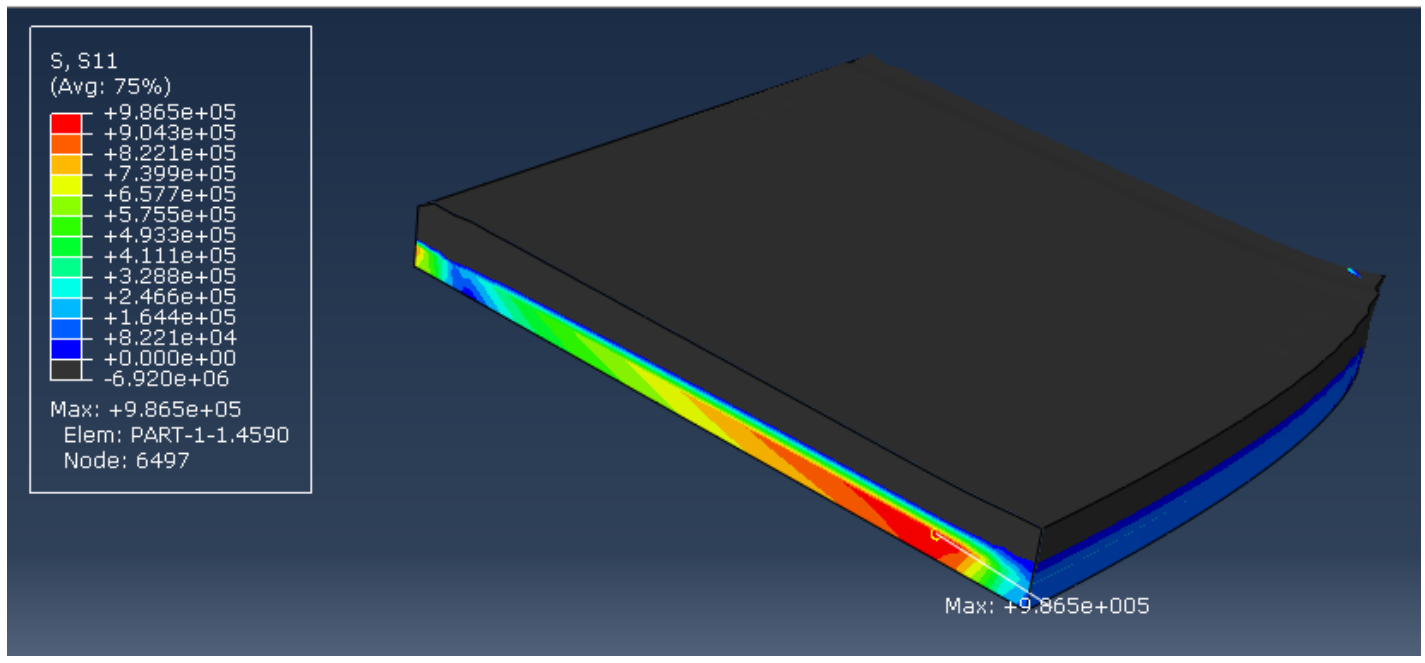

(c)

Figura 6. 4: Exemplo de distribuição de tensões de tração em placa submetida à variação não uniforme de temperatura ( $t=1,5$ dias): (a)Perspectiva isométrica (b) Vista inferior (c) Seção transversal central 


\subsubsection{2.}

\section{Caso II}

O primeiro e o segundo dia da simulação foram precedidos por altas temperaturas e, apesar da variação negativa de temperatura ter sido considerável, o núcleo permaneceu mais quente.

A diminuição brusca da temperatura superficial reduziu a temperatura interna da placa, porém em menor grau. Como resultado, o interior se contrai menos do que a superfície da placa, sendo comprimido por ela, apesar de ambos estarem acima de $20^{\circ} \mathrm{C}$. As áreas superficiais sob compressão ( regiões escuras da Figura 6. 5) são reflexo da restrição que os engastes empoem à expansão das faces decorrente da temperatura superficial acima de $20^{\circ} \mathrm{C}$. A Figura 6.5 apresenta a distribuição de tensões de tração para $\mathrm{t}=2$ dias.

As tensões máximas de tração e compressão são apresentadas na Tabela 6 .

4. Novamente, as tensões geradas não se aproximam do valor de resistência à tração da rocha e, portanto, não oferecem risco imediato de ruptura por tração.

Tabela 6. 4: Tensões de tração e compressão máximas desenvolvidas na placa intacta em decorrência da variação não uniforme de temperatura: caso II

\begin{tabular}{|c|c|c|c|c|c|c|c|c|}
\hline $\begin{array}{c}\text { Tempo } \\
(\mathbf{d i a s})\end{array}$ & $\begin{array}{c}\mathbf{T}_{\text {face }} \\
\text { superior } \\
\left({ }^{\circ} \mathbf{C}\right)\end{array}$ & $\begin{array}{c}\mathbf{T}_{\text {face }} \\
\text { inferior } \\
\left({ }^{\circ} \mathbf{C}\right)\end{array}$ & $\begin{array}{c}\mathbf{T}_{\text {máx }} \\
\text { núcleo } \\
\left({ }^{\circ} \mathbf{C}\right)\end{array}$ & $\begin{array}{c}\Delta \mathbf{T} \text { face } \\
\text { superior } \\
\left({ }^{\circ} \mathbf{C}\right)\end{array}$ & $\begin{array}{c}\Delta \mathbf{T} \text { face } \\
\text { inferior } \\
\left({ }^{\circ} \mathbf{C}\right)\end{array}$ & $\begin{array}{c}\Delta \mathbf{T} \\
\text { núcleo } \\
\left({ }^{\circ} \mathbf{C}\right)\end{array}$ & $\begin{array}{c}\boldsymbol{\sigma}_{\mathbf{t} \text { máx }} \\
(\mathbf{M P a})\end{array}$ & $\begin{array}{c}\mathbf{\sigma}_{\mathbf{c} \text { máx }} \\
(\mathbf{M P a})\end{array}$ \\
\hline 1 & 17 & 20 & 23 & -11 & -8 & $-2,6$ & 0,63 & 1,16 \\
\hline 2 & 22 & 23 & 26 & -19 & -7 & $-0,6$ & 0,33 & 2,54 \\
\hline
\end{tabular}




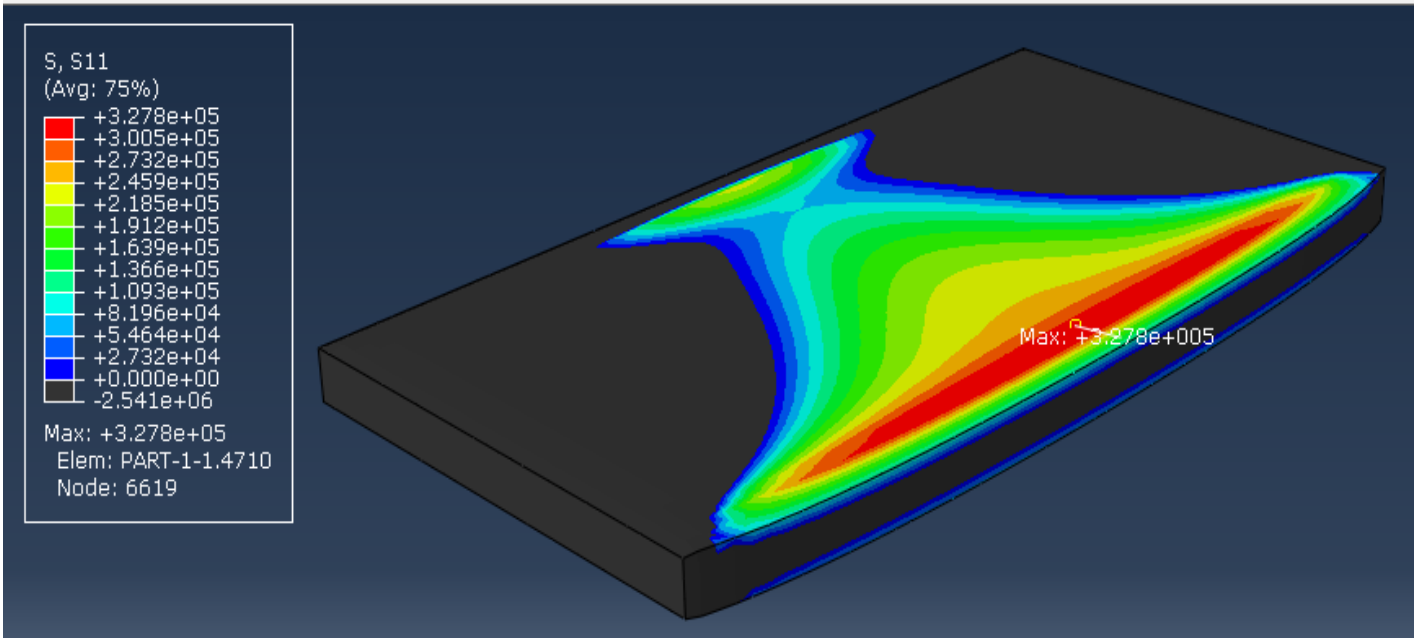

(a)

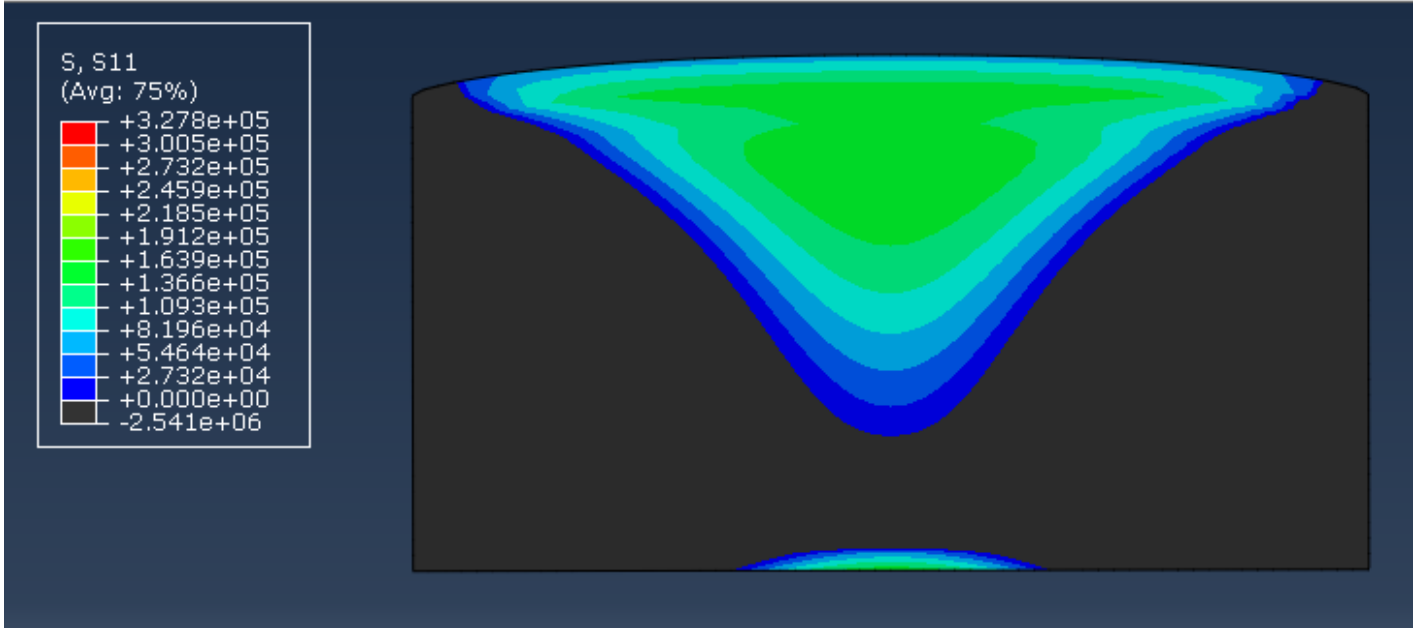

(b)

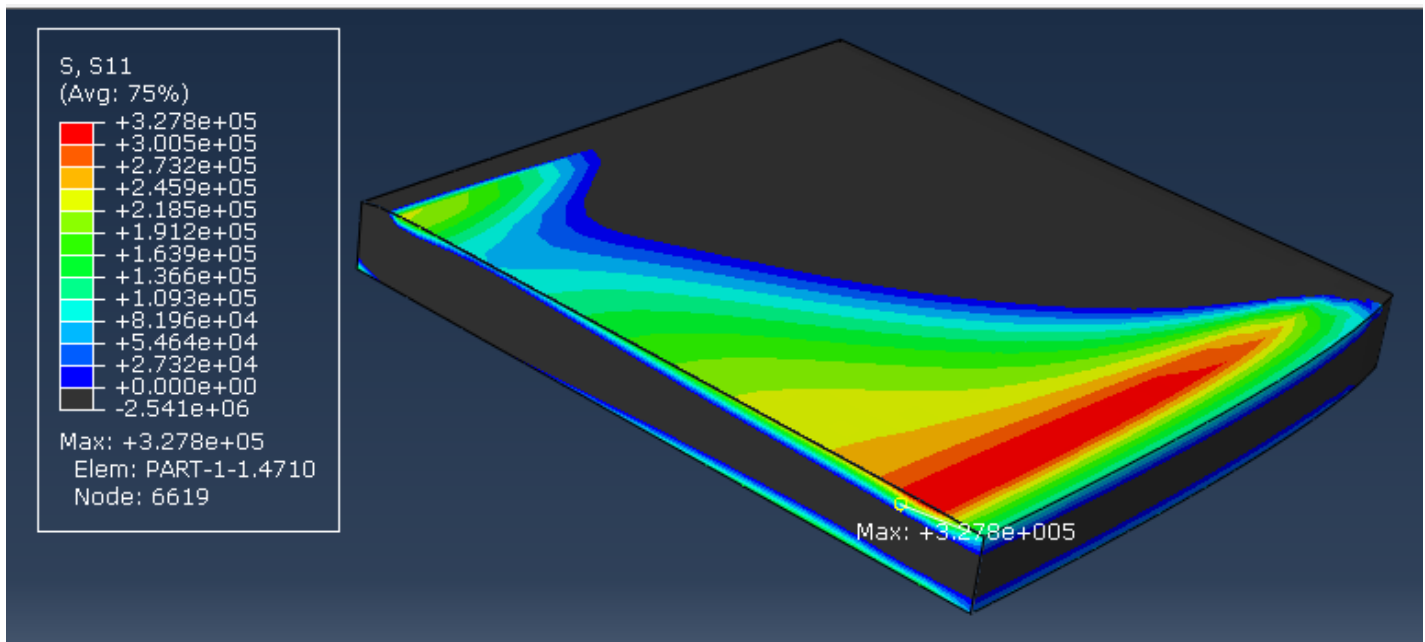

(c)

Figura 6. 5: Exemplo de distribuição de tensões de tração em placa submetida à variação não uniforme de temperatura ( $\mathrm{t}=2$ dias): (a)Perspectiva isométrica (b) Vista inferior (c) Seção transversal central 


\subsubsection{3.}

\section{Caso III}

Neste caso a placa é submetida à tração em toda a superfície, exceto na face anterior (Figura 6. 6). Já ao longo da espessura há predominância de compressão. A presença de compressão na parte interna e na face anterior da placa é motivada por dois fatores: a possibilidade de deformação parcial da face anterior e a existência do interior mais aquecido do que a superfície, podendo chegar a mais de $4^{\circ} \mathrm{C}$ de diferença.

Já a tração ocorre em virtude da redução da temperatura superficial. As temperaturas inferiores a $20^{\circ} \mathrm{C}$ induzem à contração, que por sua vez é impedida em quase toda a placa devido à existência dos engastes, gerando tensões de tração. Verifica-se compressão na face anterior, pois sua deformação é parcialmente restringida pelos engastes.

Na Tabela 6. 5 é possível observar que as maiores tensões de compressão ocorrem nas situações onde se verifica as maiores variações de temperatura interna. Já as maiores tensões de tração ocorrem em dias nos quais a temperatura superficial é mais baixa. Nota-se que o gradiente térmico interno também influencia na magnitude das tensões de tração, mesmo quando a temperatura superficial é igual (exemplo: dias 3 e 8,5). Destaca-se que para $t=9,5$ dias a tensão de tração máxima chegou a quase $25 \%$ do valor de resistência à tração considerado, representando o efeito das baixas temperaturas sobre a geração de tensões de tração importantes.

Tabela 6. 5: Tensões de tração e compressão máximas desenvolvidas na placa intacta em decorrência da variação não uniforme de temperatura: caso III

\begin{tabular}{|c|c|c|c|c|c|}
\hline $\begin{array}{c}\text { Tempo } \\
(\mathbf{d i a s})\end{array}$ & $\begin{array}{c}\mathbf{T}_{\text {faces superior }} \\
\mathrm{e} \text { inferior }\left({ }^{\circ} \mathbf{C}\right)\end{array}$ & $\begin{array}{c}\mathbf{T}_{\text {núcleo } \mathbf{m a x}} \\
\left({ }^{\circ} \mathbf{C}\right)\end{array}$ & $\begin{array}{c}\Delta \mathbf{T}_{\text {interno }} \\
\left({ }^{\circ} \mathbf{C}\right)\end{array}$ & $\begin{array}{c}\boldsymbol{\sigma}_{\mathbf{t} \text { máx }} \\
(\mathbf{M P a})\end{array}$ & $\begin{array}{c}\boldsymbol{\sigma}_{\mathbf{c} \text { máx }} \\
(\mathbf{M P a})\end{array}$ \\
\hline 3 & 17 & 24,5 & 7,5 & 0,56 & 1,80 \\
\hline 4 & 17 & 20,4 & 3,4 & 0,73 & 0,18 \\
\hline 4,5 & 19 & 19,8 & 0,8 & 0,33 & 0,04 \\
\hline 5 & 17 & 18,7 & 1,7 & 1,04 & 0,09 \\
\hline 6,5 & 16 & 18,1 & 2,1 & 1,41 & 0,14 \\
\hline 8,5 & 17 & 17,5 & 0,5 & 1,33 & 0,10 \\
\hline 9,5 & 13,5 & 16,8 & 3,3 & 2,42 & 0,23 \\
\hline 11 & 15 & 19,8 & 4,8 & 1,37 & 0,28 \\
\hline
\end{tabular}




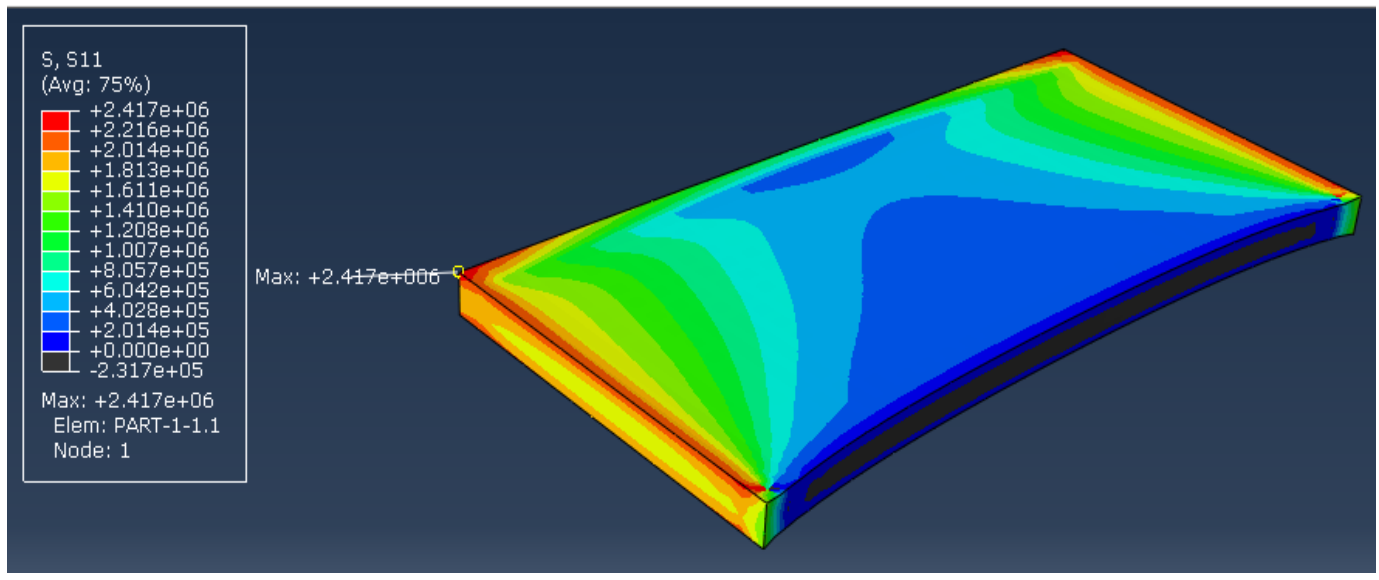

(a)

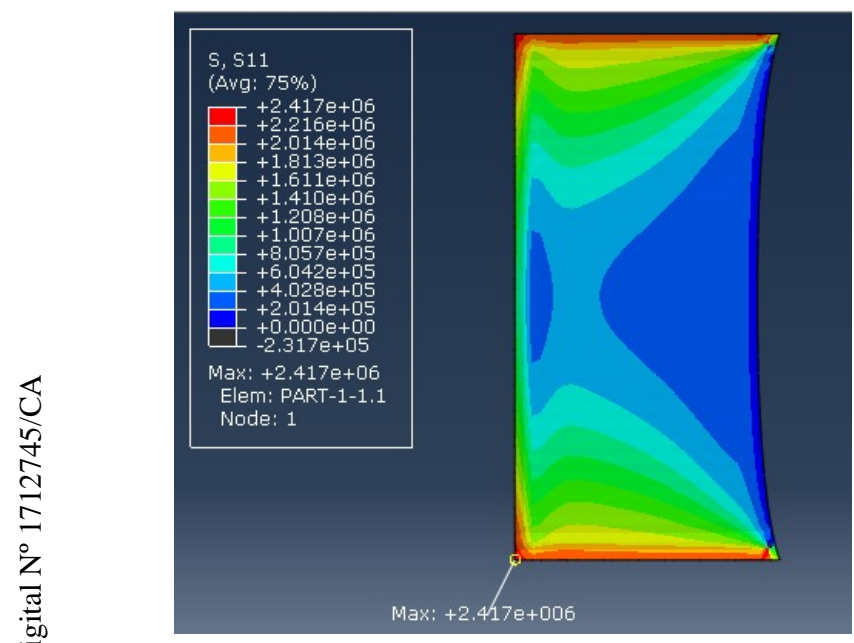

(b)

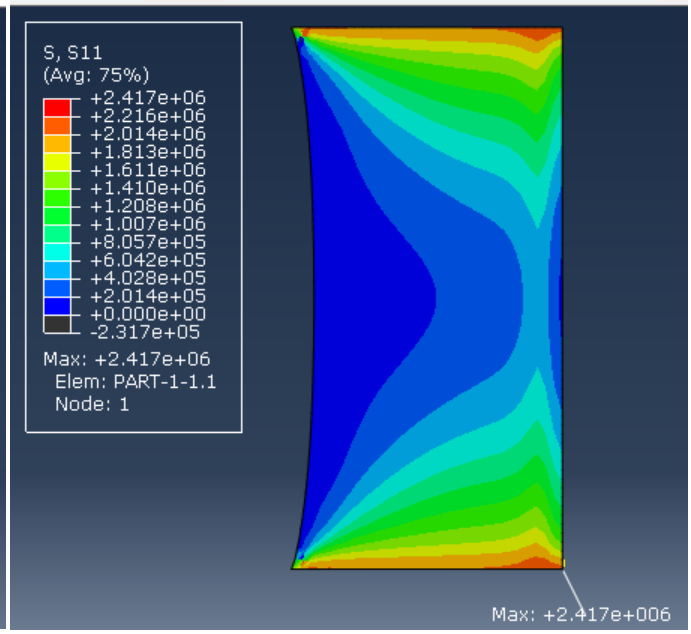

(c)

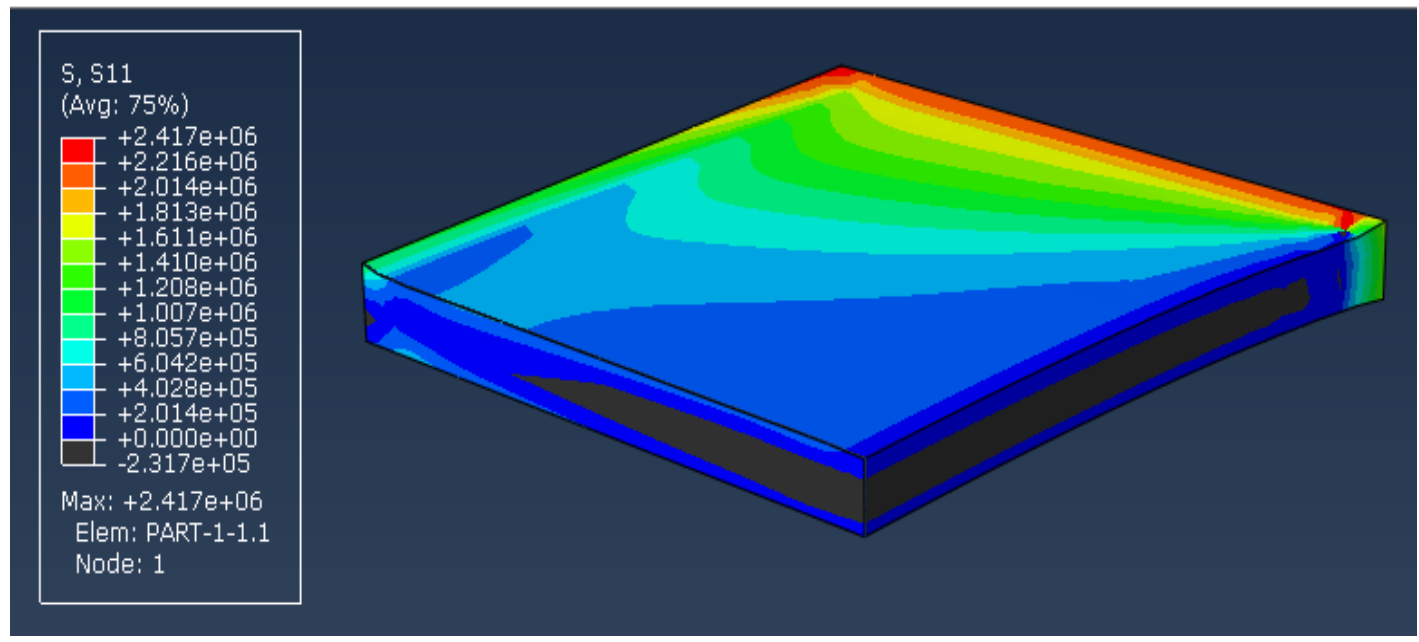

(c)

Figura 6. 6: Exemplo de distribuição de tensões de tração em placa submetida à variação não uniforme de temperatura ( $t=9,5$ dias): (a)Perspectiva isométrica (b) Vista superior (c) Vista inferior (d) Seção transversal central 


\subsubsection{4.}

Caso IV

As temperaturas superficial e interna inferiores a $20^{\circ} \mathrm{C}$, associadas ao pequeno gradiente térmico interno positivo, fizeram com que houvesse tração em praticamente toda a placa. A pequena parcela de compressão surge em porções das faces superior e inferior que possuem certa liberdade de deformação. A face anterior, apesar de também dispor de alguma liberdade de deformação, sofre influência do núcleo ligeiramente mais frio e, portanto, desenvolve tensões de tração (Figura 6. 7).

A Tabela 6. 6 apresenta os valores máximos de tração e compressão obtidos. As tensões máximas de tração são muito inferiores ao valor de resistência à tração determinado e as tensões de compressão são mínimas.

Tabela 6. 6: Tensões de tração e compressão máximas desenvolvidas na placa intacta em decorrência da variação não uniforme de temperatura: caso IV

\begin{tabular}{|c|c|c|c|c|c|}
\hline $\begin{array}{c}\text { Tempo } \\
\text { (dias) }\end{array}$ & $\begin{array}{c}\mathbf{T}_{\text {faces superior }} \\
\text { e inferior }\left({ }^{\circ} \mathbf{C}\right)\end{array}$ & $\begin{array}{c}\mathbf{T}_{\text {núcleo }} \\
\operatorname{mín}^{\circ}\left({ }^{\circ} \mathbf{C}\right)\end{array}$ & $\begin{array}{c}\Delta \mathbf{T} \text { interno } \\
\left({ }^{\circ} \mathbf{C}\right)\end{array}$ & $\begin{array}{c}\boldsymbol{\sigma}_{\text {t máx }} \\
(\mathbf{M P a})\end{array}$ & $\begin{array}{c}\boldsymbol{\sigma}_{\mathbf{c} \text { máx }} \\
(\mathbf{M P a})\end{array}$ \\
\hline 5,5 & 19 & 18,6 & 0,4 & 0,56 & 0,05 \\
\hline 8 & 18 & 17,8 & 0,2 & 1,02 & 0,08 \\
\hline
\end{tabular}




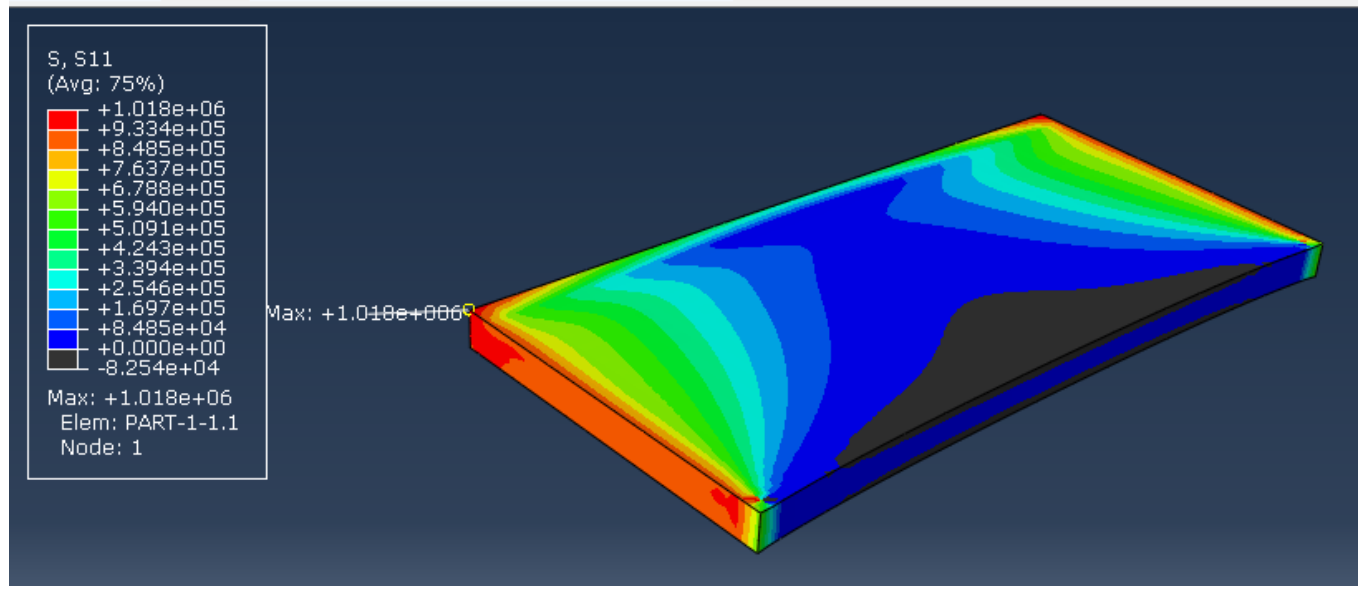

(a)

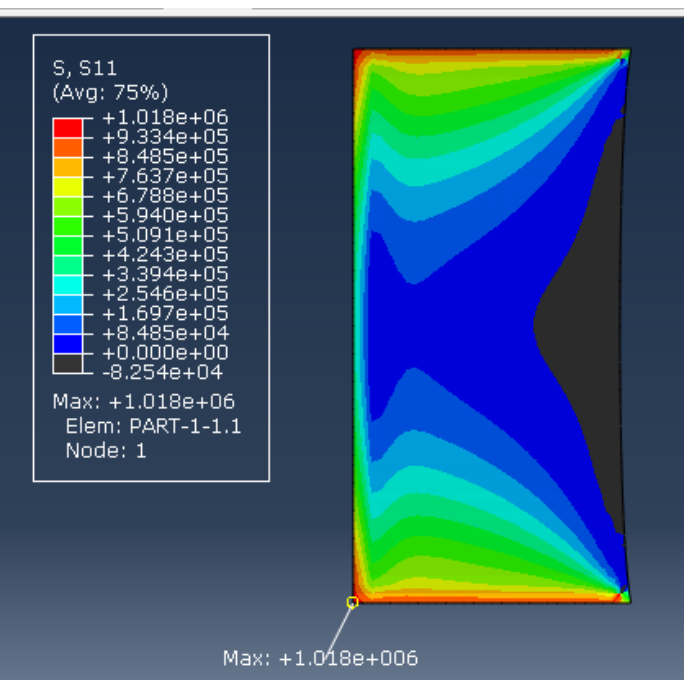

(b)

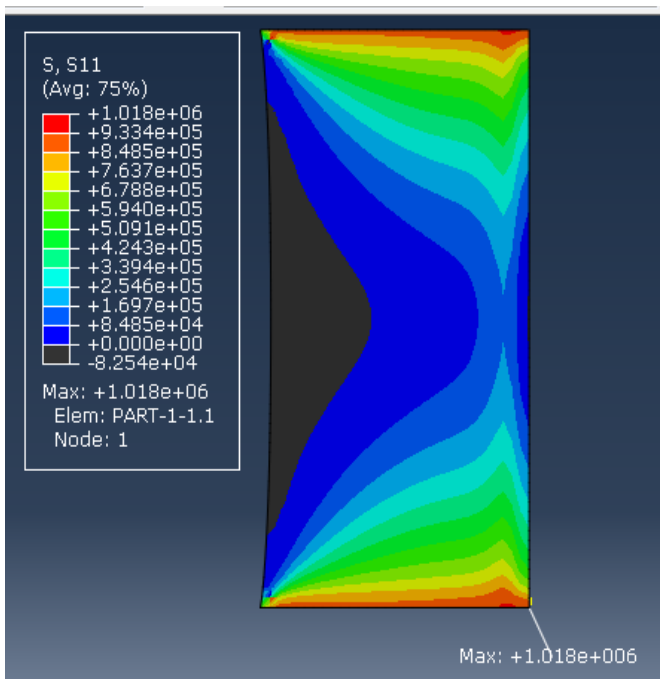

(c)

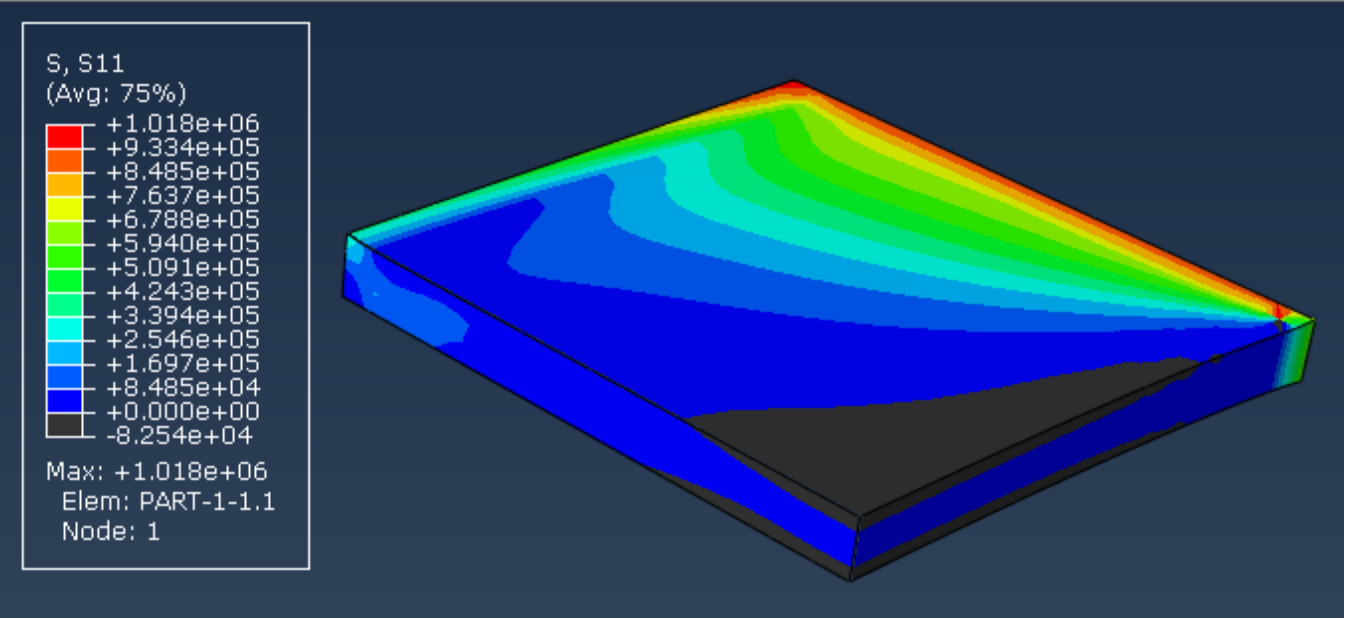

(c)

Figura 6. 7: Exemplo de distribuição de tensões de tração em placa submetida à variação não uniforme de temperatura ( $\mathrm{t}=8$ dias): (a)Perspectiva isométrica (b) Vista superior (c) Vista inferior (d) Seção transversal central 


\subsubsection{5.}

\section{Caso V}

Quando uma das faces está a mais de $20^{\circ} \mathrm{C}$, se verifica tração da face mais fria até o limite onde a temperatura interna é igual a inicial $\left(20^{\circ} \mathrm{C}\right)$. Os maiores valores de tração são encontrados próximos aos engastes (Figura 6. 8). A compressão é verificada da face mais aquecida até o limite onde a temperatura se iguala a inicial (áreas escuras da Figura 6. 8)

A Tabela 6. 7evidencia que quanto menor a temperatura de uma das faces, maior será a tensão de tração gerada, ao passo em que a compressão de faces abaixo de $20^{\circ} \mathrm{C}$ surge em virtude do gradiente entre as faces. Observa-se também que as tensões de tração giram em torno de $10 \%$ do valor de resistência à tração.

Tabela 6. 7: Tensões de tração e compressão máximas desenvolvidas na placa intacta em decorrência da variação não uniforme de temperatura: caso $\mathrm{V}$

\begin{tabular}{|c|c|c|c|c|c|}
\hline $\begin{array}{c}\text { Tempo } \\
(\mathbf{d i a s})\end{array}$ & $\begin{array}{c}\mathbf{T}_{\text {face superior }} \\
\left({ }^{\circ} \mathbf{C}\right)\end{array}$ & $\begin{array}{c}\mathbf{T}_{\text {face inferior }} \\
\left({ }^{\circ} \mathbf{C}\right)\end{array}$ & $\begin{array}{c}\Delta \mathbf{T} \\
\text { faces }\left({ }^{\circ} \mathbf{C}\right)\end{array}$ & $\begin{array}{c}\boldsymbol{\sigma}_{\mathbf{t} \text { máx }} \\
(\mathbf{M P a})\end{array}$ & $\begin{array}{c}\boldsymbol{\sigma}_{\mathbf{c} \text { máx }} \\
(\mathbf{M P a})\end{array}$ \\
\hline 3,5 & 22 & 18 & 4 & 0,67 & 1,14 \\
\hline 6 & 22 & 18 & 4 & 0,73 & 0,56 \\
\hline 7 & 18 & 17 & 1 & 1,23 & 0,11 \\
\hline 7,5 & 17 & 18 & 1 & 1,28 & 0,10 \\
\hline 9 & 24 & 17 & 7 & 1,19 & 1,03 \\
\hline 10 & 25 & 19 & 6 & 0,70 & 1,03 \\
\hline
\end{tabular}




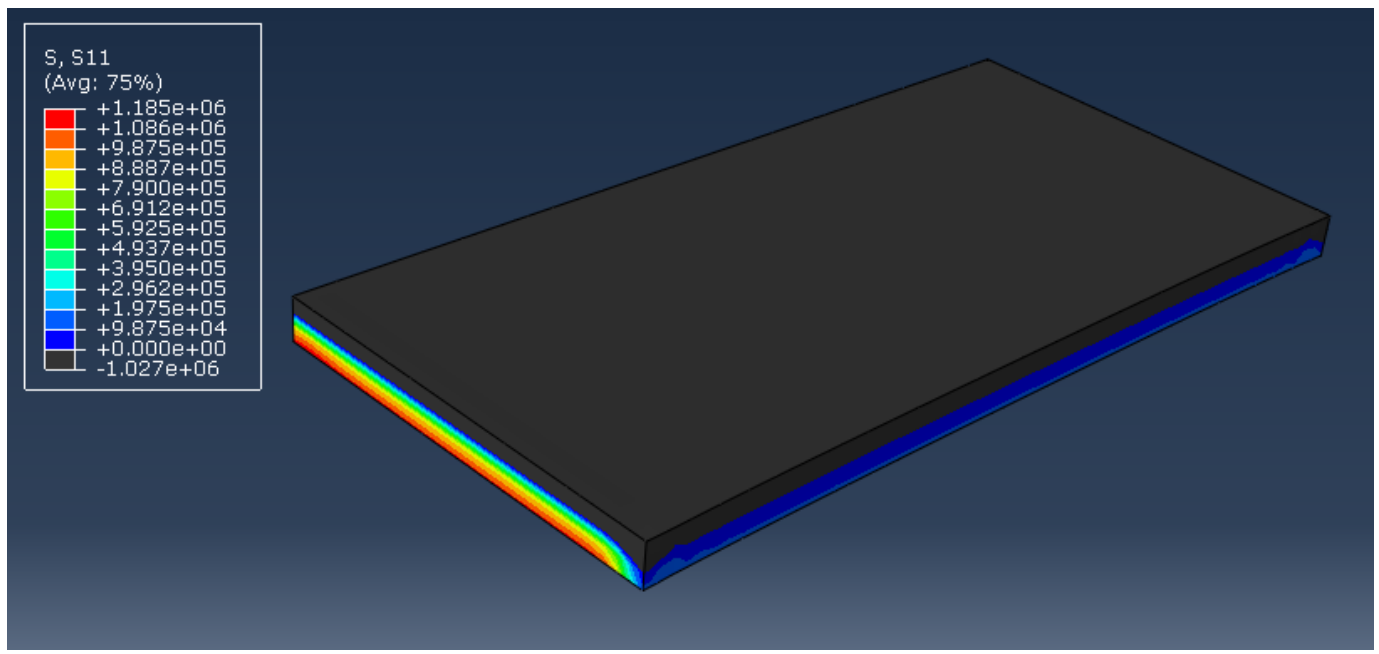

(a)

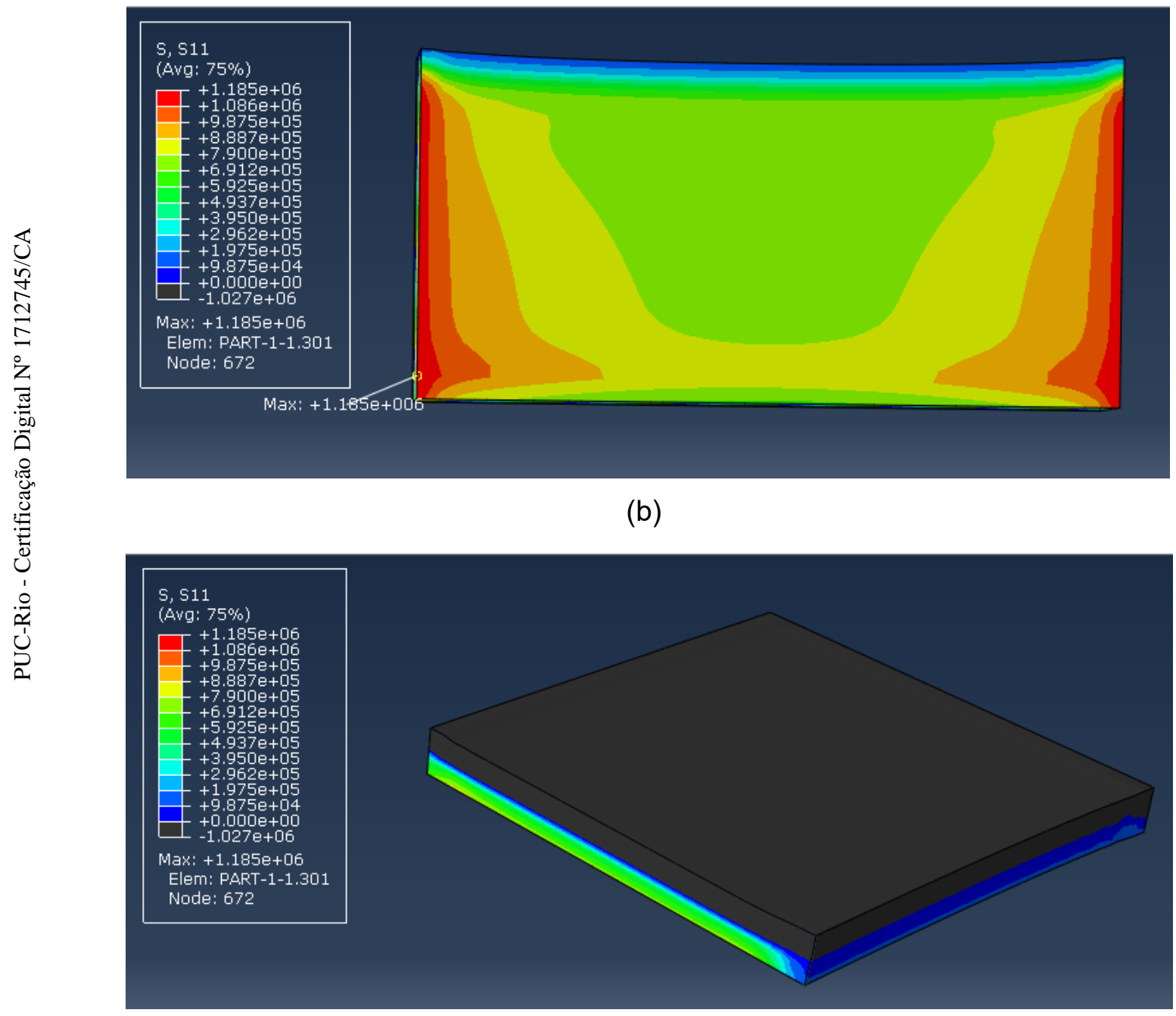

(c)

Figura 6. 8: Exemplo de distribuição de tensões de tração em placa submetida à variação não uniforme de temperatura ( $\mathrm{t}=9$ dias): (a)Perspectiva isométrica (b) Vista inferior (c) Seção transversal central 


\subsection{2.}

\section{Placa rochosa fraturada}

A geometria foi alterada pela inserção da fratura central, porém foram mantidas todas as condições de contorno mecânicas e de temperatura do item anterior. Desta forma, foram obtidos os mesmos 5 padrões de distribuição de temperatura apresentados anteriormente. Será analisado, portanto, o comportamento da fratura mediante variações não uniformes de temperatura, bem como os fatores de intensidade de tensão desenvolvidos (Figura 6. 9). Foi observado também o impacto da existência da fratura sobre a distribuição das tensões de tração.

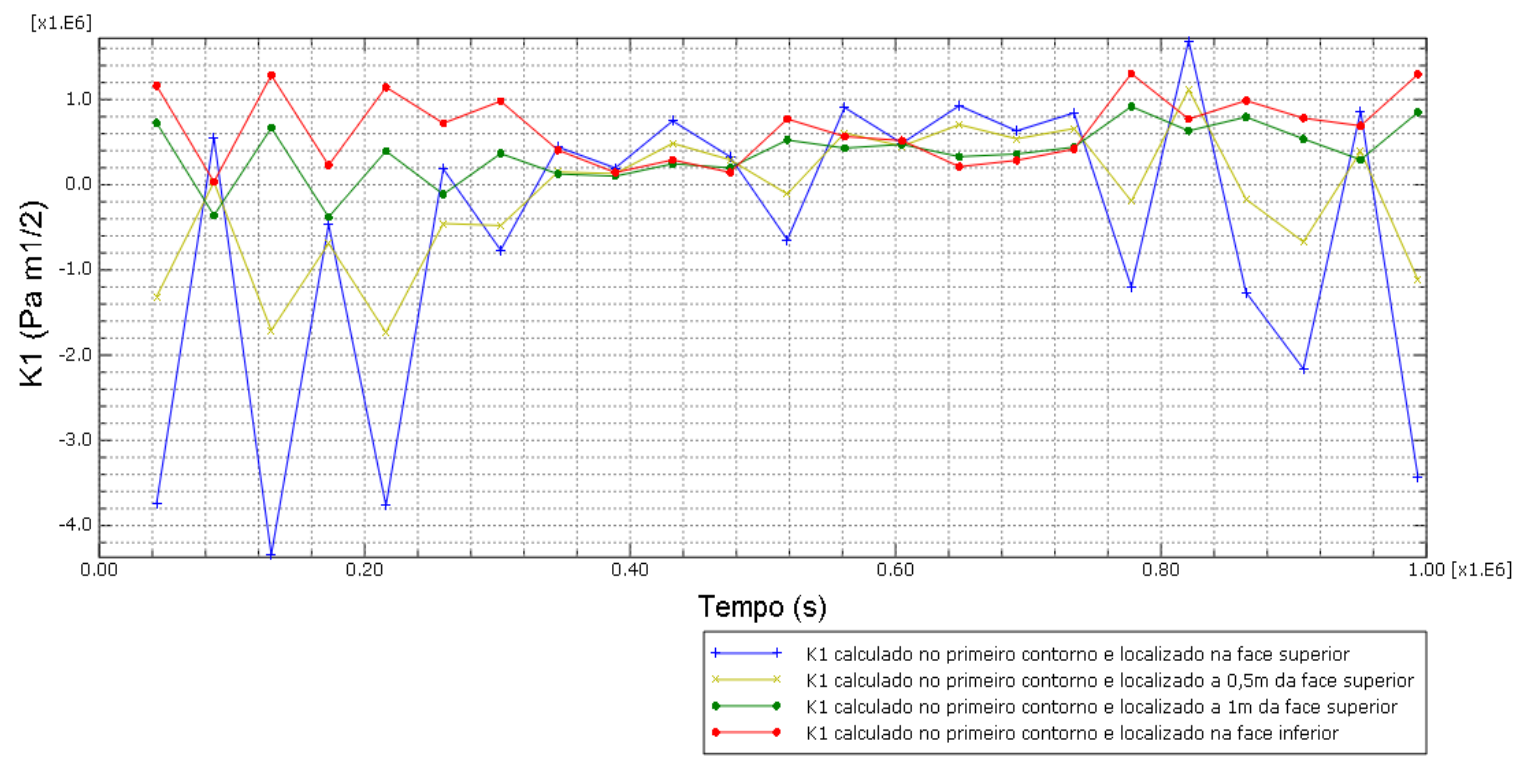

Figura 6. 9: $\mathrm{K}_{1}\left(\mathrm{~Pa} \mathrm{~m}^{1 / 2}\right)$ ao longo do tempo para placa submetida a variações não uniformes de temperatura

\subsubsection{1.}

\section{Caso I}

A diferença de temperatura entre as faces faz com uma delas tenda a se expandir mais do que a outra. A existência da fratura permite que a placa se curve, fazendo com que a face inferior, mais fria, apresente compressão, exceto na região ao redor das pontas da fratura, onde a abertura ocasiona a formação de regiões de concentração de tensões de tração (Figura 6. 10). É importante destacar que a máxima tensão de tração agora ocorre nas pontas da fratura e não a meia espessura da seção transversal central como antes. 
A Tabela 6. 8 traz os valores dos fatores de intensidade de tensão desenvolvidos no cenário em questão. Nota-se, como esperado, que os valores positivos ocorrem nos dois contornos inferiores, o que é coerente com a abertura da fratura e consequentemente com a concentração de tensões de tração que se verificou. Na face superior e até cerca da metade, a fratura está fechada e sob compressão, o que condiz com os fatores de intensidade de tensão negativos encontrados. Destaca-se também que os maiores valores positivos de K1ocorrem quando há maior variação de temperatura entre as faces e que sua magnitude é superior aos valores de tenacidade do material, o que indica propagação da fratura pelo modo I.

Tabela 6. 8: Valores de $\mathrm{K}_{1}\left(\mathrm{MPa} \mathrm{m}^{1 / 2}\right)$ desenvolvidos em decorrência variação não uniforme de temperatura: caso I

\begin{tabular}{|c|c|c|c|c|}
\hline \multirow{2}{*}{$\begin{array}{c}\text { Tempo } \\
\text { (dias) }\end{array}$} & \multicolumn{4}{|c|}{$\mathbf{K}_{\mathbf{1}}\left(\mathbf{M P a ~}^{\mathbf{1 / 2}}\right)$} \\
\cline { 2 - 5 } & $\begin{array}{c}\text { Na face } \\
\text { superior }\end{array}$ & $\begin{array}{c}\mathbf{A} \mathbf{0 , 5 m} \text { da } \\
\text { face superior }\end{array}$ & $\begin{array}{c}\mathbf{A} \mathbf{1} \text { m da face } \\
\text { superior }\end{array}$ & Na face inferior \\
\hline 0,5 & $-3,75$ & $-1,30$ & 0,75 & 1,20 \\
\hline 1,5 & $-4,40$ & $-1,70$ & 0,70 & 1,30 \\
\hline 2,5 & $-3,75$ & $-1,75$ & 0,40 & 1,20 \\
\hline 10,5 & $-2,20$ & $-0,65$ & 0,55 & 0,80 \\
\hline 11,5 & $-3,40$ & $-1,10$ & 0,80 & 1,30 \\
\hline
\end{tabular}




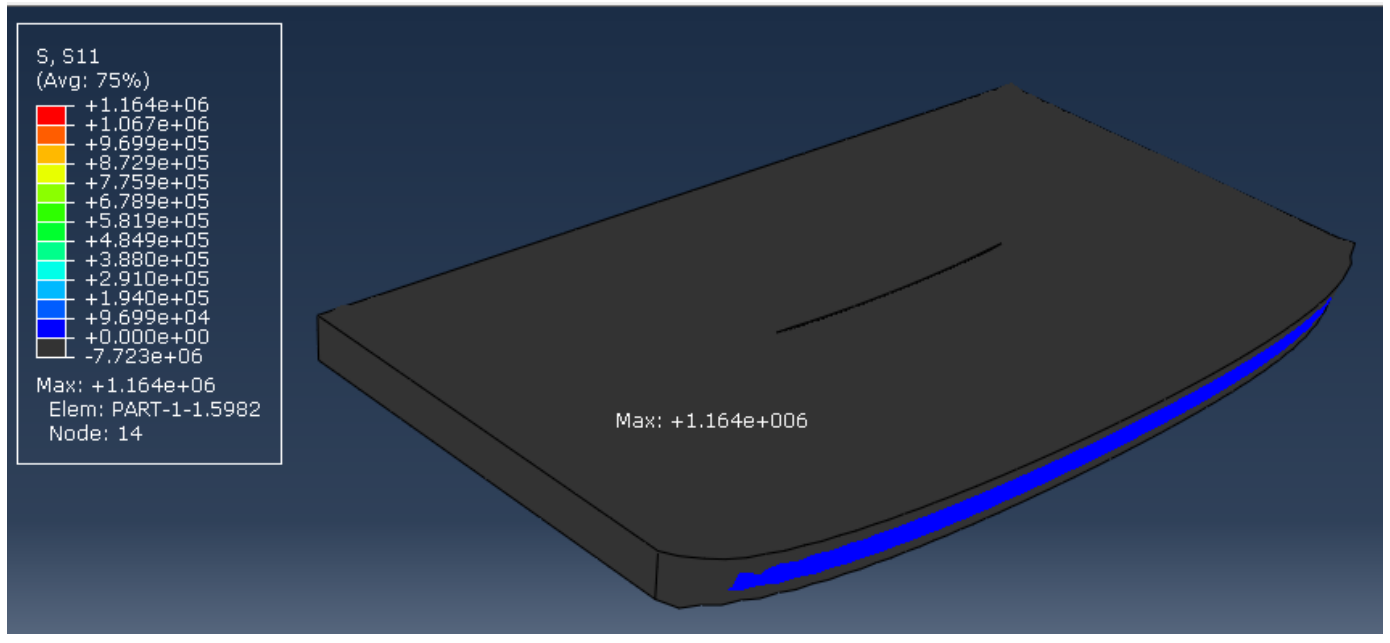

(a)

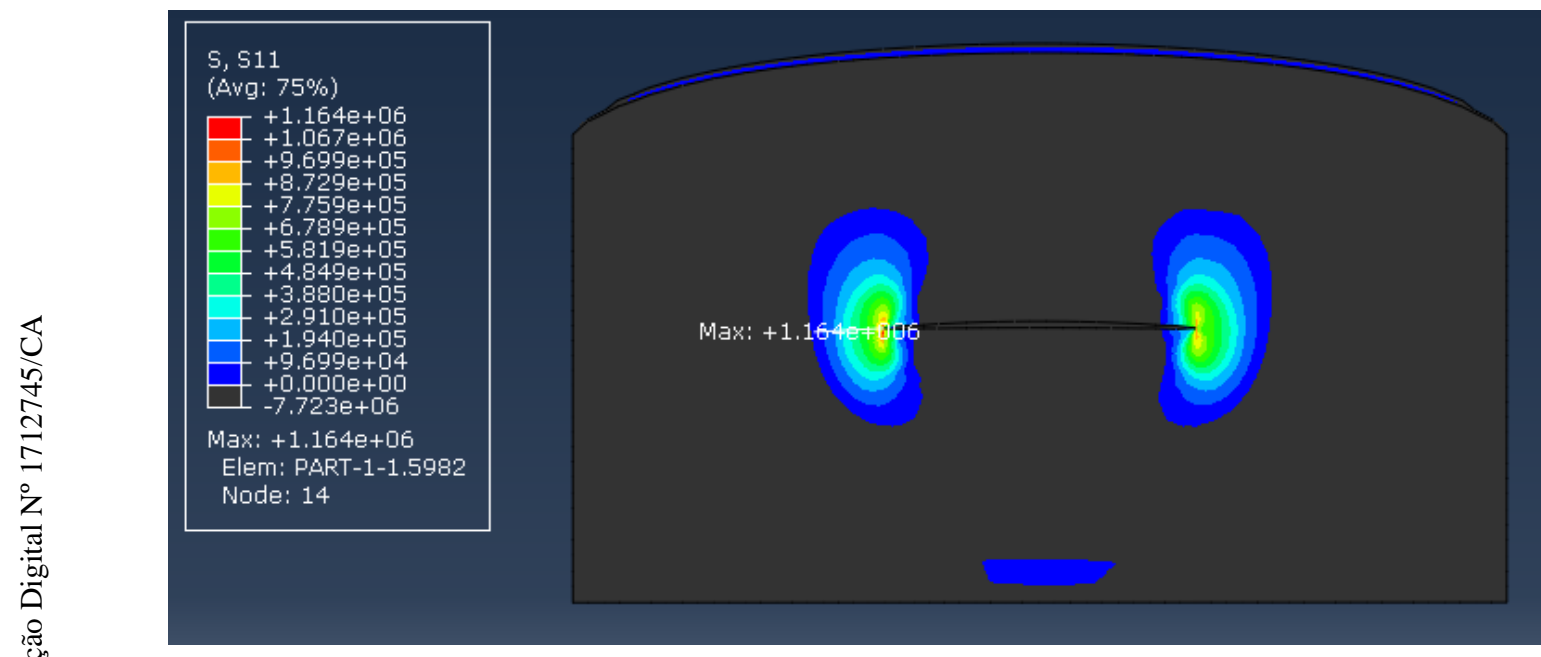

(b)

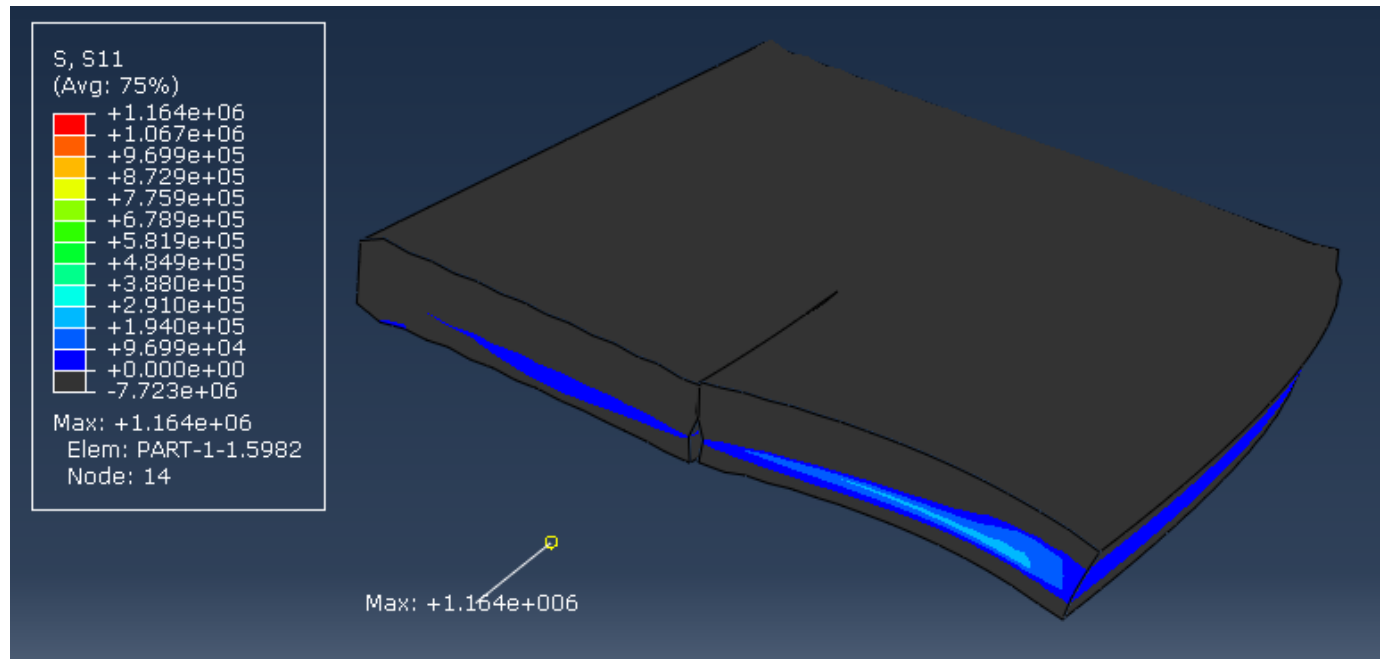

(c)

Figura 6. 10: Exemplo de distribuição de tensões de tração em placa fraturada submetida à variação não uniforme de temperatura ( $\mathrm{t}=1,5$ dias): (a)Perspectiva isométrica (b) Vista inferior (c) Seção transversal central 


\subsubsection{2.}

\section{Caso II}

Nas regiões onde a temperatura é superior a $20^{\circ} \mathrm{C}$ foi verificado o fechamento da fratura, ao passo em que em locais onde a temperatura é inferior a $20^{\circ} \mathrm{C}$ ocorre a abertura. Entretanto, a fratura pode se abrir em virtude do gradiente de temperatura, mesmo que na parte interna da placa não se verifique temperaturas inferiores a $20^{\circ} \mathrm{C}$. A parcela mais aquecida se expande mais do que as demais fazendo com que as faces da fratura se afastem (Figura 6.11), gerando valores de $K_{1}$ positivos que merecem atenção (Tabela 6.9).

Tabela 6. 9: Valores de $\mathrm{K} 1\left(\mathrm{MPa} \mathrm{m}^{1 / 2}\right)$ desenvolvidos em decorrência variação não uniforme de temperatura: caso II

\begin{tabular}{|c|c|c|c|c|}
\hline \multirow{2}{*}{\begin{tabular}{c}
\multirow{2}{*}{$\begin{array}{c}\text { Tempo } \\
\text { (dias) }\end{array}$} \\
\cline { 2 - 5 }
\end{tabular}} & $\begin{array}{c}\text { Na face } \\
\text { superior }\end{array}$ & $\begin{array}{c}\text { A 0,5m da } \\
\text { face superior }\end{array}$ & $\begin{array}{c}\mathbf{A} \mathbf{1 m} \text { da face } \\
\text { superior }\end{array}$ & Na face inferior \\
\hline 1 & 0,60 & 0,00 & $-0,40$ & 0,00 \\
\hline 2 & $-0,45$ & $-0,70$ & $-0,40$ & 0,20 \\
\hline
\end{tabular}




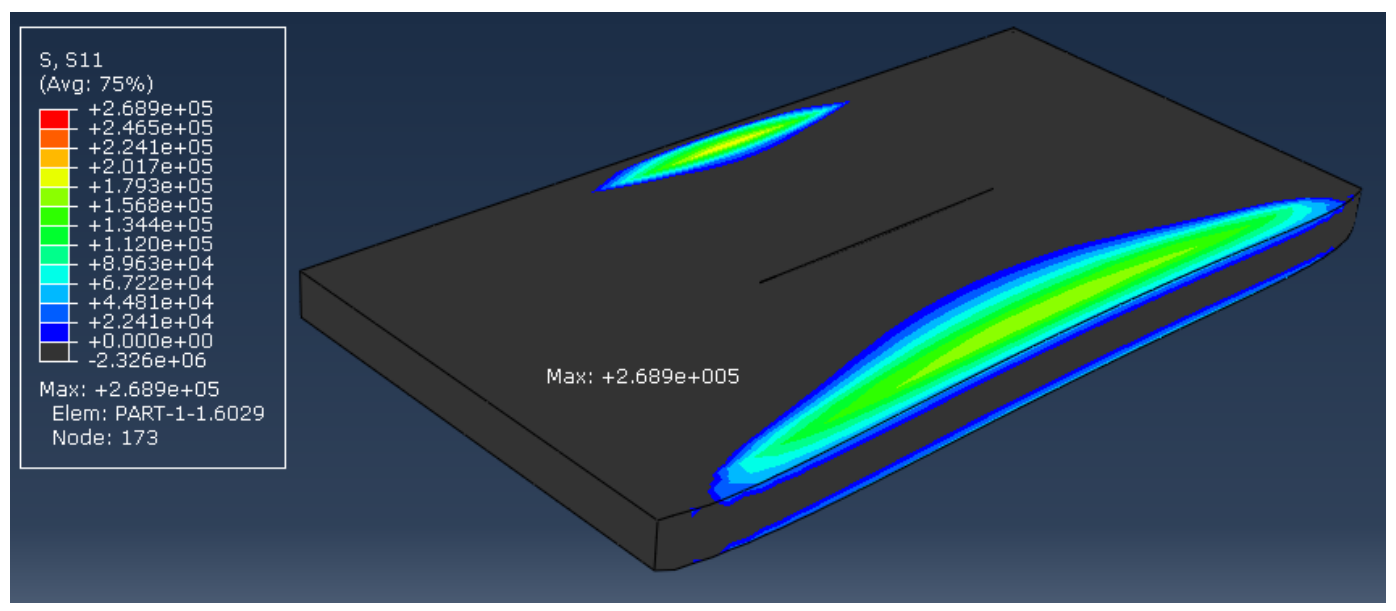

(a)

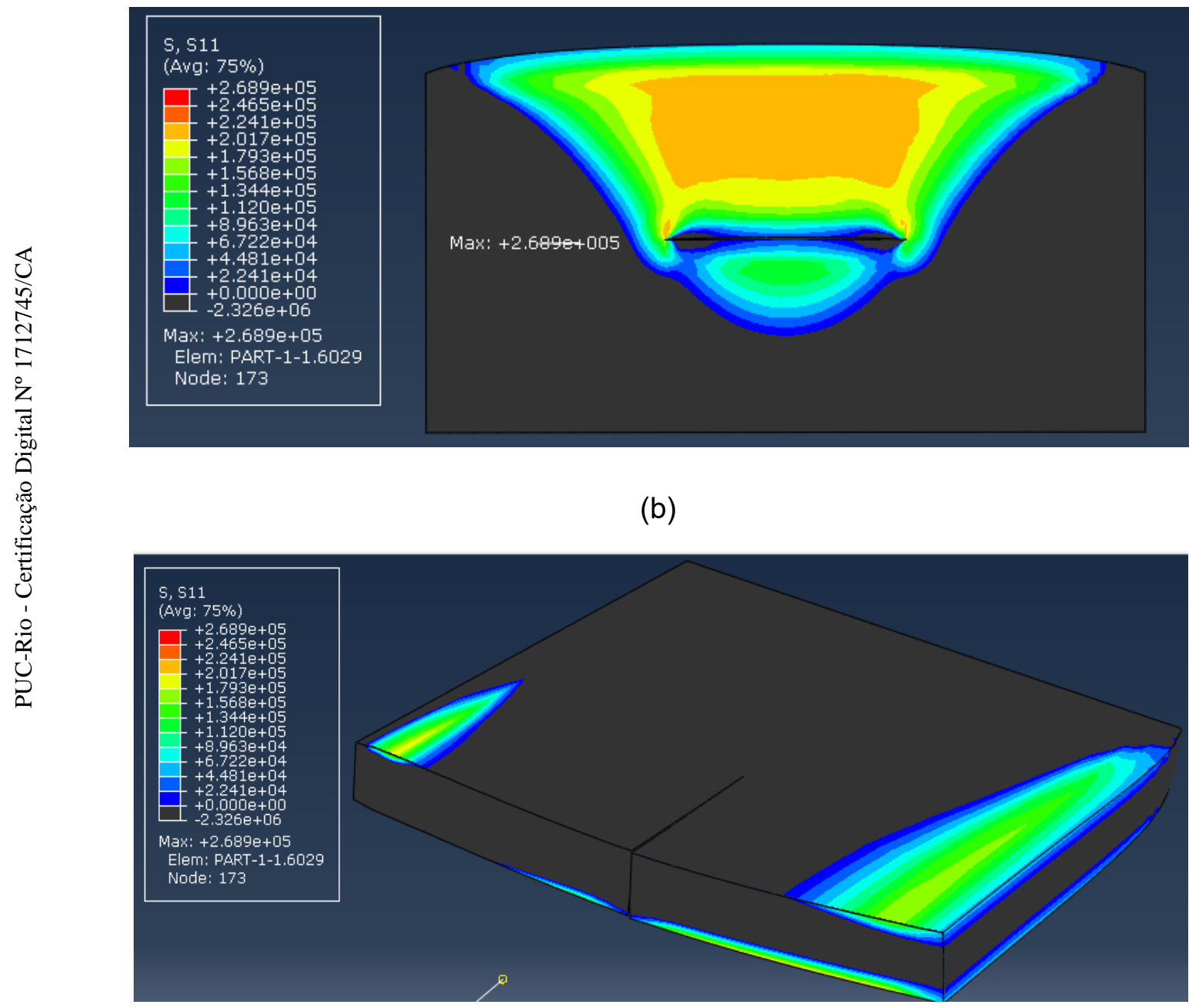

(c)

Figura 6. 11: Exemplo de distribuição de tensões de tração em placa fraturada submetida à variação não uniforme de temperatura ( $\mathrm{t}=2$ dias): (a)Perspectiva isométrica (b) Vista inferior (c) Seção transversal central 
6.2.2.3.

Caso III

Nesta configuração observa-se que a abertura da fratura é maior nos momentos onde as variações negativas de temperatura são maiores, como se pode verificar comparando os valores da Tabela $6.10 \mathrm{com}$ os fatores de intensidade de tensão da Tabela 6. 11. É importante destacar o alto valor de $\mathrm{K}_{1}$ na face superior em $\mathrm{t}=9,5$ dias, bem como o tamanho da abertura (Figura 6.12)

Tabela 6. 10: Tensões de tração e compressão máximas desenvolvidas na placa fraturada em decorrência da variação não uniforme de temperatura: caso III

\begin{tabular}{|c|c|c|c|}
\hline $\begin{array}{c}\text { Tempo } \\
\text { (dias) }\end{array}$ & $\mathbf{T}_{\text {faces }}\left({ }^{\circ} \mathbf{C}\right)$ & $\mathbf{T}_{\text {núcleo máx }}\left({ }^{\circ} \mathbf{C}\right)$ & $\Delta \mathbf{T}_{\text {núcleo }}\left({ }^{\circ} \mathbf{C}\right)$ \\
\hline 3 & 17 & 24,5 & 7,5 \\
\hline 4 & 17 & 20,4 & 3,4 \\
\hline 4,5 & 19 & 19,8 & 0,8 \\
\hline 5 & 17 & 18,7 & 1,7 \\
\hline 6,5 & 16 & 18,1 & 2,1 \\
\hline 8,5 & 17 & 17,5 & 0,5 \\
\hline 9,5 & 13,5 & 16,8 & 3,3 \\
\hline 11 & 15 & 19,8 & 4,8 \\
\hline
\end{tabular}

Tabela 6. 11: Valores de K1 (MPa $\left.\mathrm{m}^{1 / 2}\right)$ desenvolvidos em decorrência variação não uniforme de temperatura: caso III

\begin{tabular}{|c|c|c|c|c|}
\hline \multirow{2}{*}{$\begin{array}{c}\text { Tempo } \\
\text { (dias) }\end{array}$} & \multicolumn{4}{|c|}{$\mathbf{K}_{\mathbf{1}}\left(\mathbf{M P a} \mathbf{~ m}^{\mathbf{1 / 2}}\right)$} \\
\cline { 2 - 5 } & $\begin{array}{c}\text { Na face } \\
\text { superior }\end{array}$ & $\begin{array}{c}\text { A 0,5m da } \\
\text { face superior }\end{array}$ & $\begin{array}{c}\mathbf{A} \mathbf{1 m} \text { da face } \\
\text { superior }\end{array}$ & Na face inferior \\
\hline 3 & 0,20 & $-0,45$ & $-0,10$ & 0,75 \\
\hline 4 & 0,40 & 0,15 & 0,15 & 0,40 \\
\hline 4,5 & 0,20 & 0,15 & 0,10 & 0,15 \\
\hline 5 & 0,75 & 0,50 & 0,20 & 0,30 \\
\hline 6,5 & 0,90 & 0,60 & 0,45 & 0,60 \\
\hline 8,5 & 0,80 & 0,65 & 0,40 & 0,40 \\
\hline 9,5 & 1,75 & 1,15 & 0,65 & 0,80 \\
\hline 11 & 0,90 & 0,40 & 0,30 & 0,70 \\
\hline
\end{tabular}




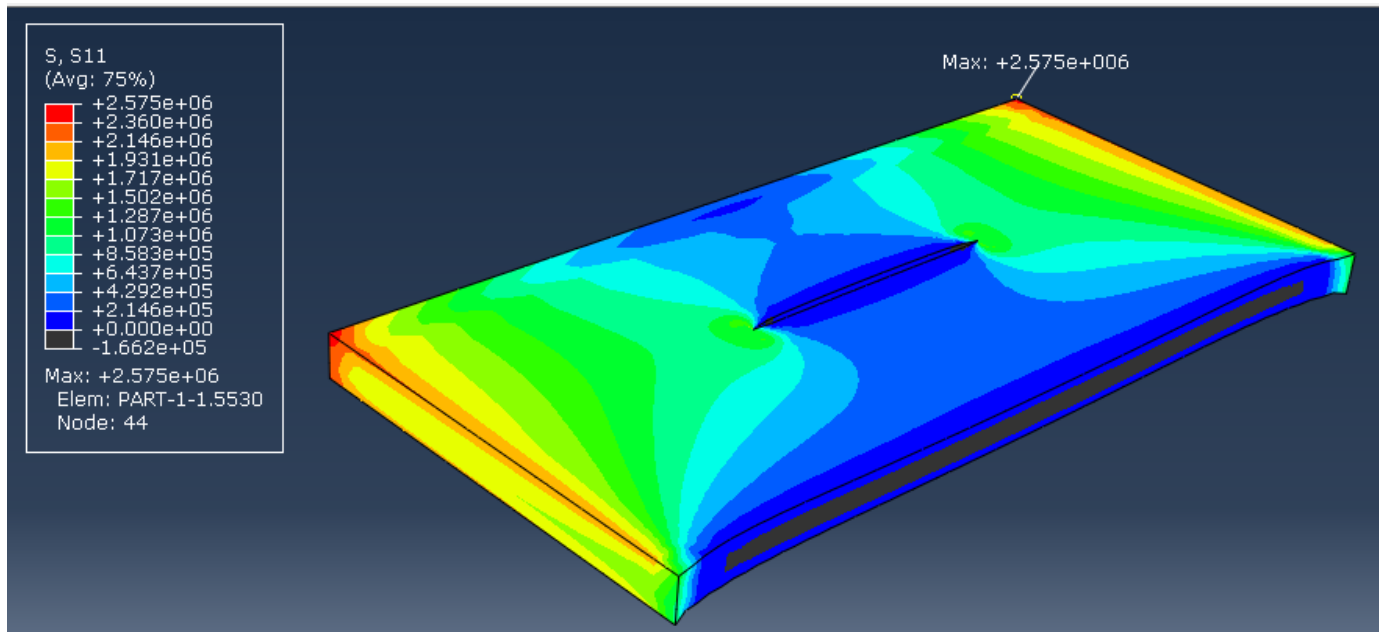

(a)

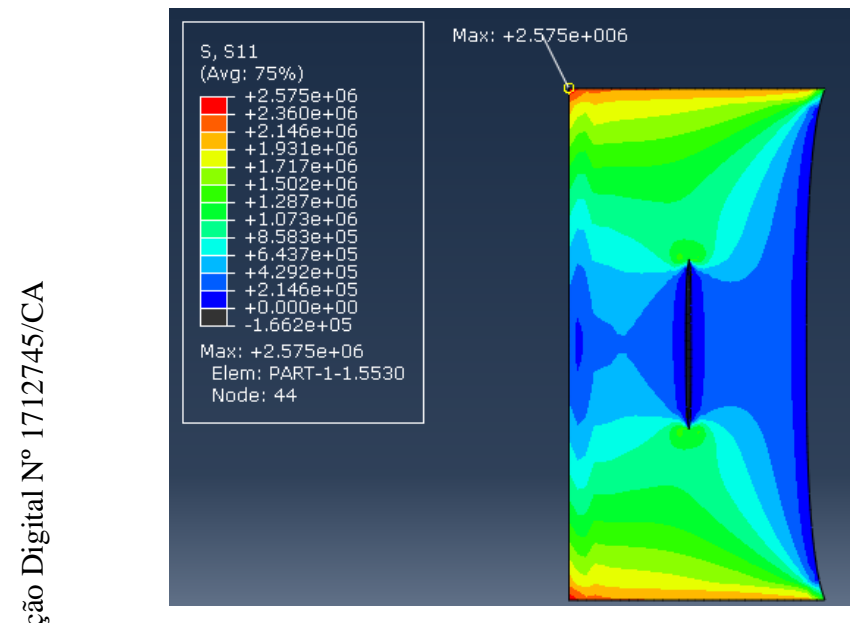

(b)

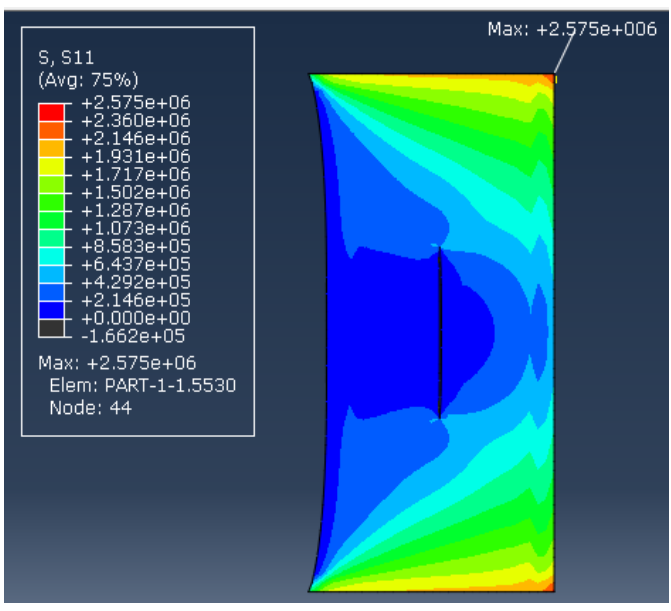

(c)

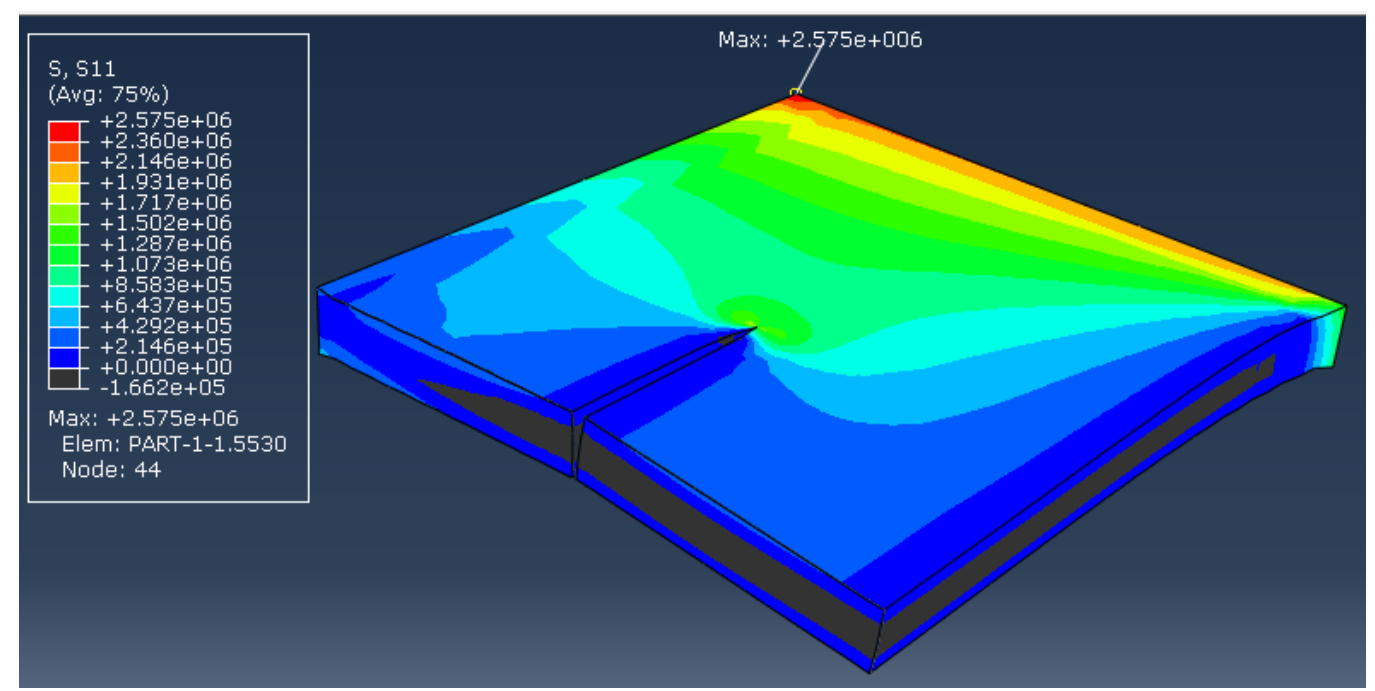

(c)

Figura 6. 12: Exemplo de distribuição de tensões de tração em placa fraturada submetida à variação não uniforme de temperatura ( $t=9,5$ dias): (a)Perspectiva isométrica (b) Vista superior (c) Vista inferior (d) Seção transversal central 


\subsubsection{4.}

Caso IV

A Tabela 6. 12 traz os valores de $\mathrm{K}_{1}$ desenvolvidos ao longo da altura da fratura. Para a condição de temperatura global inferior a $20^{\circ} \mathrm{C}$, a fratura se abre totalmente, variando apenas a largura da abertura (função da variação negativa de temperatura ao longo da espessura, das deformações permitidas pela geometria e dos vínculos da placa).

Em $\mathrm{t}=8$ dias, a deformada que a placa assume devido à variação térmica faz com que a abertura da fratura na face superior seja maior do que a abertura na face inferior, apesar de ambas estarem com a mesma temperatura. Isto é confirmado pelos valores de $\mathrm{K}_{1}$ positivos e maiores na face superior do que nos demais pontos considerados. Comparando os resultados de $\mathrm{K}_{1}$ com os valores de tenacidade para rochas graníticas e gnáissicas, percebe-se que são números importantes, mas não suficientes para ocasionar a propagação.

Tabela 6. 12: Valores de K1 (MPa m1/2) desenvolvidos em decorrência variação não uniforme de temperatura: caso IV

\begin{tabular}{|c|c|c|c|c|}
\hline \multirow{2}{*}{$\begin{array}{c}\text { Tempo } \\
\text { (dias) }\end{array}$} & \multicolumn{4}{|c|}{$\mathbf{K}_{\mathbf{1}}\left(\mathbf{M P a ~ m}^{\mathbf{1 / 2}}\right)$} \\
\cline { 2 - 5 } & $\begin{array}{c}\text { Na face } \\
\text { superior }\end{array}$ & $\begin{array}{c}\mathbf{A ~ 0 , 5 m} \mathbf{~ d a} \\
\text { face superior }\end{array}$ & $\begin{array}{c}\mathbf{A} \mathbf{1 m} \text { da face } \\
\text { superior }\end{array}$ & Na face inferior \\
\hline 5,5 & 0,35 & 0,30 & 0,20 & 0,15 \\
\hline 8 & 0,65 & 0,55 & 0,35 & 0,30 \\
\hline
\end{tabular}




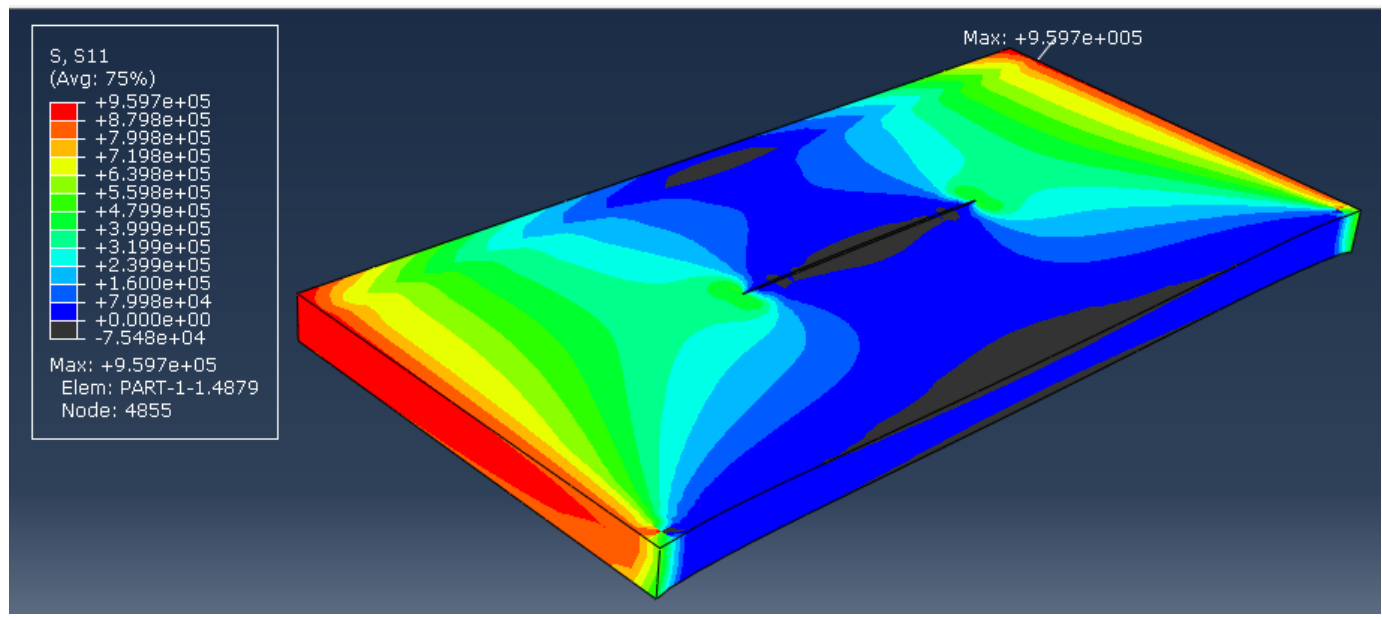

(a)

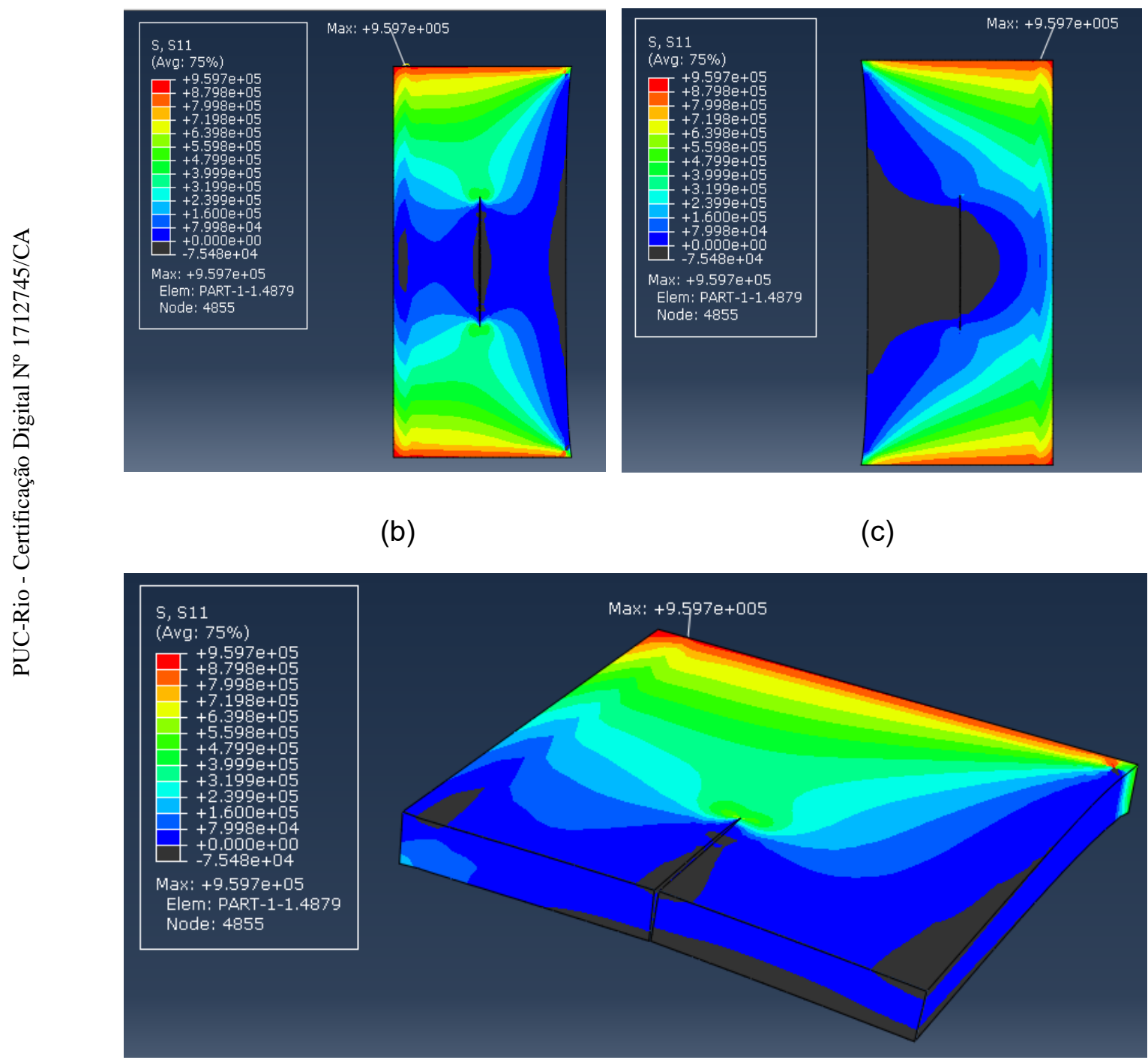

(c)

Figura 6. 13: Exemplo de distribuição de tensões de tração em placa fraturada submetida à variação não uniforme de temperatura ( $\mathrm{t}=8$ dias): (a)Perspectiva isométrica (b) Vista superior (c) Vista inferior (d) Seção transversal central 


\subsubsection{5.}

\section{Caso V}

A presença da descontinuidade, associada à variação de temperatura positiva em uma das faces e negativa na outra, promove a curvatura da placa, fazendo com que haja compressão na parte superior e tração na parte inferior, com concentração de tensão nas pontas da fratura (Figura 6. 14). Como é possível observar na Tabela 6. 13, os valores de $\mathrm{K}_{1}$ ratificam o que foi dito acima, e indicam a propagação da fratura.

Tabela 6. 13: Valores de K1 (MPa m1/2) desenvolvidos em decorrência variação não uniforme de temperatura: caso $\mathrm{V}$

\begin{tabular}{|c|c|c|c|c|}
\hline \multirow{2}{*}{$\begin{array}{c}\text { Tempo } \\
\text { (dias) }\end{array}$} & \multicolumn{4}{|c|}{$\mathbf{K}_{\mathbf{1}}\left(\mathbf{M P a} \mathbf{~ m}^{\mathbf{1 / 2}}\right)$} \\
\cline { 2 - 5 } & $\begin{array}{c}\text { Na face } \\
\text { superior }\end{array}$ & $\begin{array}{c}\mathbf{A ~ 0 , 5 m} \text { da } \\
\text { face superior }\end{array}$ & $\begin{array}{c}\mathbf{A} \mathbf{~ m} \text { da face } \\
\text { superior }\end{array}$ & Na face inferior \\
\hline 3,5 & $-0,80$ & $-0,45$ & 0,40 & 1,00 \\
\hline 6 & $-0,60$ & $-0,10$ & 0,55 & 0,80 \\
\hline 7 & 0,50 & 0,45 & 0,45 & 0,50 \\
\hline 7,5 & 0,90 & 0,70 & 0,35 & 0,20 \\
\hline 9 & $-1,20$ & $-0,20$ & 0,95 & 1,30 \\
\hline 10 & $-1,30$ & $-0,20$ & 0,80 & 1,00 \\
\hline
\end{tabular}




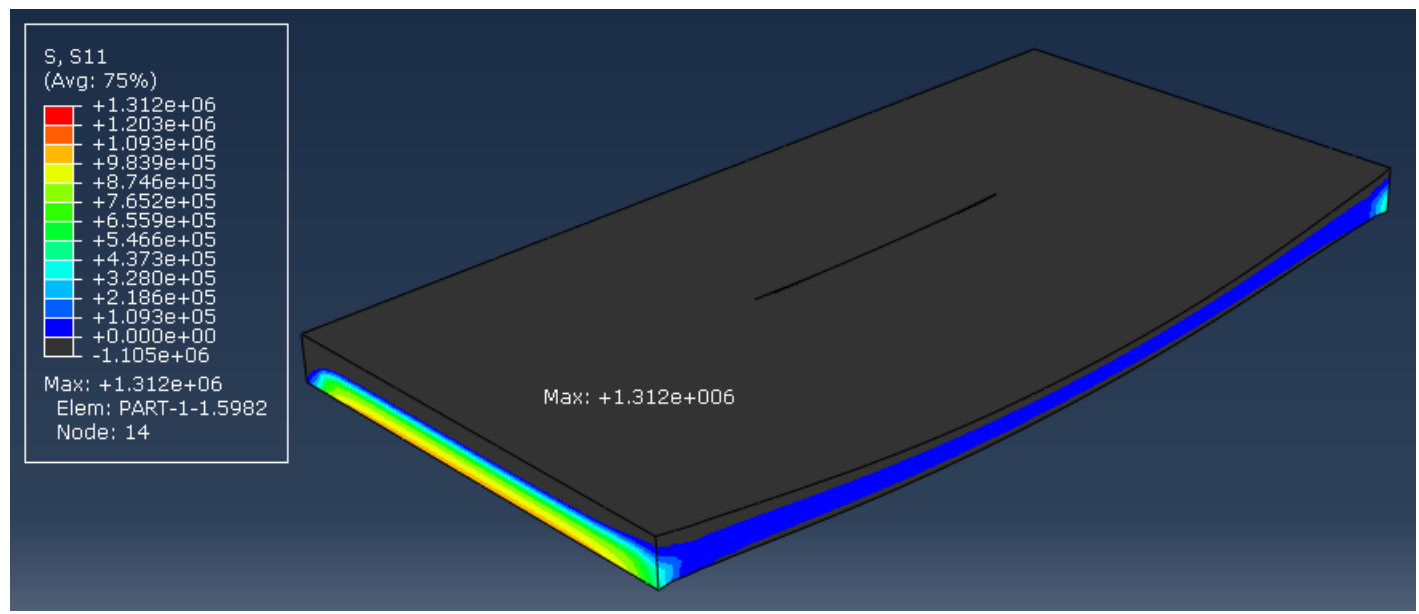

(a)

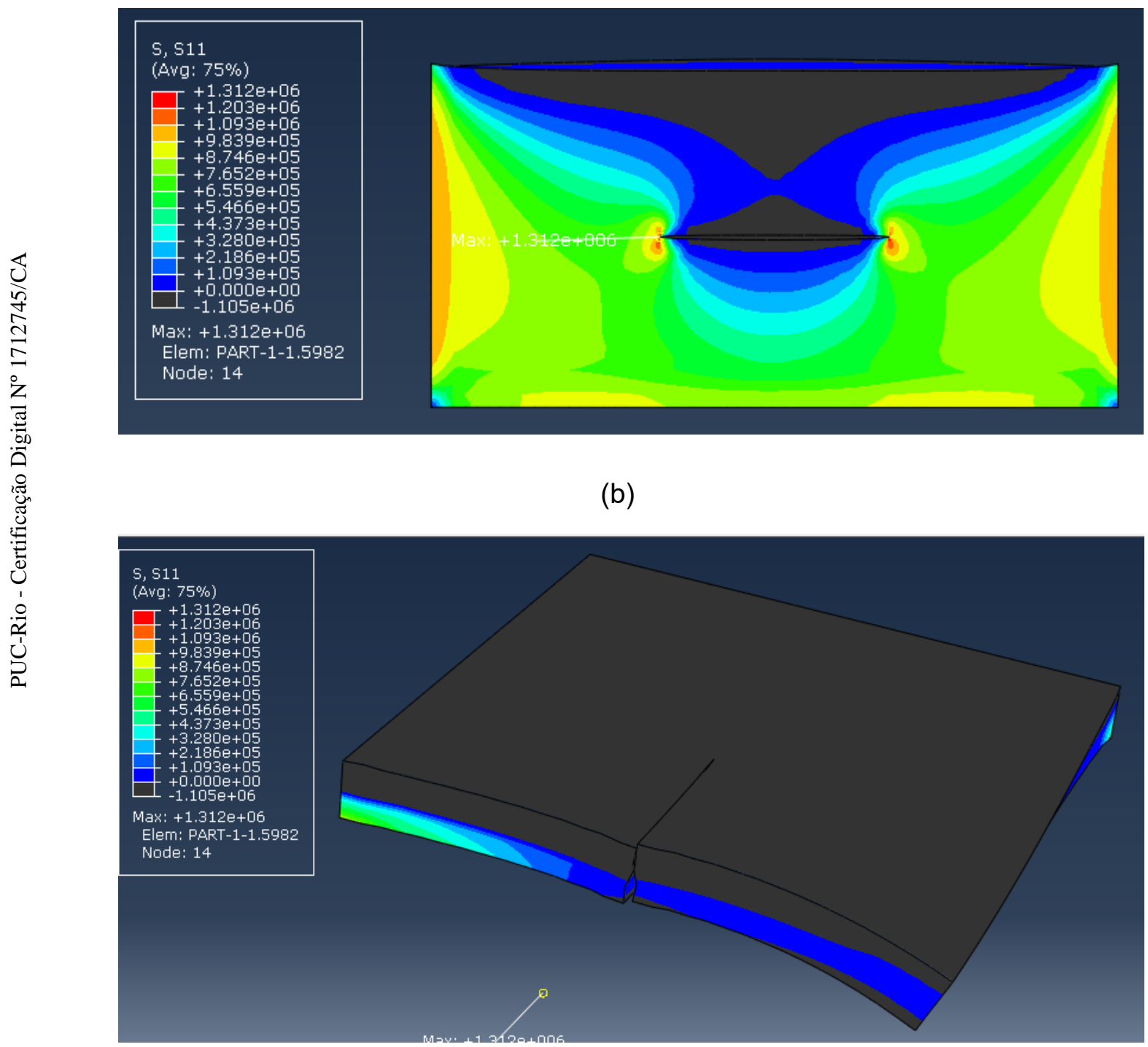

(c)

Figura 6. 14: Exemplo de distribuição de tensões de tração em placa fraturada submetida à variação não uniforme de temperatura ( $\mathrm{t}=9$ dias): (a)Perspectiva isométrica (b) Vista inferior (c) Seção transversal central 


\section{3.}

\section{Placa submetida à gravidade e a variações não uniformes de temperatura}

Este cenário é o que mais se assemelha ao que ocorre em campo, pois associa os efeitos da gravidade com as variações não uniformes de temperatura. De fato, as rochas expostas ao tempo geralmente experimentam variações de temperatura não uniformes, já que a radiação não incide igualmente sobre elas e muitas vezes não é suficiente para aquecê-las como um todo. Além disso, como apresentado anteriormente, a gravidade isoladamente é responsável por gerar tensões de tração e fatores de intensidade de tensão importantes, principalmente em altas inclinações, potencializando os efeitos das variações de temperatura.

\subsection{1.}

\section{Placa rochosa intacta}

Como é possível observar da Figura 6. 15 até a Figura 6. 25, a distribuição das tensões pouco muda quando se insere a ação da gravidade. A diferença reside na maior solicitação de tração no engaste posterior, no aumento das tensões de tração (média de 15\%) e na redução das tensões de compressão. As tabelas a seguir (Tabela 6. 14 à Tabela 6. 18) apresentam as tensões de tração e compressão máximas obtidas. Salienta-se que apesar do aumento das tensões de tração, os valores obtidos ainda não fazem frente à resistência à tração adotada.

\subsubsection{1.}

\section{Caso I}

Tabela 6. 14: Tensões de tração e compressão máximas desenvolvidas na placa intacta em decorrência da ação da gravidade combinada à variação não uniforme de temperatura: caso I

\begin{tabular}{|c|c|c|c|c|c|}
\hline $\begin{array}{c}\text { Tempo } \\
(\mathbf{d i a s})\end{array}$ & $\begin{array}{c}\mathbf{T}_{\text {face superior }} \\
\left({ }^{\circ} \mathbf{C}\right)\end{array}$ & $\begin{array}{c}\mathbf{T}_{\text {face inferior }} \\
\left({ }^{\circ} \mathbf{C}\right)\end{array}$ & $\Delta \mathbf{T}_{\text {faces }}\left({ }^{\circ} \mathbf{C}\right)$ & $\begin{array}{c}\boldsymbol{\sigma}_{\mathbf{t} \text { máx }} \\
(\mathbf{M P a})\end{array}$ & $\begin{array}{c}\boldsymbol{\sigma}_{\mathbf{c} \text { máx }} \\
(\mathbf{M P a})\end{array}$ \\
\hline 0,5 & 38 & 28 & 10 & 1,11 & 5,65 \\
\hline 1,5 & 41 & 30 & 11 & 1,16 & 6,93 \\
\hline 2,5 & 38 & 29 & 9 & 1,00 & 6,45 \\
\hline 10,5 & 30 & 24 & 6 & 0,82 & 3,07 \\
\hline 11,5 & 36 & 26 & 10 & 1,10 & 4,90 \\
\hline
\end{tabular}




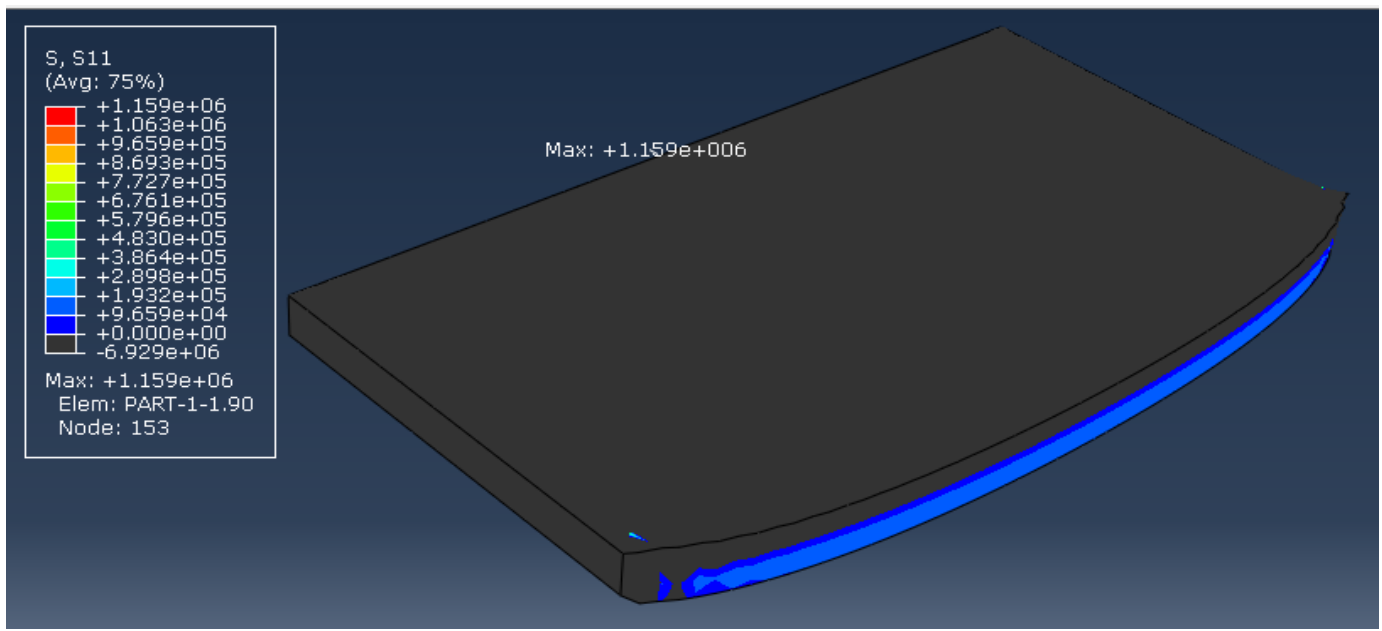

(a)

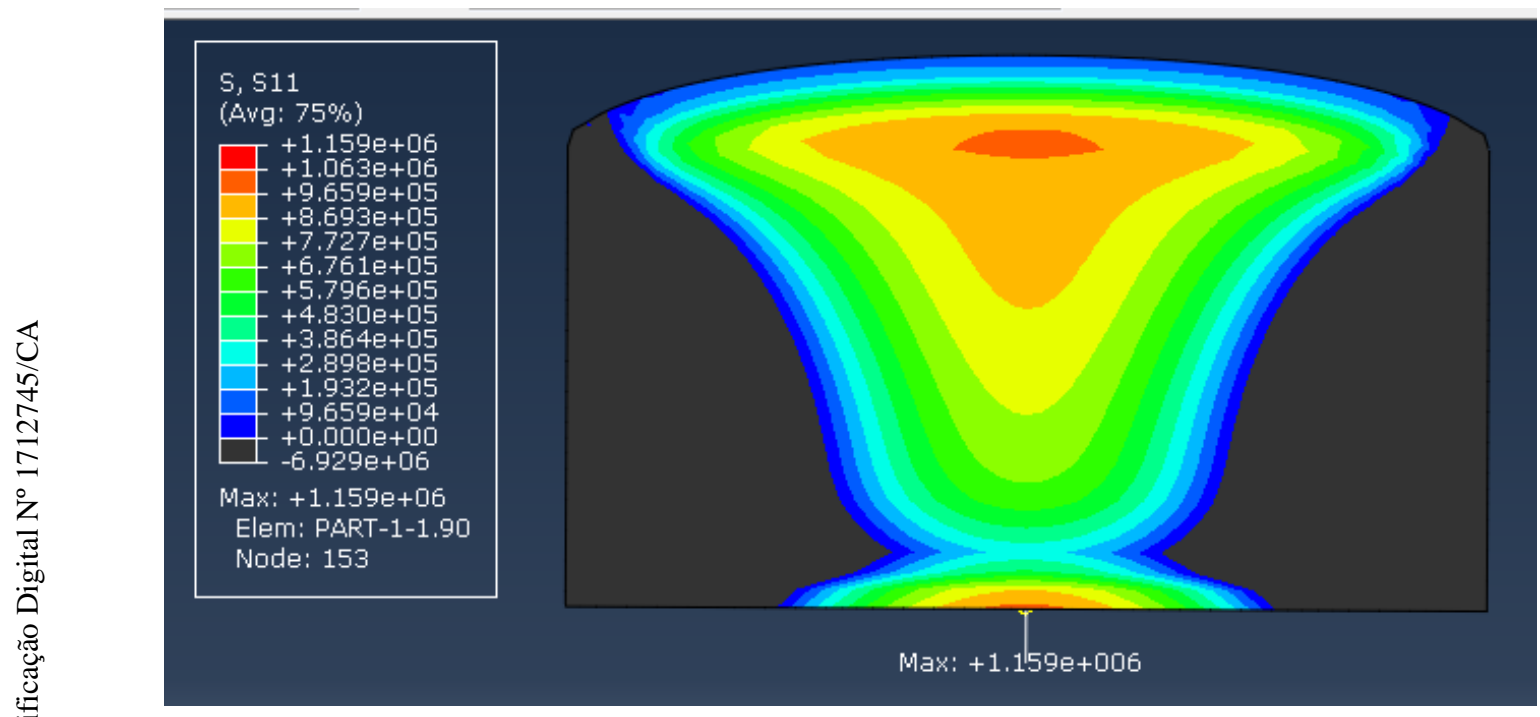

(b)

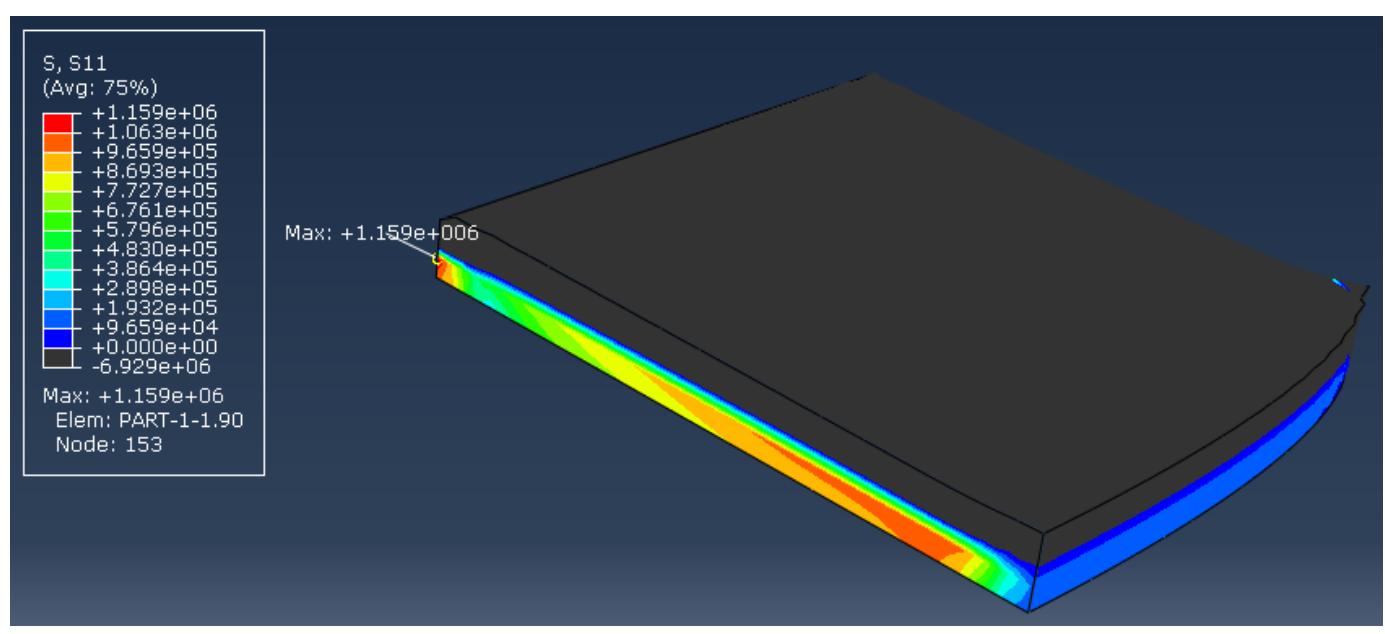

(c)

Figura 6. 15: Exemplo de distribuição de tensões de tração em placa submetida à gravidade e à variação não uniforme de temperatura ( $\mathrm{t}=1,5$ dias): (a)Perspectiva isométrica (b) Vista inferior (c) Seção transversal central 


\subsubsection{2.}

Caso II

Tabela 6. 15: Tensões de tração e compressão máximas desenvolvidas na placa intacta em decorrência da ação da gravidade combinada à variação não uniforme de temperatura: caso II

\begin{tabular}{|c|c|c|c|c|c|c|}
\hline $\begin{array}{c}\text { Tempo } \\
\text { (dias) }\end{array}$ & $\begin{array}{c}\mathbf{T}_{\text {face }} \\
\text { superior } \\
\left({ }^{\circ} \mathbf{C}\right)\end{array}$ & $\begin{array}{c}\mathbf{T}_{\text {face inferior }} \\
\left({ }^{\circ} \mathbf{C}\right)\end{array}$ & $\begin{array}{c}\Delta \mathbf{T}_{\text {face }} \\
\text { superior } \\
\left({ }^{\circ} \mathbf{C}\right)\end{array}$ & $\begin{array}{c}\Delta \mathbf{T}_{\text {face }} \\
\text { inferior } \\
\left({ }^{\circ} \mathbf{C}\right)\end{array}$ & $\begin{array}{c}\boldsymbol{\sigma}_{\mathbf{t} \text { máx }} \\
(\mathbf{M P a})\end{array}$ & $\begin{array}{c}\boldsymbol{\sigma}_{\mathbf{c} \text { máx }} \\
(\mathbf{M P a})\end{array}$ \\
\hline 1 & 17 & 20 & -11 & -8 & 0,88 & 0,88 \\
\hline 2 & 22 & 23 & -19 & -7 & 0,53 & 2,59 \\
\hline
\end{tabular}




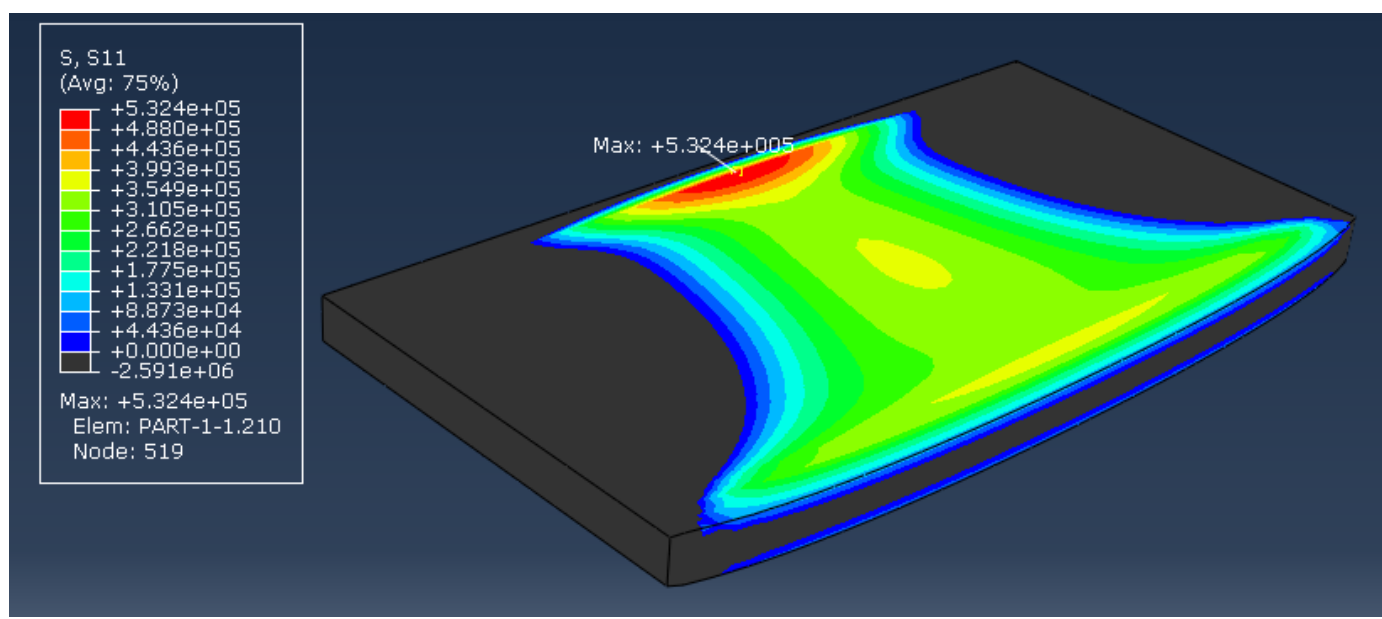

(a)

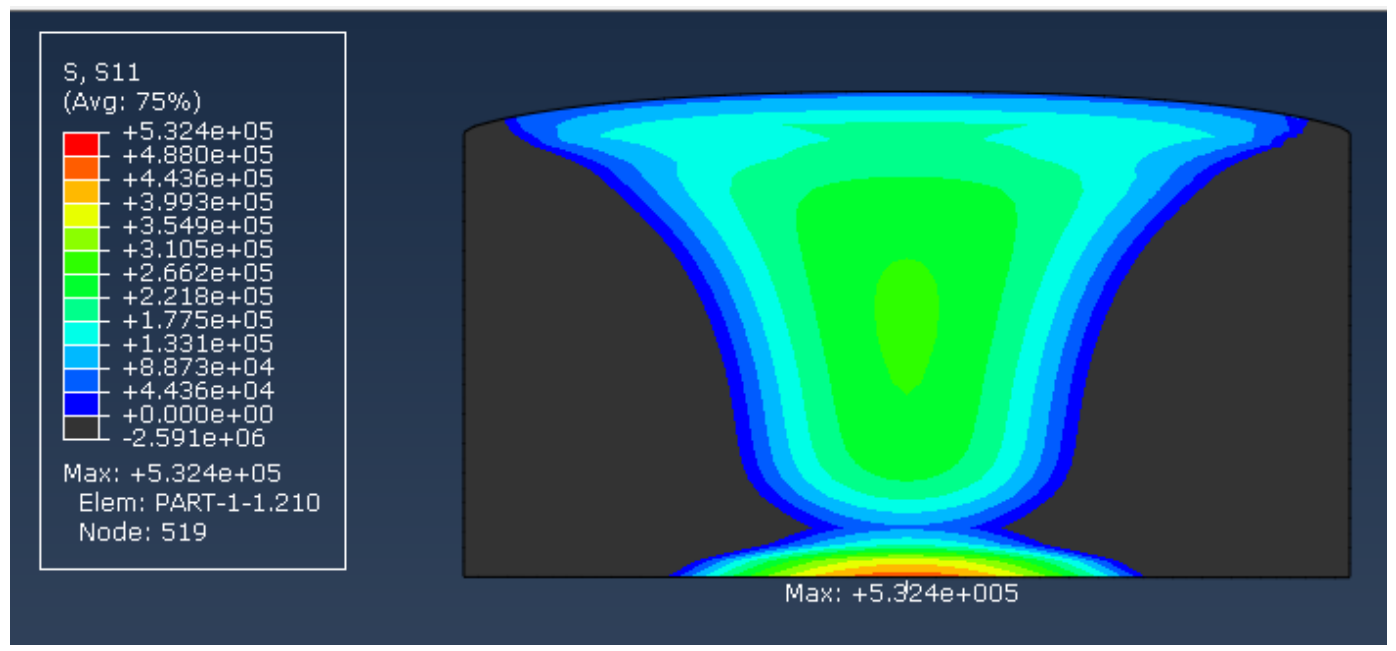

(b)

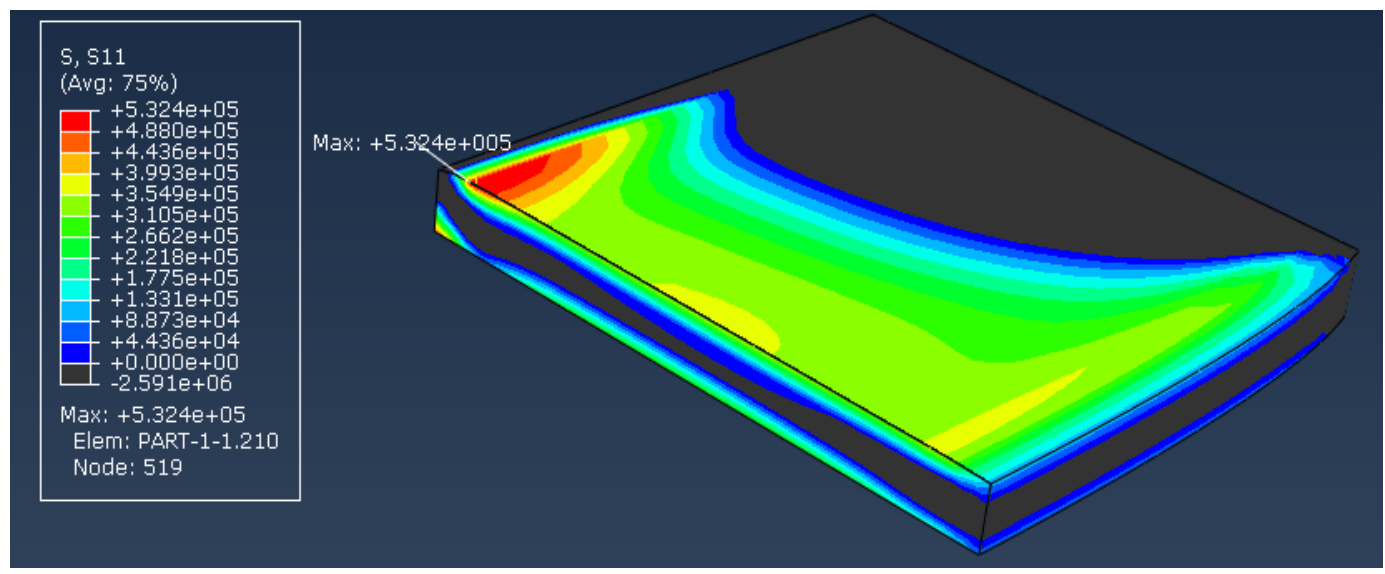

(c)

Figura 6. 16: Exemplo de distribuição de tensões de tração em placa submetida à gravidade e à variação não uniforme de temperatura ( $\mathrm{t}=2$ dias): (a)Perspectiva isométrica (b) Vista inferior (c) Seção transversal central 


\subsubsection{3.}

Caso III

Tabela 6. 16: Tensões de tração e compressão máximas desenvolvidas na placa intacta em decorrência da ação da gravidade combinada à variação não uniforme de temperatura: caso III

\begin{tabular}{|c|c|c|c|c|c|}
\hline $\begin{array}{c}\text { Tempo } \\
(\mathbf{d i a s})\end{array}$ & $\mathbf{T}_{\text {faces }}\left({ }^{\circ} \mathbf{C}\right)$ & $\begin{array}{c}\mathbf{T}_{\text {núcleo }} \\
\left.\text { máx }^{\circ} \mathbf{C}\right)\end{array}$ & $\begin{array}{c}\Delta \mathbf{T} \text { núcleo } \\
\left({ }^{\circ} \mathbf{C}\right)\end{array}$ & $\begin{array}{c}\boldsymbol{\sigma}_{\text {t máx }} \\
(\mathbf{M P a})\end{array}$ & $\begin{array}{c}\boldsymbol{\sigma}_{\mathbf{c} \text { máx }} \\
\mathbf{( M P a})\end{array}$ \\
\hline 3 & 17 & 24,5 & 7,5 & 0,85 & 1,83 \\
\hline 4 & 17 & 20,4 & 3,4 & 0,72 & 0,19 \\
\hline 4,5 & 19 & 19,8 & 0,8 & 0,49 & 0,002 \\
\hline 5 & 17 & 18,7 & 1,7 & 1,08 & 0,09 \\
\hline 6,5 & 16 & 18,1 & 2,1 & 1,44 & 0,13 \\
\hline 8,5 & 17 & 17,5 & 0,5 & 1,37 & 0,09 \\
\hline 9,5 & 13,5 & 16,8 & 3,3 & 2,46 & 0,23 \\
\hline 11 & 15 & 19,8 & 4,8 & 1,40 & 0,27 \\
\hline
\end{tabular}




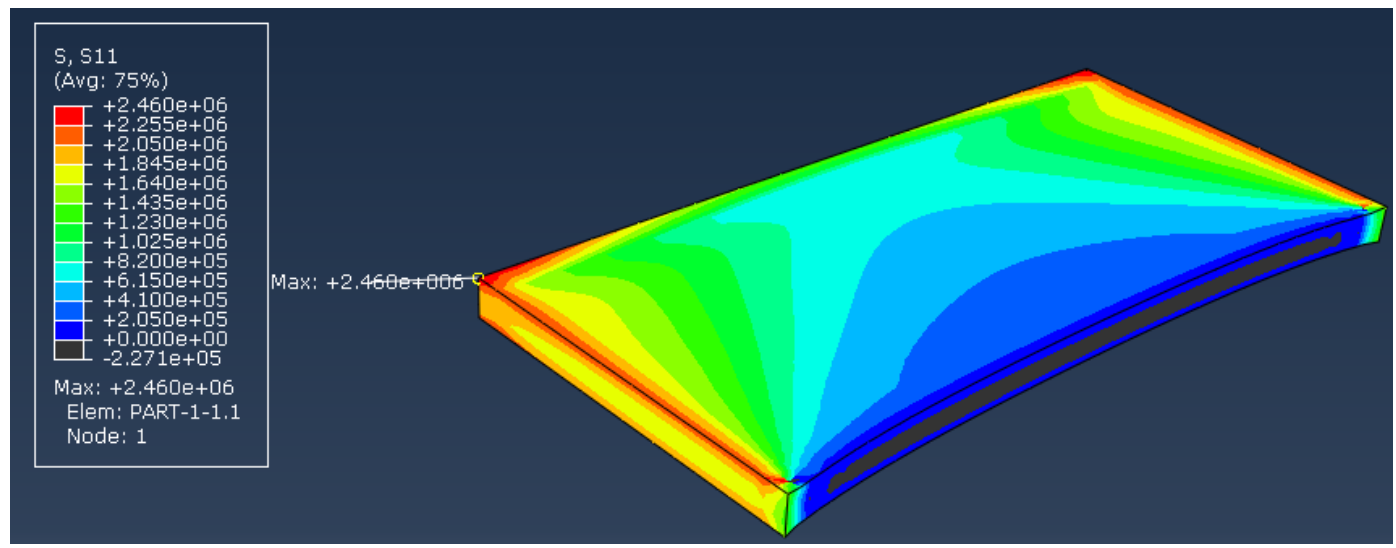

(a)

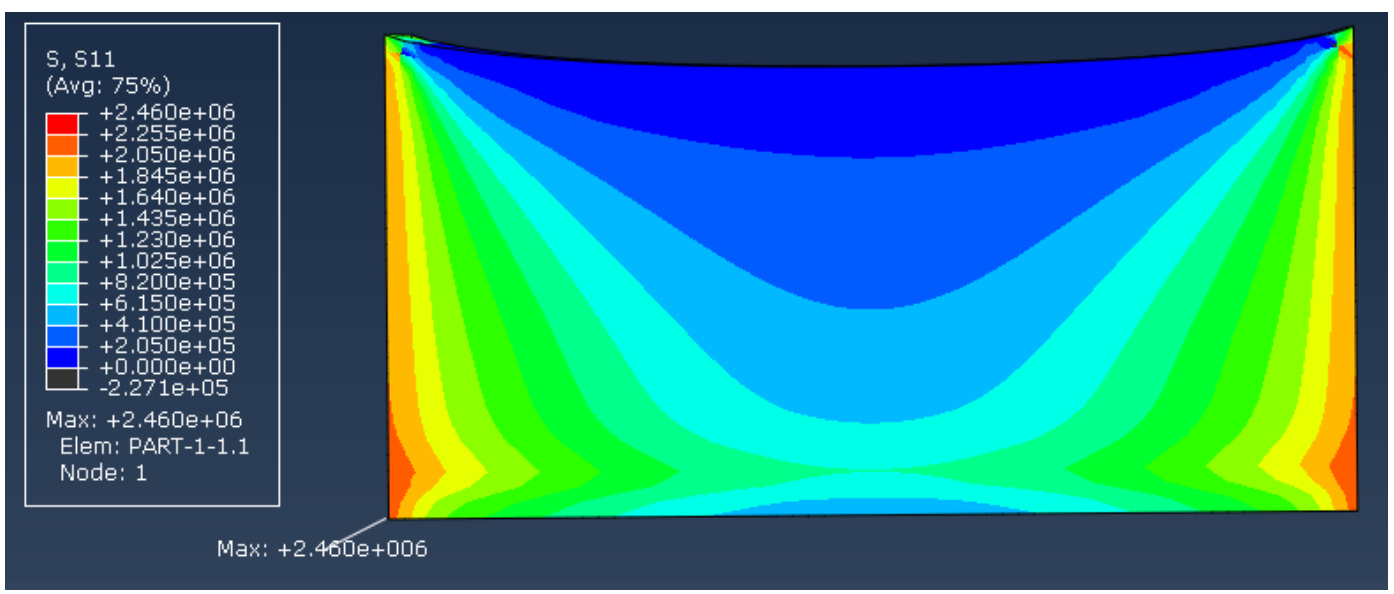

(b)

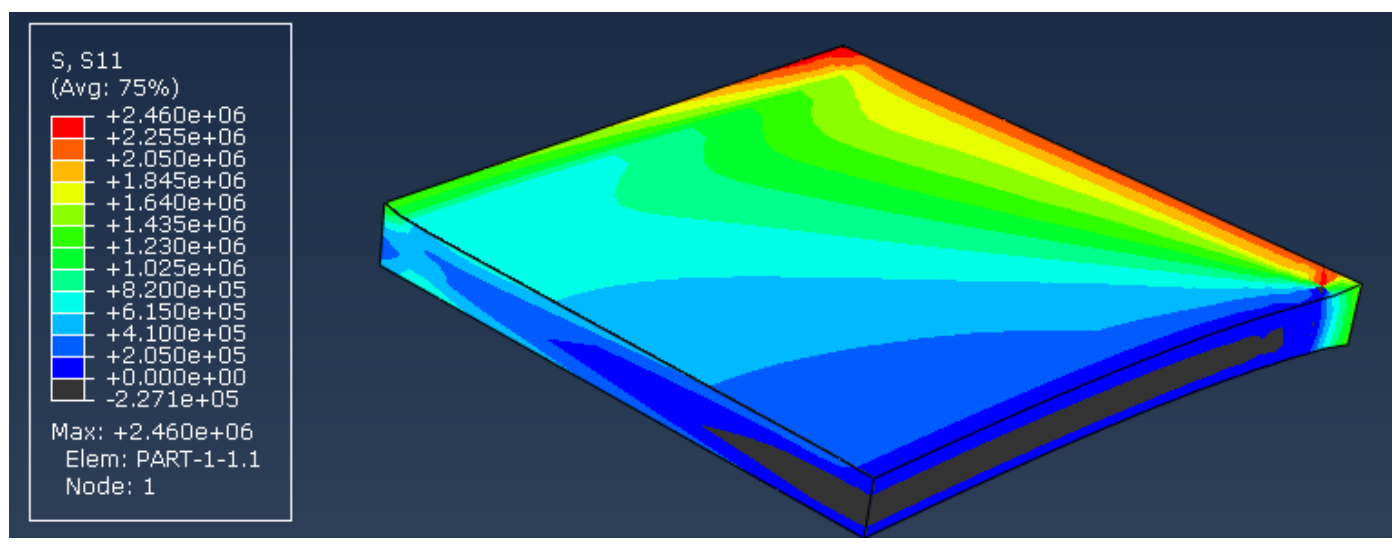

(c)

Figura 6. 17: Exemplo de distribuição de tensões de tração em placa submetida à gravidade e à variação não uniforme de temperatura ( $\mathrm{t}=9,5$ dias): (a)Perspectiva isométrica (b) Vista inferior (c) Seção transversal central 


\subsubsection{4.}

Caso IV

Tabela 6. 17: Tensões de tração e compressão máximas desenvolvidas na placa intacta em decorrência da ação da gravidade combinada à variação não uniforme de temperatura: caso IV

\begin{tabular}{|c|c|c|c|c|c|}
\hline $\begin{array}{c}\text { Tempo } \\
\text { (dias) }\end{array}$ & $\mathbf{T}_{\text {faces }}\left({ }^{\circ} \mathbf{C}\right)$ & $\begin{array}{c}\mathbf{T}_{\text {núcleo }} \\
\left.\text { mín }^{\circ} \mathbf{C}\right)\end{array}$ & $\begin{array}{c}\Delta \mathbf{T}_{\text {núcleo }} \\
\left({ }^{\circ} \mathbf{C}\right)\end{array}$ & $\begin{array}{c}\boldsymbol{\sigma}_{\mathbf{t} \text { máx }} \\
(\mathbf{M P a})\end{array}$ & $\begin{array}{c}\boldsymbol{\sigma}_{\mathbf{c} \text { máx }} \\
\mathbf{( M P a})\end{array}$ \\
\hline 5,5 & 19 & 18,6 & 0,4 & 0,64 & 0,04 \\
\hline 8 & 18 & 17,8 & 0,2 & 1,08 & 0,07 \\
\hline
\end{tabular}

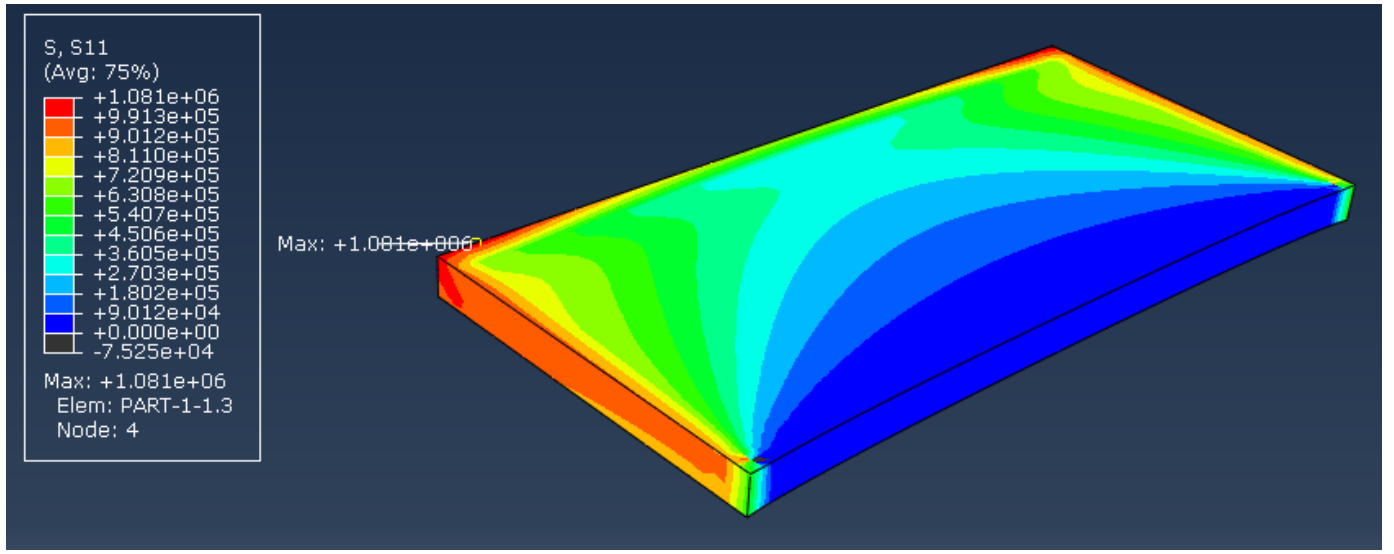

(a)

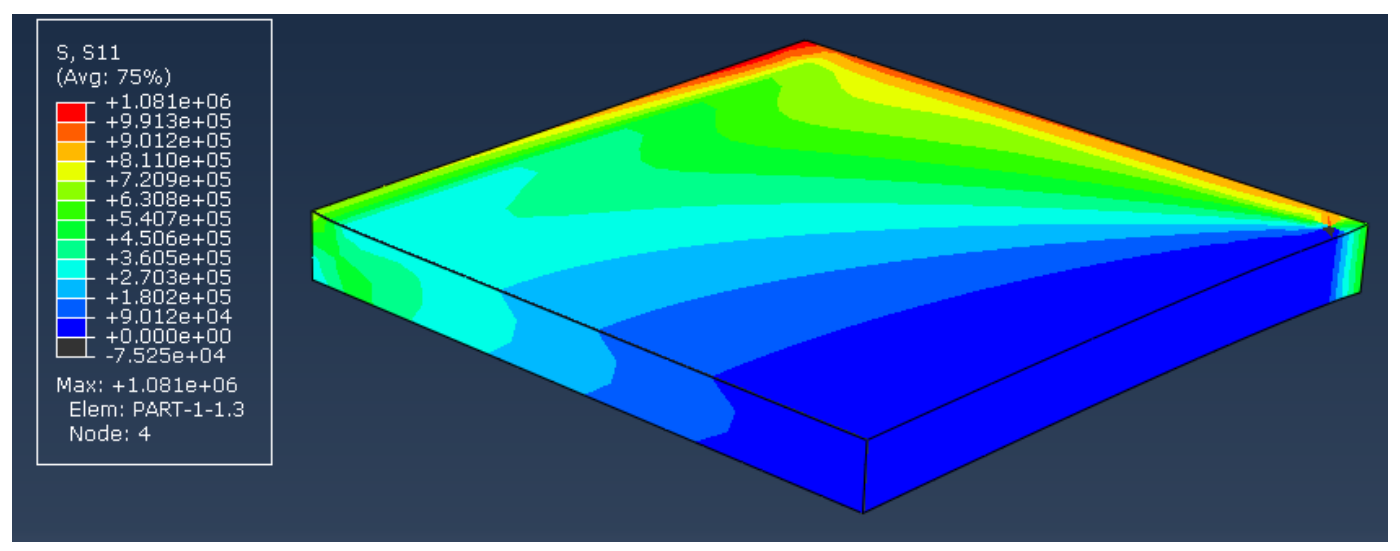

(b)

Figura 6. 18: Exemplo de distribuição de tensões de tração em placa submetida à gravidade e à variação não uniforme de temperatura ( $\mathrm{t}=\mathbf{8}$ dias): (a)Perspectiva isométrica (b) Seção transversal central 
6.3.1.5.

\section{Caso V}

Tabela 6. 18: Tensões de tração e compressão máximas desenvolvidas na placa intacta em decorrência da ação da gravidade combinada à variação não uniforme de temperatura: caso $\mathrm{V}$

\begin{tabular}{|c|c|c|c|c|c|}
\hline $\begin{array}{c}\text { Tempo } \\
(\mathbf{d i a s})\end{array}$ & $\begin{array}{c}\mathbf{T}_{\text {face superior }} \\
\left({ }^{\circ} \mathbf{C}\right)\end{array}$ & $\begin{array}{c}\mathbf{T}_{\text {face inferior }} \\
\left({ }^{\circ} \mathbf{C}\right)\end{array}$ & $\begin{array}{c}\Delta \mathbf{T} \\
\text { face }^{\circ}\left({ }^{\circ} \mathbf{C}\right)\end{array}$ & $\begin{array}{c}\boldsymbol{\sigma}_{\mathbf{t} \text { máx }} \\
(\mathbf{M P a})\end{array}$ & $\begin{array}{c}\boldsymbol{\sigma}_{\mathbf{c} \text { máx }} \\
(\mathbf{M P a})\end{array}$ \\
\hline 3,5 & 22 & 18 & 4 & 0,96 & 1,09 \\
\hline 6 & 22 & 18 & 4 & 0,83 & 0,50 \\
\hline 7 & 18 & 17 & 1 & 1,26 & 0,08 \\
\hline 7,5 & 17 & 18 & 1 & 1,32 & 0,09 \\
\hline 9 & 24 & 17 & 7 & 1,21 & 0,09 \\
\hline 10 & 25 & 19 & 6 & 0,09 & 1,04 \\
\hline
\end{tabular}




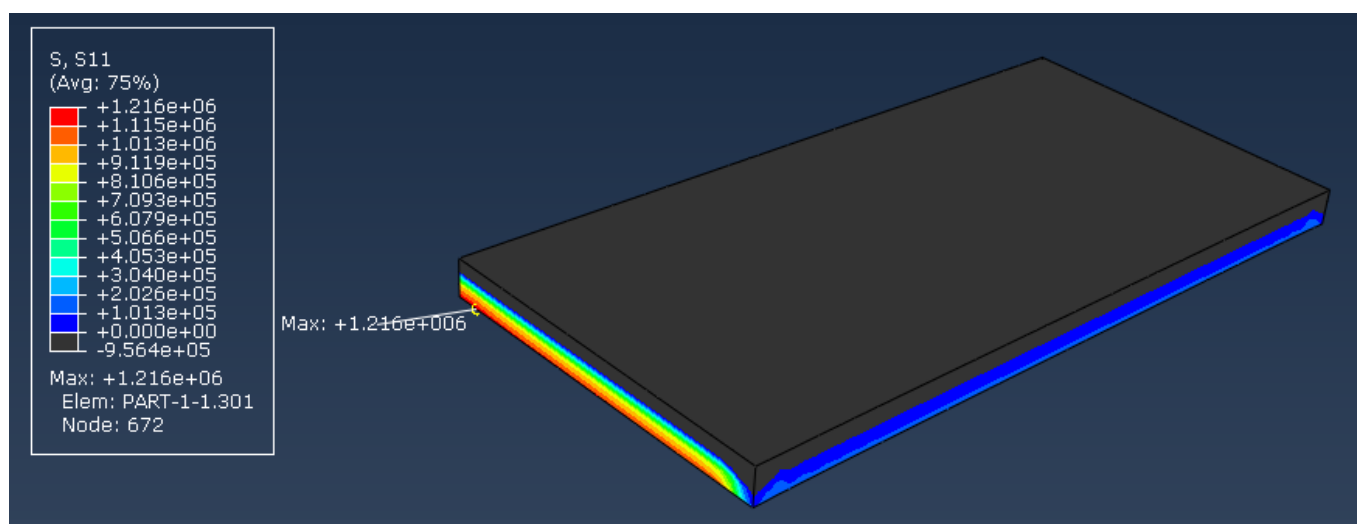

(a)

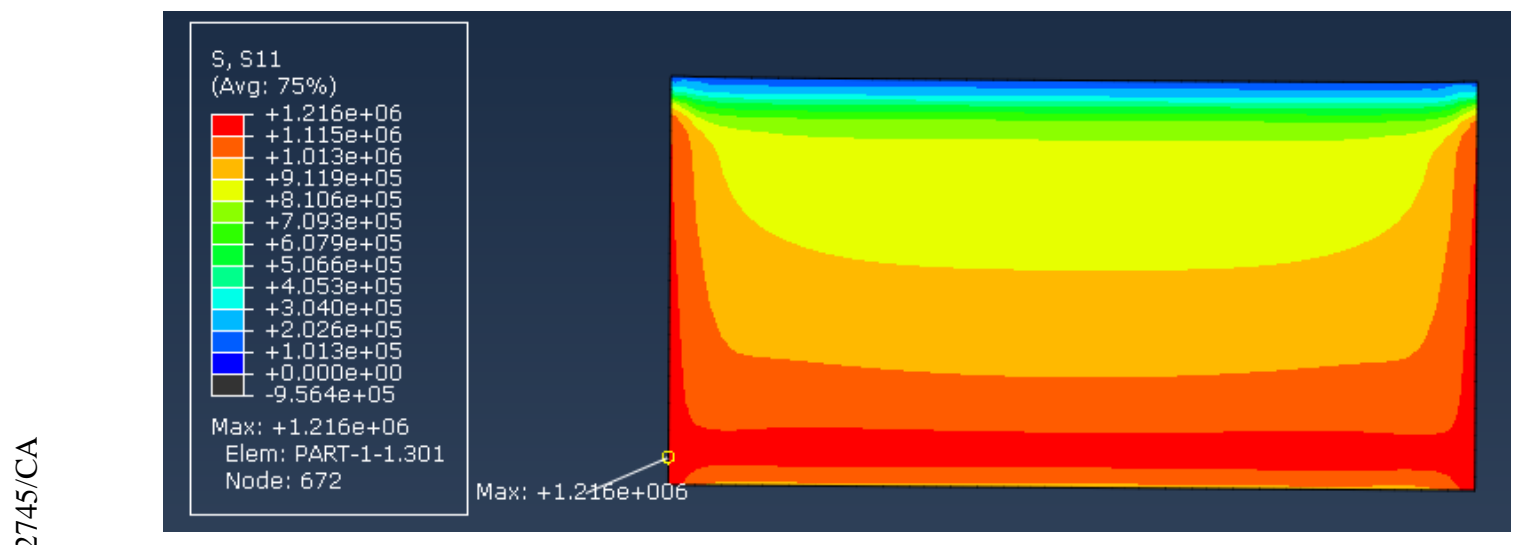

(b)

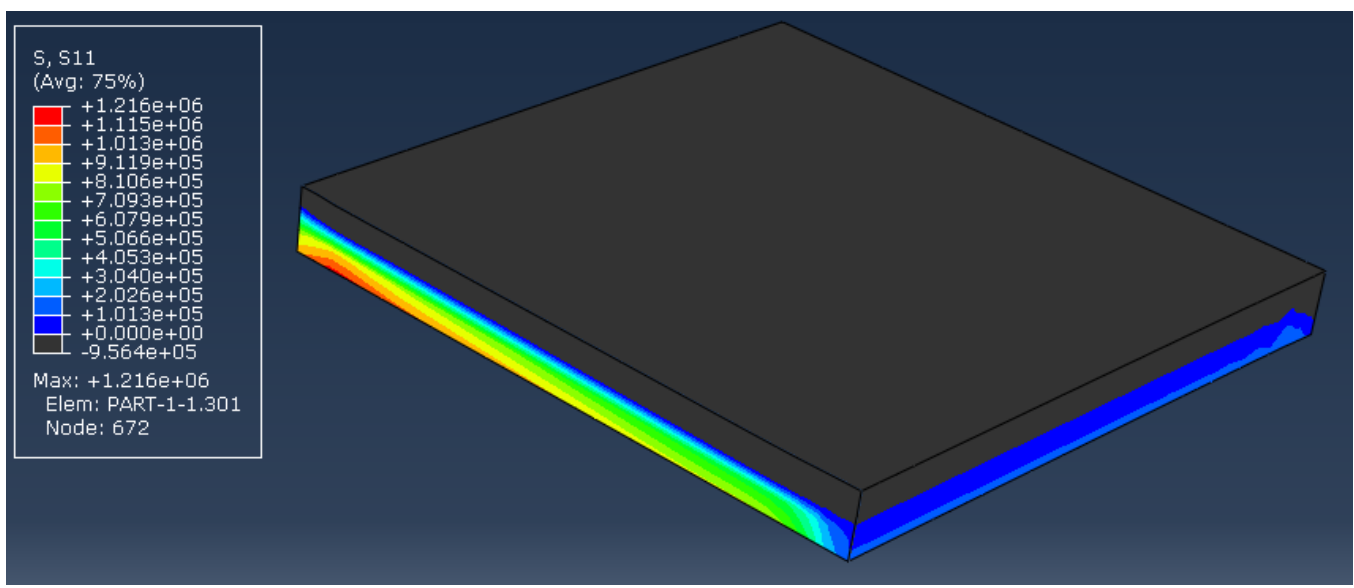

(c)

Figura 6. 19: Exemplo de distribuição de tensões de tração em placa submetida à gravidade e à variação não uniforme de temperatura ( $t=9$ dias): (a)Perspectiva isométrica (b) Vista inferior (c) Seção transversal central 


\subsection{2.}

\section{Placa rochosa fraturada}

No caso da placa rochosa fraturada a distribuição das tensões também é muito similar àquela obtida apenas com as variações não uniformes de temperatura. As diferenças residem no maior predomínio da tração, com valores máximos na área no entorno das pontas da fratura, cujas aberturas são maiores e as regiões de concentração de tensão mais bem delimitadas do que as obtidas anteriormente.

Os fatores de intensidade de tensão para o modo I (Figura 6. 20) apresentaram aumento significativo, estando próximo ou acima de $1 \mathrm{MPa} \mathrm{m}^{1 / 2}$ na maioria dos casos, chegando a 2,20 $\mathrm{MPa} \mathrm{m}^{1 / 2}$ na face superior em $\mathrm{t}=9,5$. Isto significa que há propagação da fratura em vários momentos da simulação, principalmente quando as temperaturas são baixas ou quando o gradiente térmico entre as faces é significativo.

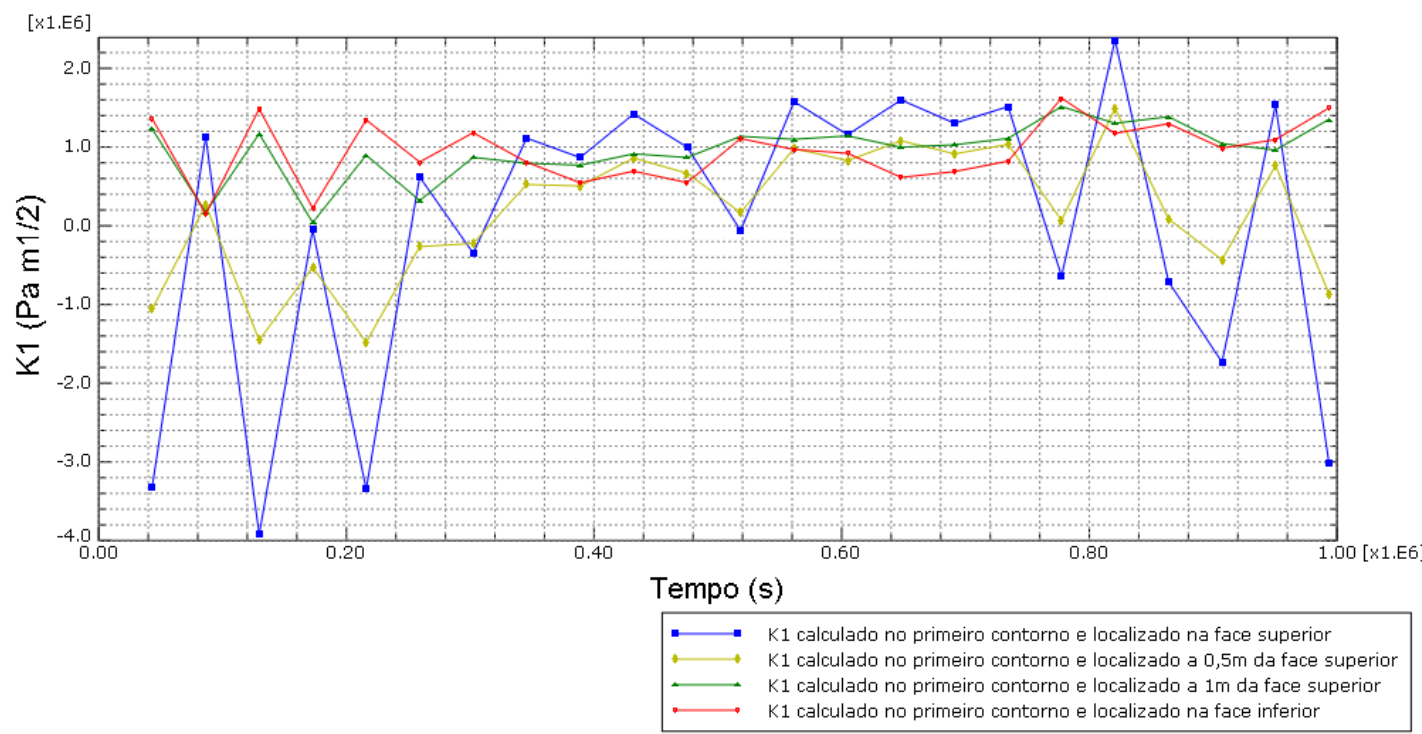

Figura 6. 20: K1 (Pa m1/2) ao longo do tempo para placa submetida à ação da gravidade e a variações não uniformes de temperatura 


\subsubsection{1.}

Caso I

Tabela 6. 19: Valores de K1 (MPa m1/2) desenvolvidos em decorrência da ação da gravidade combinada à variação não uniforme de temperatura: caso I

\begin{tabular}{|c|c|c|c|c|}
\hline \multirow{2}{*}{$\begin{array}{c}\text { Tempo } \\
\text { (dias) }\end{array}$} & \multicolumn{4}{|c|}{$\mathbf{K}_{\mathbf{1}}\left(\mathbf{M P a} \mathbf{~ m}^{\mathbf{1 / 2}}\right)$} \\
\cline { 2 - 5 } & $\begin{array}{c}\text { Na face } \\
\text { superior }\end{array}$ & $\begin{array}{c}\mathbf{A} \mathbf{0 , 5} \mathbf{m} \text { da } \\
\text { face superior }\end{array}$ & $\begin{array}{c}\mathbf{A} \mathbf{1 m} \text { da face } \\
\text { superior }\end{array}$ & Na face inferior \\
\hline 0,5 & $-3,30$ & $-1,00$ & 1,20 & 1,40 \\
\hline 1,5 & $-3,90$ & $-1,40$ & 1,20 & 1,50 \\
\hline 2,5 & $-3,40$ & $-1,20$ & 0,90 & 1,35 \\
\hline 10,5 & $-1,80$ & $-0,40$ & 1,00 & 1,00 \\
\hline 11,5 & $-3,00$ & $-0,90$ & 1,35 & 1,50 \\
\hline
\end{tabular}




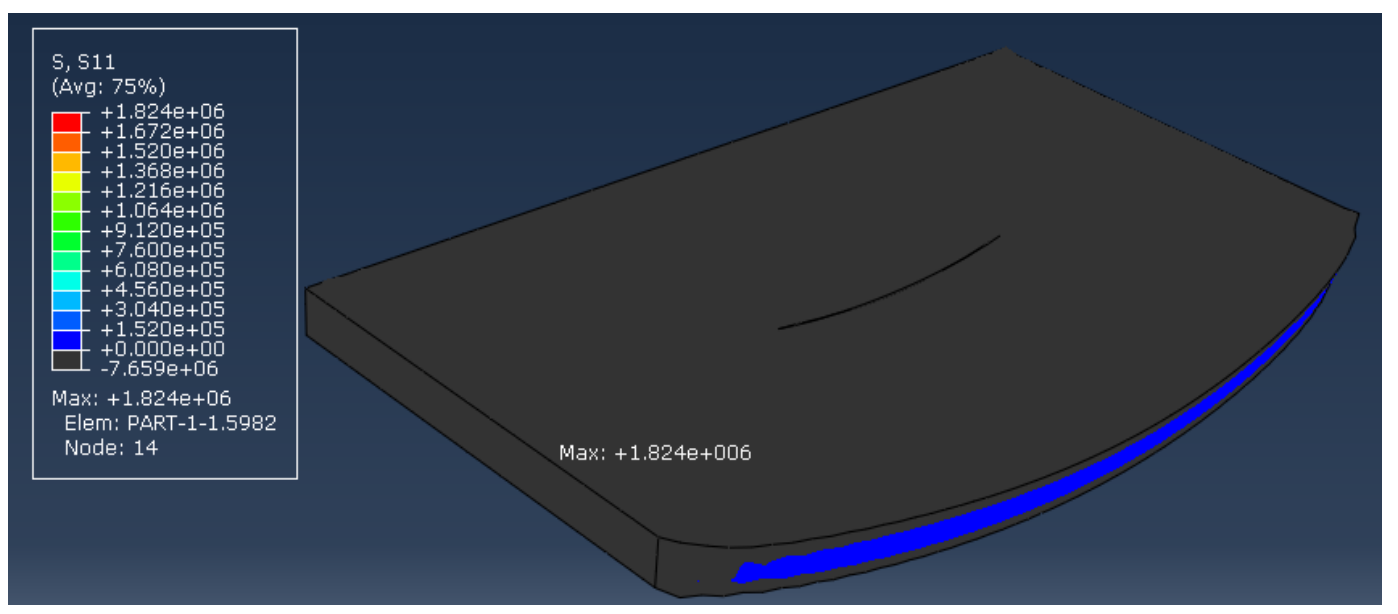

(a)

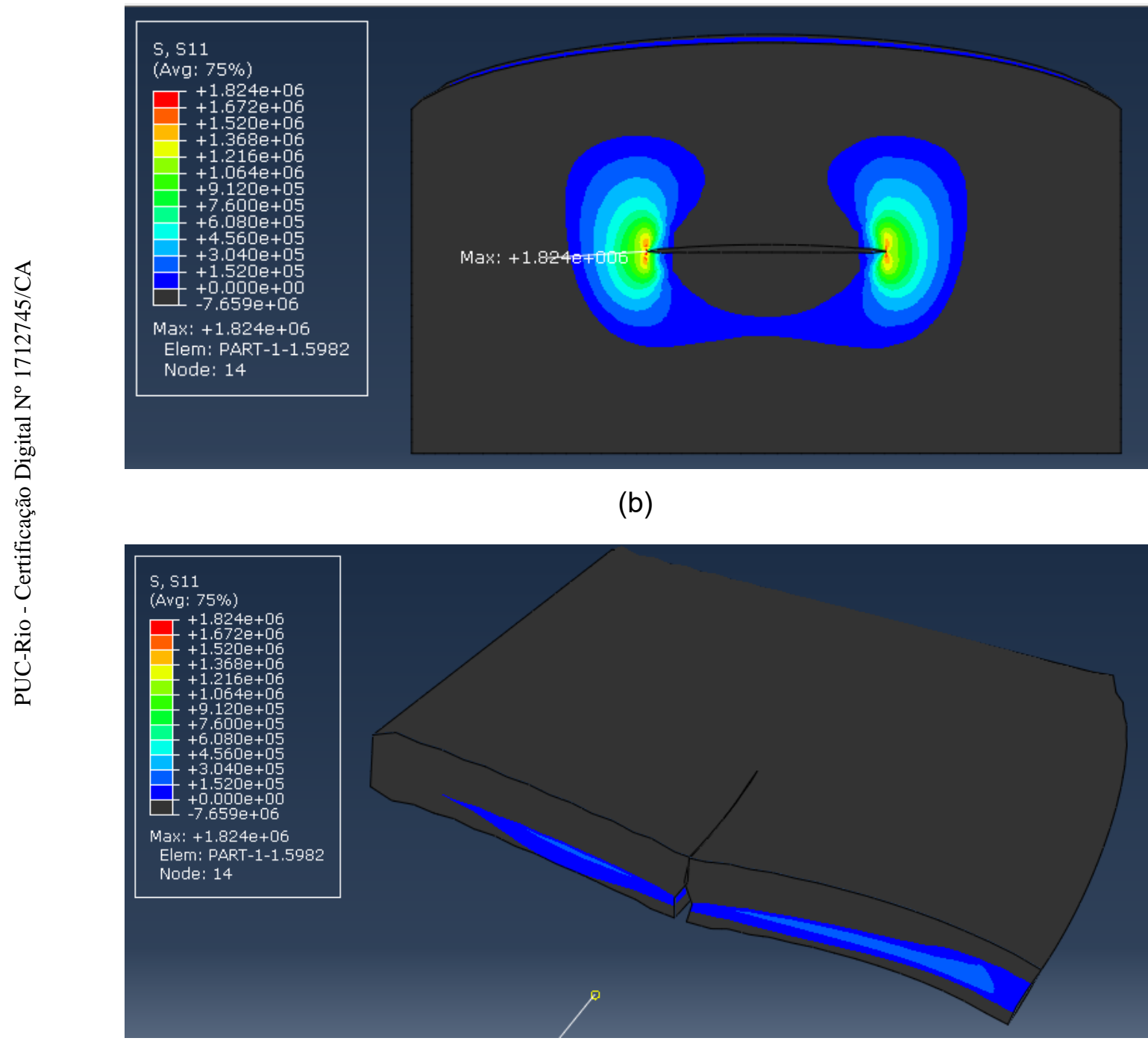

(c)

Figura 6. 21: Exemplo de distribuição de tensões de tração em placa fraturada submetida à gravidade e à variação não uniforme de temperatura ( $\mathrm{t}=1,5$ dias): (a)Perspectiva isométrica (b) Vista inferior (c) Seção transversal central 


\subsubsection{2.}

Caso II

Tabela 6. 20: Valores de K1 (MPa m1/2) desenvolvidos em decorrência da ação da gravidade combinada à variação não uniforme de temperatura: caso II

\begin{tabular}{|c|c|c|c|c|}
\hline \multirow{2}{*}{$\begin{array}{c}\text { Tempo } \\
\text { (dias) }\end{array}$} & \multicolumn{4}{|c|}{ K1 $\left(\mathbf{M P a ~ m}^{\mathbf{1 / 2}}\right)$} \\
\cline { 2 - 5 } & $\begin{array}{c}\text { Na face } \\
\text { superior }\end{array}$ & $\begin{array}{c}\text { A 0,5m da } \\
\text { face superior }\end{array}$ & $\begin{array}{c}\text { A 1 m da face } \\
\text { superior }\end{array}$ & Na face inferior \\
\hline 1 & 1,15 & 0,30 & 0,20 & 0,20 \\
\hline 2 & $-0,05$ & $-0,50$ & 0,05 & 0,20 \\
\hline
\end{tabular}




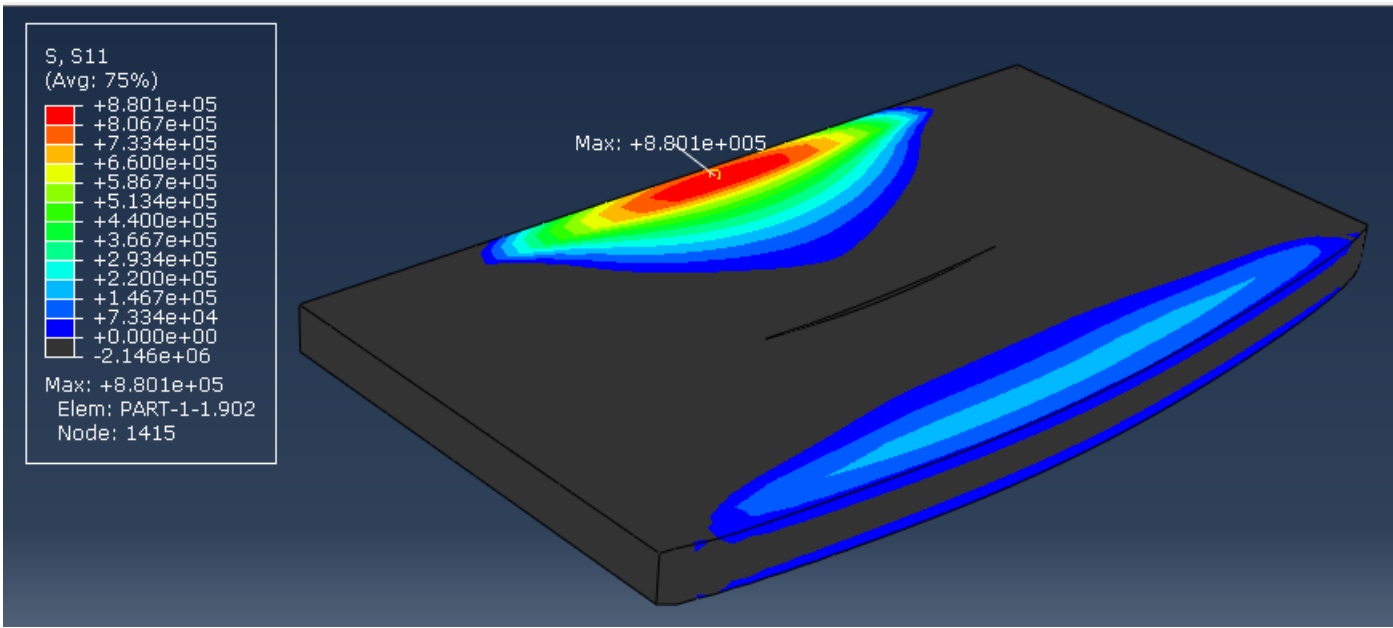

(a)

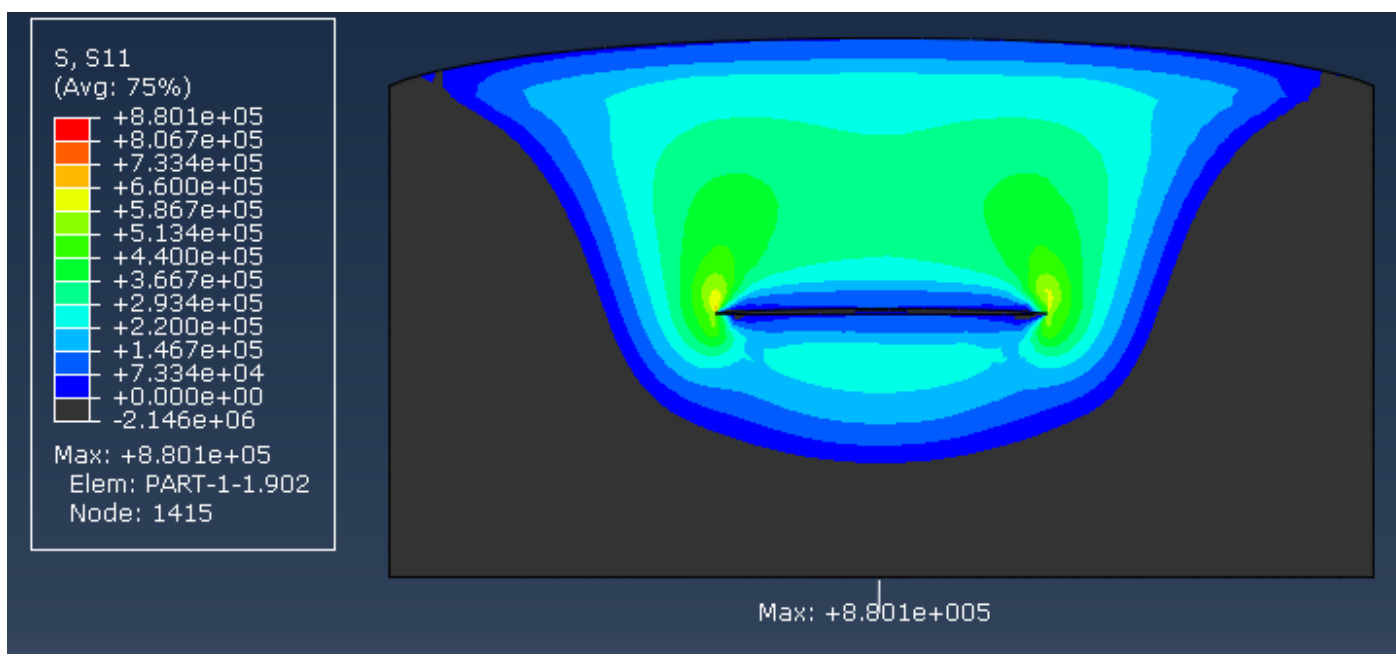

(b)

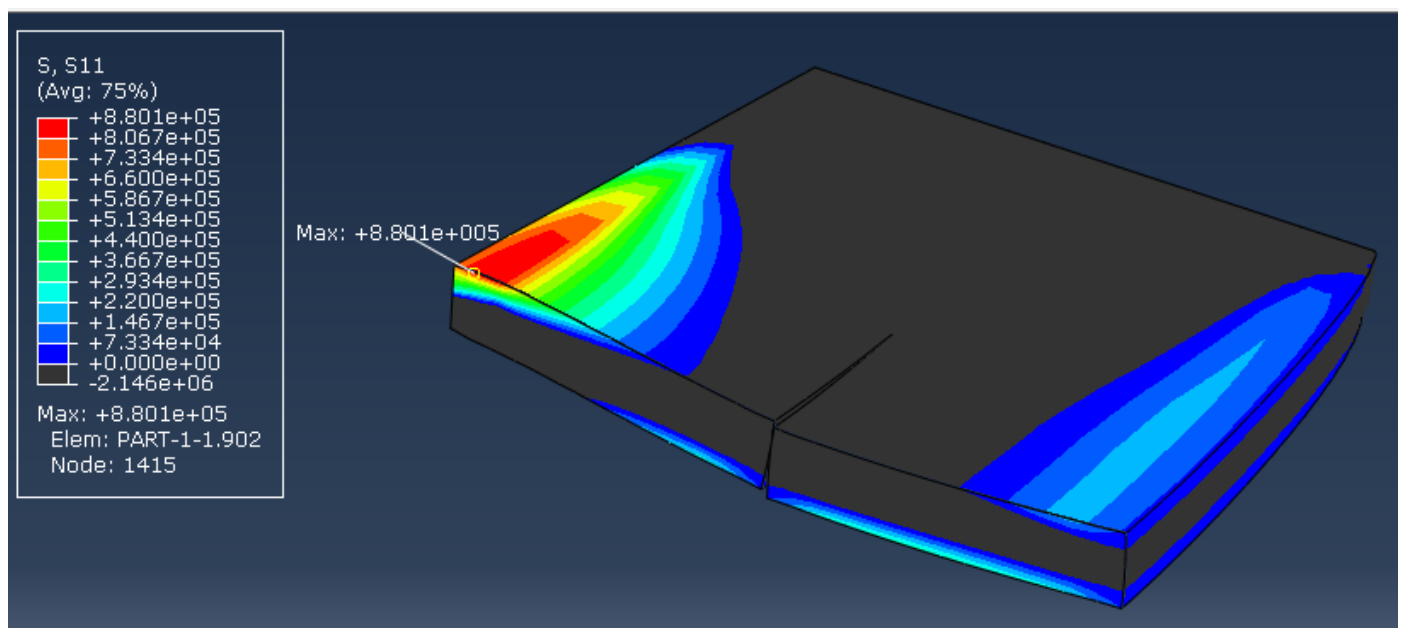

(c)

Figura 6. 22: Exemplo de distribuição de tensões de tração em placa fraturada submetida à gravidade e à variação não uniforme de temperatura ( $\mathrm{t}=2$ dias): (a)Perspectiva isométrica (b) Vista inferior (c) Seção transversal central 


\subsubsection{3.}

Caso III

Tabela 6. 21: Valores de K1 (MPa m1/2) desenvolvidos em decorrência da ação da gravidade combinada à variação não uniforme de temperatura: caso III

\begin{tabular}{|c|c|c|c|c|}
\hline \multirow{2}{*}{$\begin{array}{c}\text { Tempo } \\
\text { (dias) }\end{array}$} & \multicolumn{4}{|c|}{$\mathbf{K}_{\mathbf{1}}\left(\mathbf{M P a} \mathbf{~ m}^{\mathbf{1 / 2}} \mathbf{)}\right.$} \\
\cline { 2 - 5 } & $\begin{array}{c}\text { Na face } \\
\text { superior }\end{array}$ & $\begin{array}{c}\mathbf{A ~ 0 , 5 m} \mathbf{~ d a} \\
\text { face superior }\end{array}$ & $\begin{array}{c}\mathbf{A} \mathbf{~ m} \text { da face } \\
\text { superior }\end{array}$ & Na face inferior \\
\hline 3 & 0,60 & $-0,25$ & 0,30 & 0,80 \\
\hline 4 & 1,10 & 0,55 & 0,80 & 0,80 \\
\hline 4,5 & 0,90 & 0,50 & 0,80 & 0,50 \\
\hline 5 & 1,40 & 0,85 & 0,90 & 0,70 \\
\hline 6,5 & 1,60 & 1,00 & 1,10 & 1,00 \\
\hline 8,5 & 1,50 & 1,00 & 1,10 & 0,80 \\
\hline 9,5 & 2,20 & 1,50 & 1,30 & 1,20 \\
\hline 11 & 1,60 & 0,80 & 1,00 & 1,10 \\
\hline
\end{tabular}




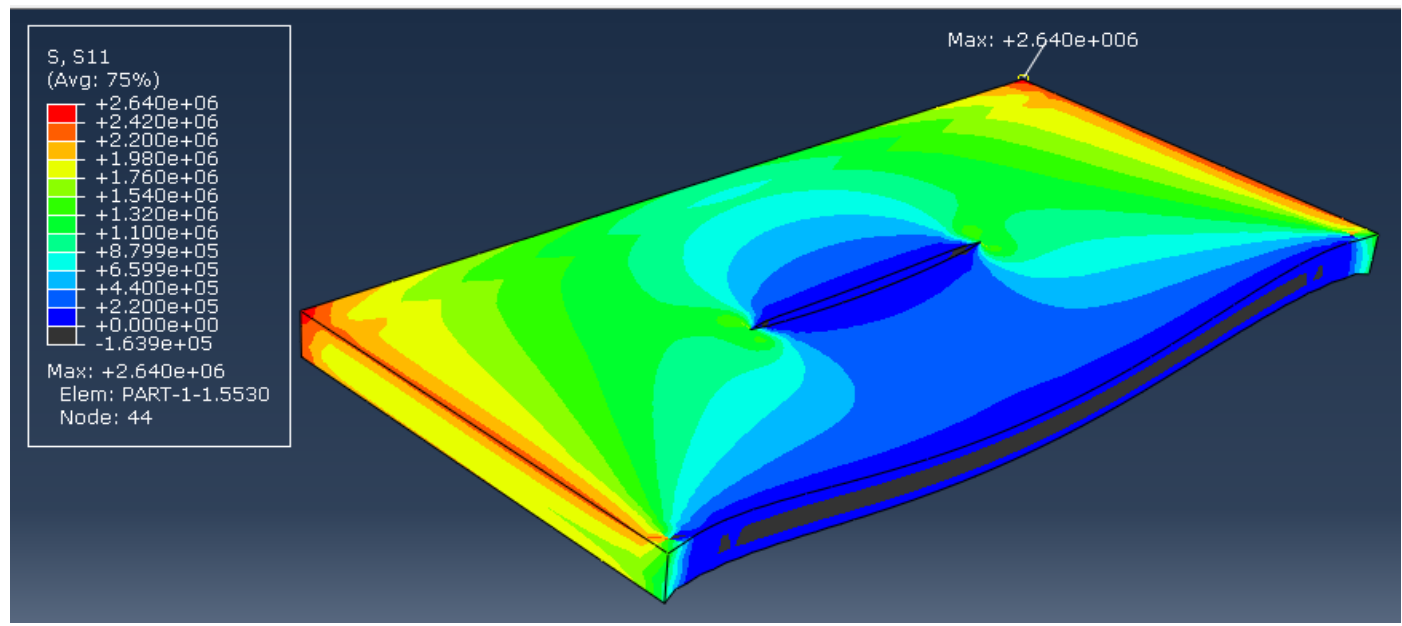

(a)

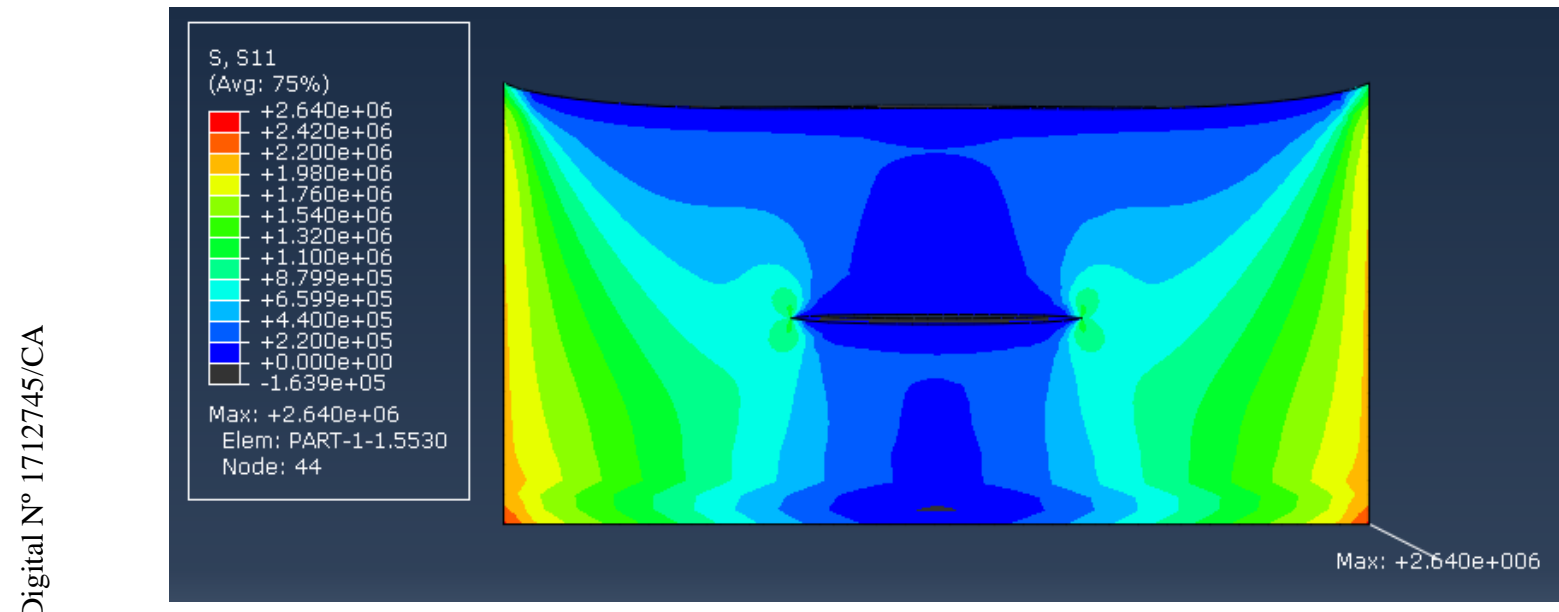

(b)

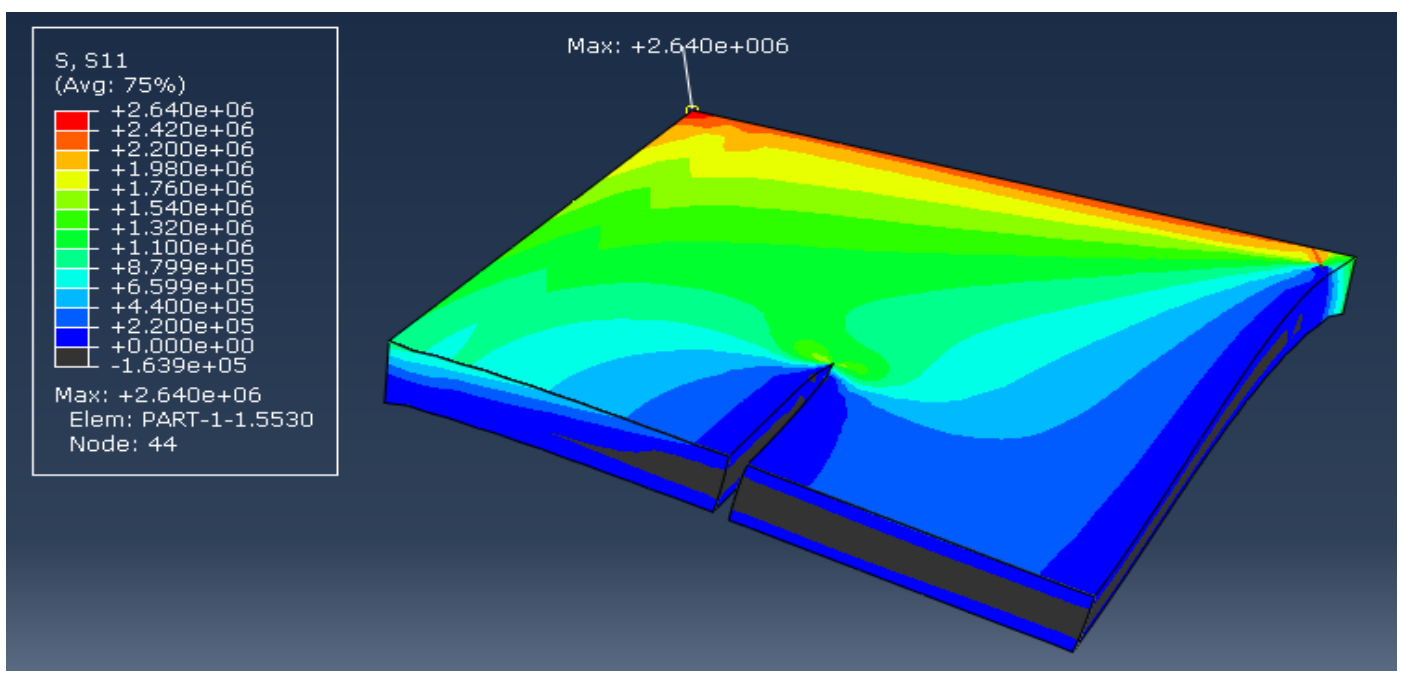

(c)

Figura 6. 23: Exemplo de distribuição de tensões de tração em placa fraturada submetida à gravidade e à variação não uniforme de temperatura ( $\mathrm{t}=9,5$ dias): (a)Perspectiva isométrica (b) Vista inferior (c) Seção transversal central 


\subsubsection{4.}

Caso IV

Tabela 6. 22: Valores de K1 (MPa m1/2) desenvolvidos em decorrência da ação da gravidade combinada à variação não uniforme de temperatura: caso IV

\begin{tabular}{|c|c|c|c|c|}
\hline \multirow{2}{*}{$\begin{array}{c}\text { Tempo } \\
\text { (dias) }\end{array}$} & \multicolumn{4}{|c|}{$\mathbf{K}_{\mathbf{1}}\left(\mathbf{M P a ~ m}^{\mathbf{1 / 2}}\right)$} \\
\cline { 2 - 5 } & $\begin{array}{c}\text { Na face } \\
\text { superior }\end{array}$ & $\begin{array}{c}\mathbf{A ~ 0 , 5 m ~ d a} \\
\text { face superior }\end{array}$ & $\begin{array}{c}\mathbf{A} \mathbf{1 m} \text { da face } \\
\text { superior }\end{array}$ & Na face inferior \\
\hline 5,5 & 1,00 & 0,70 & 0,90 & 0,60 \\
\hline 8 & 1,30 & 0,90 & 1,00 & 0,70 \\
\hline
\end{tabular}




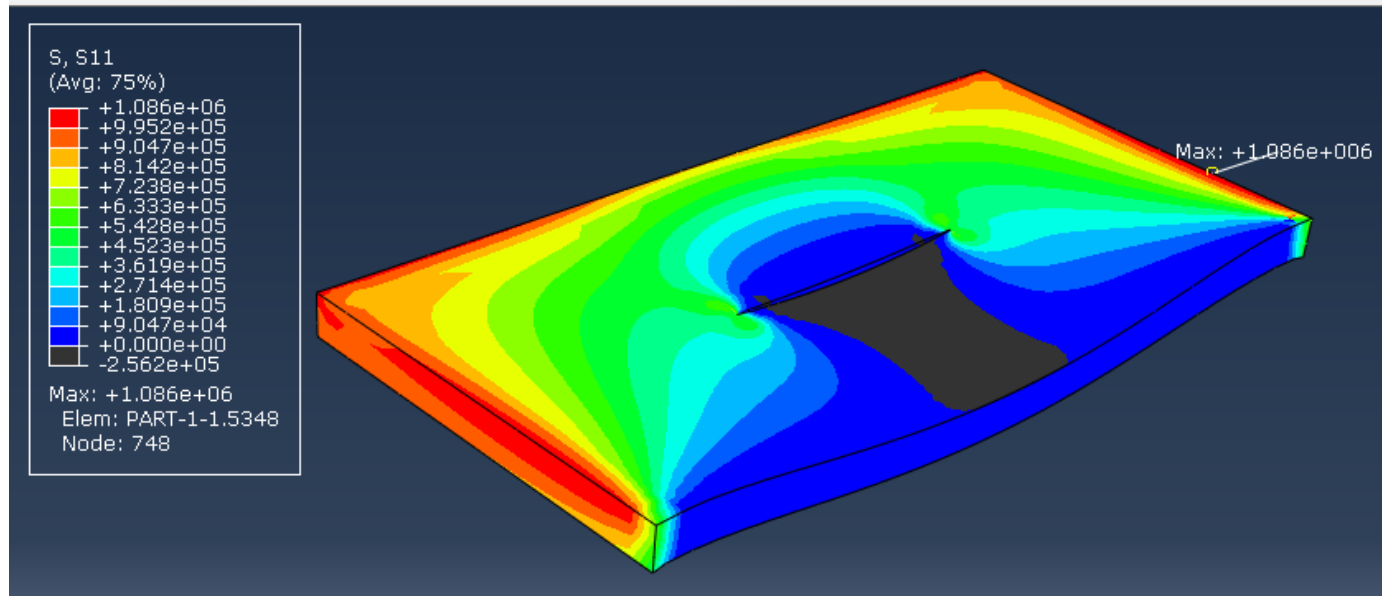

(a)

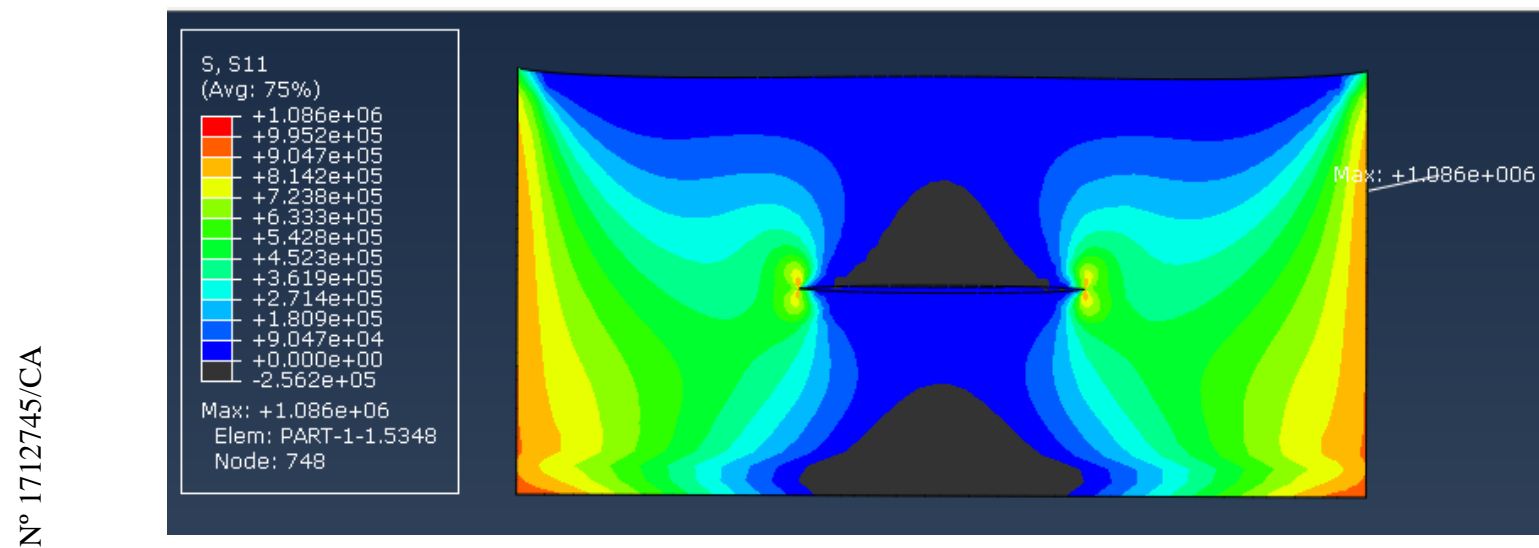

(b)

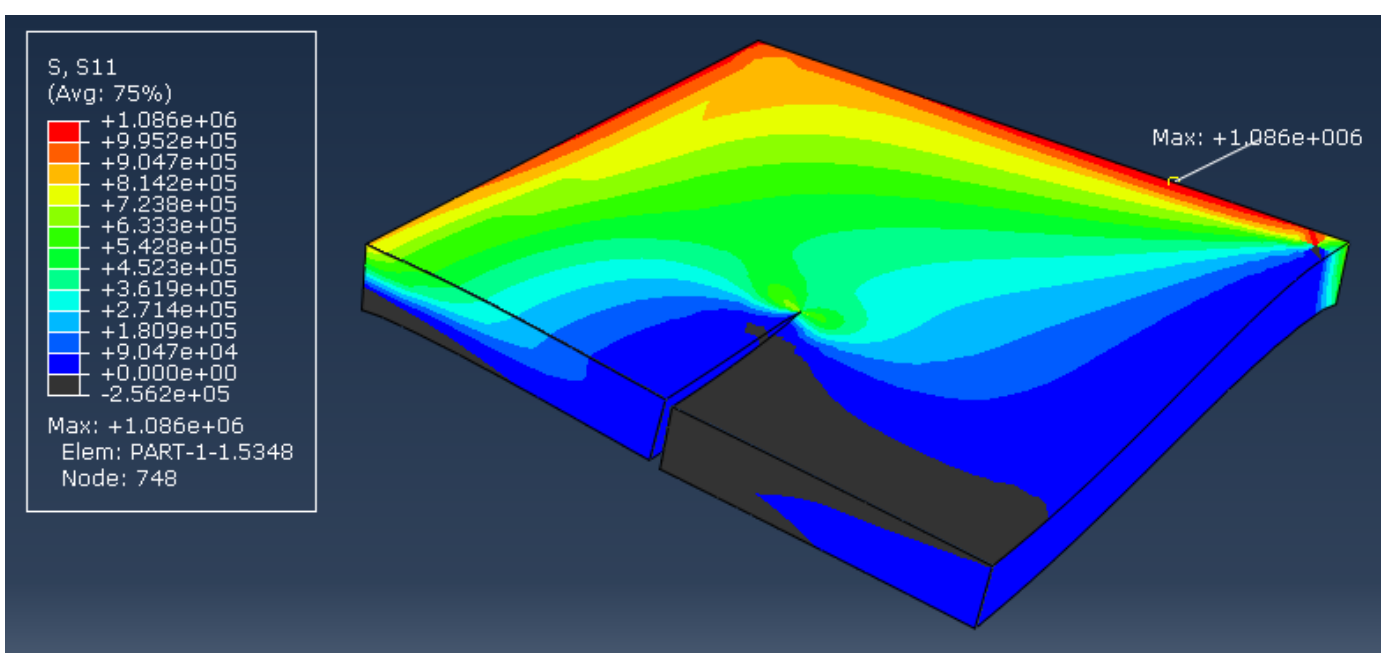

(c)

Figura 6. 24: Exemplo de distribuição de tensões de tração em placa fraturada submetida à gravidade e à variação não uniforme de temperatura ( $\mathrm{t}=8$ dias): (a)Perspectiva isométrica (b) Vista inferior (c) Seção transversal central 


\subsubsection{5.}

Caso V

Tabela 6. 23: Valores de $\mathrm{K}_{1}\left(\mathrm{MPa} \mathrm{m}^{1 / 2)}\right.$ desenvolvidos em decorrência da ação da gravidade combinada à variação não uniforme de temperatura: caso $V$

\begin{tabular}{|c|c|c|c|c|}
\hline \multirow{2}{*}{$\begin{array}{c}\text { Tempo } \\
\text { (dias) }\end{array}$} & \multicolumn{4}{|c|}{$\mathbf{K}_{\mathbf{1}}\left(\mathbf{M P a} \mathbf{~ m}^{\mathbf{1 / 2}}\right)$} \\
\cline { 2 - 5 } & $\begin{array}{c}\text { Na face } \\
\text { superior }\end{array}$ & $\begin{array}{c}\mathbf{A ~ 0 , 5 m ~ d a} \\
\text { face superior }\end{array}$ & $\begin{array}{c}\mathbf{A} \mathbf{1 m} \text { da face } \\
\text { superior }\end{array}$ & Na face inferior \\
\hline 3,5 & $-0,40$ & $-0,20$ & 0,85 & 1,20 \\
\hline 6 & $-0,05$ & 0,20 & 1,10 & 1,10 \\
\hline 7 & 1,20 & 0,80 & 1,20 & 0,95 \\
\hline 7,5 & 1,60 & 1,10 & 1,00 & 0,60 \\
\hline 9 & $-0,60$ & 0,05 & 1,50 & 1,60 \\
\hline 10 & $-0,70$ & 0,10 & 1,40 & 1,30 \\
\hline
\end{tabular}




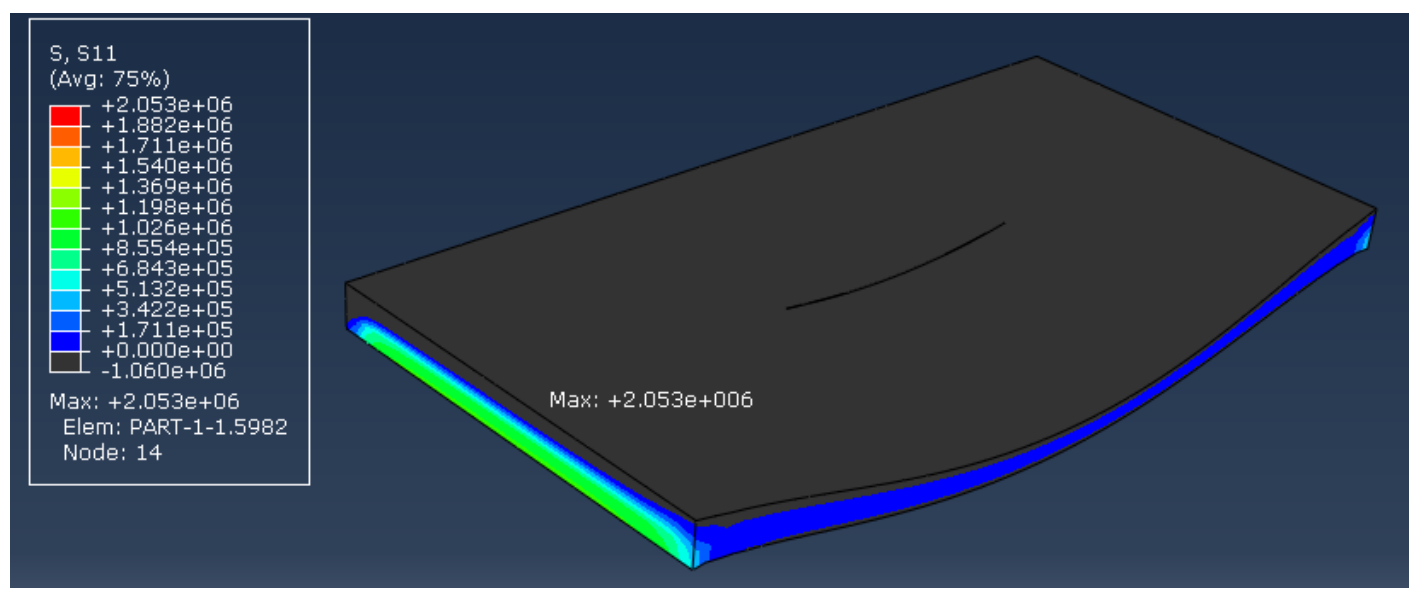

(a)

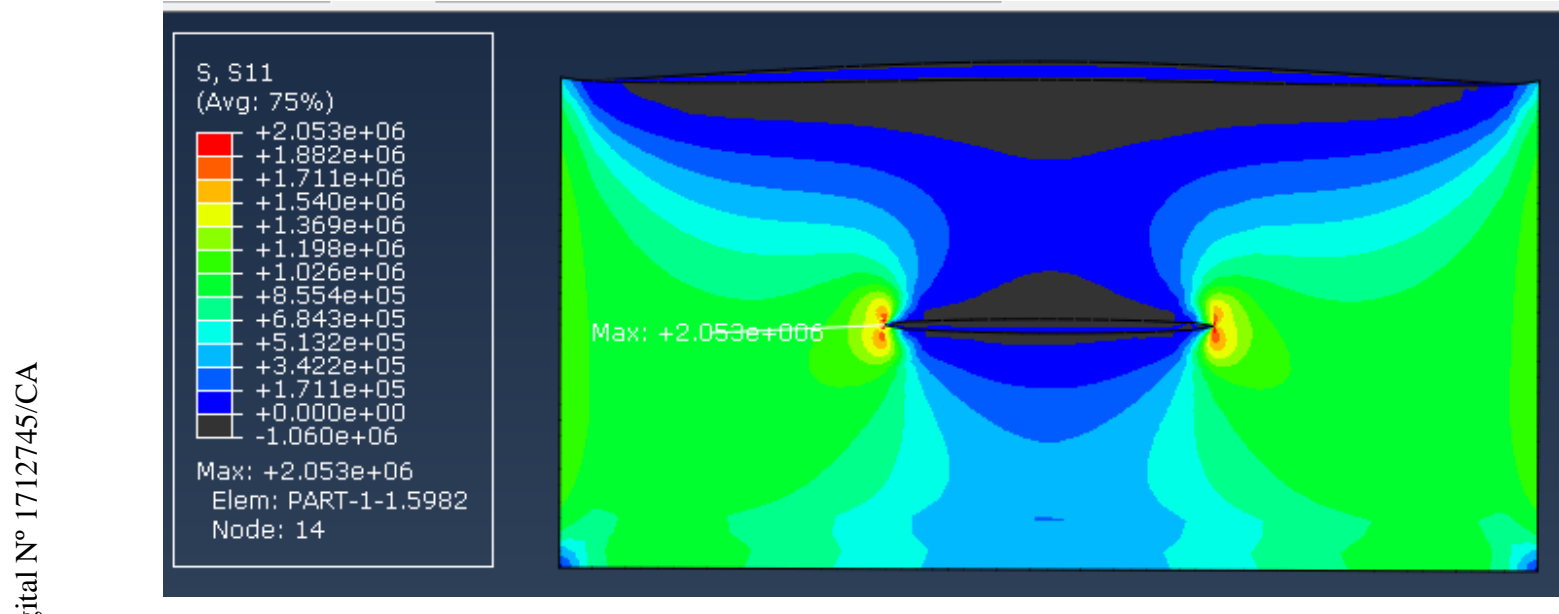

(b)

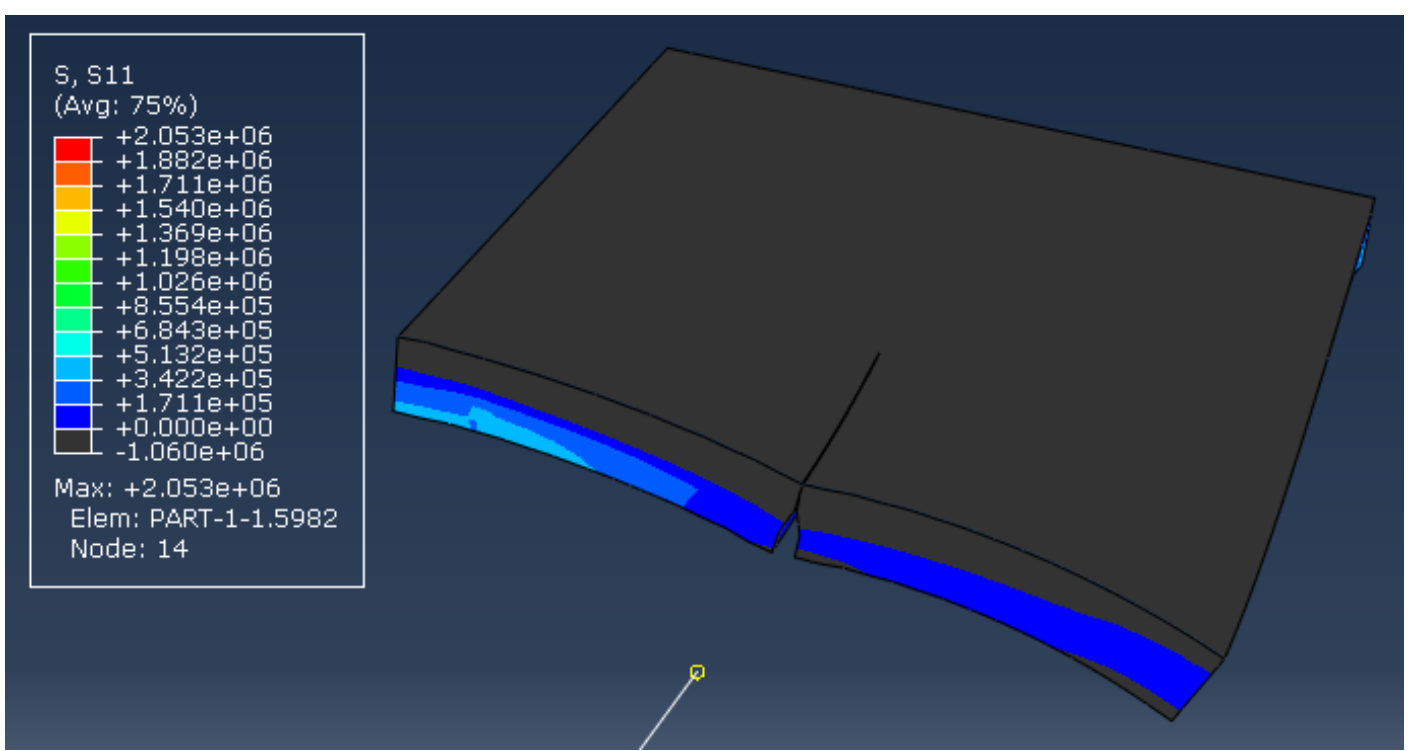

(c)

Figura 6. 25: Exemplo de distribuição de tensões de tração em placa fraturada submetida à gravidade e à variação não uniforme de temperatura ( $\mathrm{t}=9$ dias): (a)Perspectiva isométrica (b) Vista inferior (c) Seção transversal central 


\section{7.}

\section{Conclusão}

O presente trabalho visou apresentar os efeitos das tensões térmicas em placas rochosas de geometria simplificada, mediante análise numérica termomecânica realizada no software de elementos finitos Abaqus 6.14. Para tal, foram consideradas as condições de rocha intacta e fraturada as quais foram impostos cenários em que os efeitos da gravidade e das variações não uniformes de temperatura puderam ser avaliados isoladamente e em conjunto.

Constatou-se que a gravidade potencializa as tensões de tração desenvolvidas, especialmente quando a rocha se encontra fraturada, solicitando principalmente a região posterior da placa e fratura em si. A variação de temperatura não uniforme também é outra condição que aumenta consideravelmente as tensões de tração e compressão desenvolvidas ao longo do tempo, principalmente na placa fraturada. Isto, pois a existência da fratura transfixante permite que a placa possua menor restrição à deformação, o que ocasiona um menor impacto das variações térmicas não uniformes nas tensões geradas.

Apesar do exposto acima, em nenhum dos cenários simulados as tensões de tração foram superiores a cerca de $25 \%$ do valor de resistência a tração admitido inicialmente (10MPa), o que numa avaliação imediata exclui a possibilidade de ruptura por tração. Entretanto, é preciso observar que o processo de ciclagem térmica, associado a agentes de intemperismo, atuam reduzindo a resistência da rocha, o que deve ser avaliado com critério.

No que diz respeito aos fatores de intensidade de tensão desenvolvidos, os resultados são contundentes. A ação da gravidade isoladamente já se configura um fator capaz de gerar valores importantes de $\mathrm{K}_{1}$, que quando associados à variação não uniforme de temperatura atingiu, em média, $1,30 \mathrm{MPa} \mathrm{m}^{1 / 2}$,chegando a 2,20 
MPa $\mathrm{m}^{1 / 2}$ na face superior em $\mathrm{t}=9,5$ dias. Foi possível observar que os maiores valores de $\mathrm{K}_{1}$ ocorrem quando há variações negativas de temperatura consideráveis ou quando há grande gradiente térmico entre as faces, mesmo ambas estando submetidas a variações térmicas positivas.

Estes resultados vão se encontro aos obtidos por Collins \& Stock (2016), cujo modelo de placa bidimensional foi mostrado no item 2.1, neste artigo, concluiu-se que os maiores valores de $\mathrm{K}_{1}$ ocorrem em resposta à expansão da placa provocada por variações positivas de temperatura. Essa diferença nos resultados de ambos os estudos é produto dos diferentes sistemas que foram admitidos. No presente trabalho, as laterais engastadas associadas à liberdade parcial de deformação oferecida pela fratura fazem com que a fratura se abra na ocorrência de contração, diferente do que ocorre no trabalho de Collins e Stock (2016). No sistema montado pelos autores, a fratura se abre como resultado da flexão da placa, que ocorre quando há expansão. Desta forma, a influência da temperatura sobre a fratura depende fortemente da condição de vínculo, não sendo possível afirmar, sem prévia avaliação do caso em específico, que baixas ou altas temperaturas são responsáveis pelos maiores ou menores valores de $\mathrm{K}_{1}$.

Novamente, independentemente da configuração adotada, deve-se pensar que a rocha enfraquecida pelos sucessivos eventos de expansão e contração pode ter o seu valor de tenacidade reduzido, fazendo com que o processo de propagação seja ainda mais agressivo, podendo culminar na ruptura e deslizamento de grandes parcelas de rocha em situações muito menos severas de tempo.

Sendo assim, fica evidente que as variações de temperatura são um fator a mais a ser considerado nas análises de estabilidade de maciços rochosos e que deve ser analisado com cuidado e critério. Como trabalhos futuros, indica-se a avaliação do efeito da temperatura sobre outros diferentes sistemas bidimensionais e tridimensionais, considerando em um segundo momento a diminuição da resistência devido à fadiga, bem como a avaliação do modo II de propagação de fraturas. 


\section{Referências Bibliográficas}

ALBUQUERQUE, M. C. F. Determinação da tenacidade à fratura em rochas brasileiras. São Carlos, 1998. Dissertação (Mestrado em Geotecnia)- Escola de Engenharia de São Carlos, Universidade de São Paulo, São Carlos, 1998

ALMEIDA, L. C. R., VARGAS, E. A. Jr, FIGUEIREDO, R. P. Mechanical characterization of rock splitting planes in granitic rocks. International Journal of Rock Mechanics \& Mining Sciences. 43: 1139-1145,2006

ANDERSON, T. L. Fracture mechanics: Fundamentals and applications. 3.ed. Boca Raton: CRC, 2005.

ATKINSON, B. K.. Fracture mechanics of rock. London: Harcourt Brace Jovanovich Publishers, 1987

BAKUN-MAZOR, D; HATZOR, Y. H; GLASER, S. D; SANTAMARINA, J. C. Thermally vs. Seismically induced block displacements in Masada rock slopes. International Journal of Rock Mechanics \& Mining Sciences,61: 196-211, 2013

BROEK, D. .Elementary engineering fracture mechanics. 3 ed. Hague: Martinus Nijhoff Publishers, 1982

COLLINS, B. D; STOCK, G. M. Rockfall triggering by cyclic thermal stressing of exfoliation fractures. Nature geoscience, 9: 395-400, 2016.

GRIFFITH, A. A. The phenomena of rupture and flow in solids. Phil. Trans. R. Soc., vol A 221, 163-197 (1920)

GUNZBURGER, Y.; MERRIEN-SOUNKATCHOFF, V.; GUGLIELMI, Y. Influence of daily surface temperature fluctuations on rock slope stability: case study of the Rochers de valabres slope (France). International Journal of Rock Mechanics \& Mining Sciences, 42, 331-349, 2005 
LAMP, J. L.; MARCHANT, D. R; MACKAY, S. L; HEAD, J. W. Thermal stress weathering and the spalling of Antartic rocks. Journal of Geophysical Research: Earth Surface, 122, 3-24, 2016

MEDINA, J. A. H. Avaliação de previsões de fratura elastoplástica. Rio de Janeiro, 2014. 203f.Tese (Doutorado em Engenharia Mecânica) -Departamento de Engenharia Mecânica, Pontifícia Universidade Católica do Rio de Janeiro, 2014 NODA, N; HETNARSKY, R. B; TANIGAWA, Y. Thermal Stresses. 2 ed. New York:Taylor \& Francis, 2003

SILVA, P. A. B. V. Uma implementação do método estendido dos elementos finitos para análise de propagação de fraturas bidimensionais. Dissertação (Mestrado em Engenharia Civil), Pontifícia Universidade Católica do Rio de Janeiro, Rio de Janeiro, 2015

VARGAS, E.A. JR, VELLOSO, R. Q. CHÁVEZ, L. E. GUSMÃO, L. AMARAL, C. P. On the effect of thermally induced stresses in failures of some rock slopes in Rio de Janeiro, Brazil. Rock Mechanics and Rock Engineering. 46, 123-134, 2012 